UNIVERSIDADE DE SÃO PAULO

FACULDADE DE ECONOMIA, ADMINISTRAÇÃO E CONTABILIDADE. DEPARTAMENTO DE ADMINISTRAÇÃO

\title{
Um Modelo de Dois Fatores para o Cálculo do VaR de uma Carteira de Renda Fixa
}

\author{
Rafael Paschoarelli Veiga
}

Orientador: Prof. Dr. José Roberto Securato

\author{
SÃO PAULO \\ 2002
}




\title{
UNIVERSIDADE DE SÃO PAULO \\ FACULDADE DE ECONOMIA, ADMINISTRAÇÃO E CONTABILIDADE DEPARTAMENTO DE ADMINISTRAÇÃO
}

\section{Um Modelo de Dois Fatores para o Cálculo do VaR de uma Carteira de Renda Fixa}

\author{
Rafael Paschoarelli Veiga
}

Dissertação apresentada ao Departamento de Administração da Faculdade de Economia, Administração e Contabilidade da Universidade de São Paulo para a obtenção do título de Mestre em Administração.

Orientador: Prof. Dr. José Roberto Securato

SÃO PAULO 


\section{DADOS PARA FICHA CATALOGRÁFICA DE TESES E/OU DISSERTAÇÕES}

AUTOR:

TÍTULO:

DATA:

UNIDADE:

DEPARTAMENTO:

BIBLIOGRAFIA:

PAGINAÇÃO:

TESE:

ASSUNTOS:
Veiga, Rafael Paschoarelli

UM MODELO DE DOIS FATORES PARA O CÁLCULO DO VAR DE UMA CARTEIRA DE RENDA FIXA
30/07/2002

FEA-USP

Administração

Mercado de Renda Fixa, Análise de Risco, VaR 
Reitor da Universidade de São Paulo

Prof. Dr. Adolpho José Melfi

Diretor da Faculdade de Economia, Administração e Contabilidade Prof. Dr. Eliseu Martins

Chefe do Departamento de Administração

Prof. Dr. Eduardo Pinheiro Gondin de Vasconcellos 
A Lia e

minhas filhas Giulia e Luiza, pelo amor incondicional. 


\section{AGRADECIMENTOS}

A Deus pela vida.

A meus pais pelo amor e valores transmitidos.

Prof. Doutor Rubens Janny Teixeira que me incentivou a trilhar a carreira acadêmica.

Prof. Doutor José Roberto Securato, meu orientador, que é exemplo no que tange à habilidade de transmitir conceitos não triviais de maneira simples e bem humorada. 


\section{RESUMO}

No âmbito das instituições financeiras nacionais, a monitoração do risco de mercado pelo VaR é uma exigência do Banco Central do Brasil.

Contudo, o cálculo do VaR para uma carteira investimentos com diversos ativos pode se tornar uma tarefa não trivial. Para se ter idéia do grau de dificuldade envolvido no cálculo do VaR de uma carteira de investimentos, a dimensão de uma matriz utilizada para o cálculo do VaR aumenta geometricamente com o aumento no número de ativos que compõem a carteira.

Este conjunto de contingências é um terreno fértil para que os estudiosos pesquisem metodologias mais simples para o cálculo do VaR.

Neste trabalho, utiliza-se uma metodologia alternativa para o cômputo do VaR paramétrico de uma carteira de títulos de renda fixa composta por títulos públicos federais. 


\section{ABSTRACT}

Market risk monitoring through Value at Risk is a task undertaken by almost all financial institutions in Brasil due to the regulatory environment set by Banco Central.

However, VaR calculations of a portfolio of investments can get quite complicated involving the calculation of matrixes. One must bear in mind that the matrix dimensions increases geometricaly as the number of assets of the portfolio increases.

This reality is a fertile soil for researchers to find simpler methodologies for VaR calculations.

The proposed framework in this work shows a simpler methodology for VaR calculations of fixed income portfolios of government securities. 
Índice

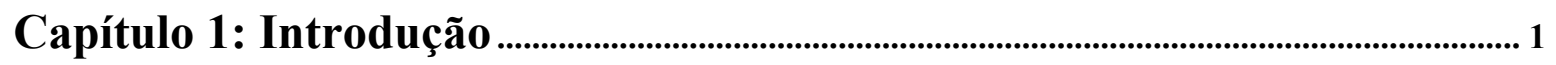

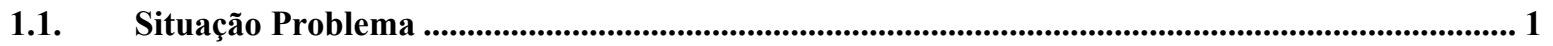

1.1.1. Acordo da Basiléia e a Supervisão Bancária.................................................................................... 3

1.1.2. As Novas Recomendações do Acordo da Basiléia e o Valor em Risco - VaR .................................. 5

1.1.3. Dificuldades no Cômputo do Valor em Risco - VaR ................................................................................ 6

1.2. Justificativa do Tema ........................................................................................................................... 7

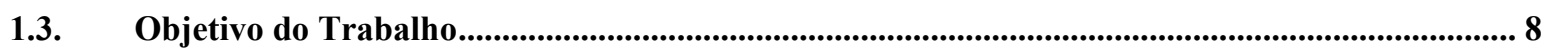

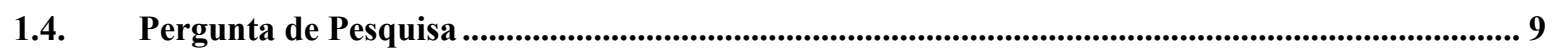

1.5. Metodologia do Trabalho …................................................................................................................ 9

1.6. Descrição dos Capítulos ............................................................................................................................ 11

Capítulo 2: Os Títulos de Renda Fixa e o VaR ............................................................ 13

2.1. Características dos Títulos de Renda Fixa ....................................................................................... 13

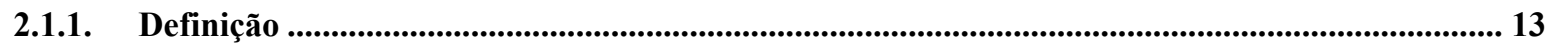

2.1.2. Classificação dos Títulos quanto aos Emissores ................................................................................. 14

2.1.3. Classificação dos Títulos quanto à Maturidade....................................................................... 16

2.1.4. Sistemas de Pagamentos ........................................................................................................................... 18

2.1.5. Construção dos Fluxos Conforme as Taxas sejam Pré-fixadas, Pós-fixadas ou Flutuantes ...... 23

2.1.6. Fluxos Construídos com Taxas Pré-fixadas e o Sistema de Amortização Francês...................... 23

2.1.7. Fluxos Construídos com Taxas Pré-fixadas e Sistema de Amortização Americano .................... 25 
2.1.8. O Sistema de Pagamento de Cupom........................................................................................... 26

2.1.9. Fluxos Construídos com Séries Irregulares de Pagamentos............................................................ 27

2.1.10. Fluxos Construídos com Taxas Pós-fixadas ....................................................................................... 28

2.1.11. Fluxos Construídos com Taxas Flutuantes ............................................................................... 30

2.1.12. O Retorno e o Preço dos Títulos de Renda Fixa ....................................................................... 32

2.1.13. Medidas de Rentabilidade de um Título.......................................................................................... 38

2.2. Os Mercados de Títulos de Renda Fixa no Brasil .............................................................................. 39

2.2.1. O Mercado de Títulos de Renda Fixa de Emissão Federal e o Mercado Aberto no Brasil......... 40

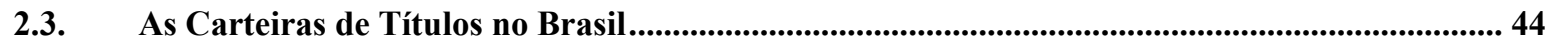

2.4. Avaliação de Risco nas Carteiras de Títulos de Renda Fixa ......................................................... 45

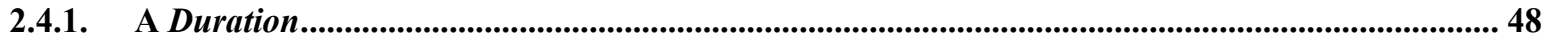

2.4.2. A Sensibilidade do Preço e a Duration .............................................................................................. 51

2.4.3. A Duration e a Administração de Risco................................................................................................ 54

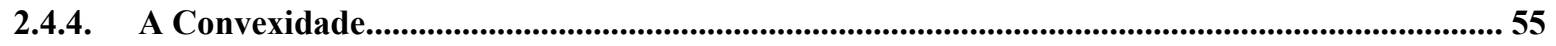

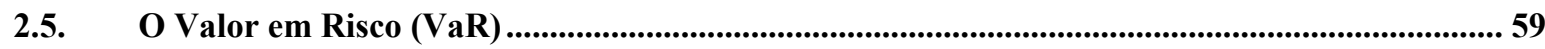

2.5.1. Metodologias para o Cálculo do Valor em Risco (VaR) .................................................................... 63

2.5.2. Comentários Quanto ao Cálculo das Covariâncias dos Fatores de Risco FR de uma Carteira de Ações 70

2.5.3. Comentários Quanto ao Cálculo das Covariâncias dos Fatores de Risco FR de uma Carteira de Títulos de Renda Fixa Pré-fixada............................................................................................................. 72

\section{Capítulo 3: O Método de Dois Fatores para o Cálculo do VaR de uma} Carteira de Títulos de Renda Fixa.

3.1. Visão das Medidas de Risco e a Simplificação no Cálculo do Valor em Risco Paramétrico por Intermédio do Modelo de Dois Fatores 
3.2. A Decomposição da Curva de Juros Utilizando um Fator ................................................. 81

3.3. A Decomposição da Curva de Juros Utilizando dois Fatores...................................................... 88

3.4. A Dedução do Modelo de Dois Fatores para o Cálculo do VaR ............................................. 93

Capítulo 4: Aplicação do Modelo e Discussão dos Resultados............................ 100

4.1. Caracterização da Carteira de Títulos a ser Analisada ................................................................ 100

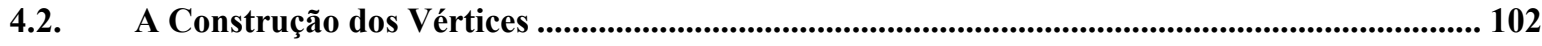

4.3. Cálculo do VaR de um dia Útil com $95 \%$ de Confiança pelo Método de Dois Fatores

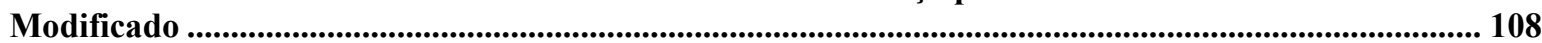

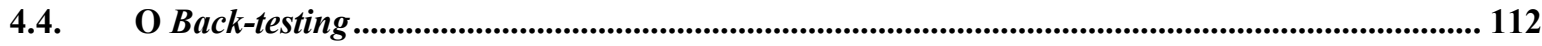

Capítulo 5: Análise e Discussão das Limitações dos Modelos ............................ 115

5.1. A Suposição da Normalidade e as Caudas Gordas.................................................................... 115

5.2. A Estimativa do VaR como Máxima Perda ....................................................................... 117

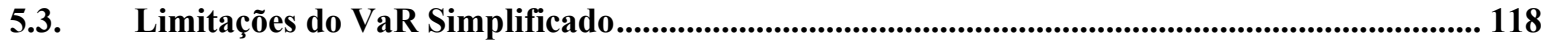

Capítulo 6: Considerações Finais.............................................................................................. 121

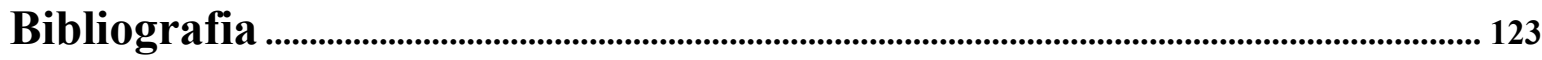




\section{Capítulo 1: Introdução}

\subsection{Situação Problema}

Independente da sua modalidade, o risco é um elemento do quotidiano dos agentes econômicos, sejam eles empresas, governos ou famílias.

OLIVEIRA (2001: 70) considera que “(...) a noção de risco está associada à idéia de incerteza". E acrescenta: "A incerteza dos eventos políticos nacionais e internacionais, tais como mudança de governo, distúrbios, greves, conflitos e crises econômicas dos mercados, colocam em polvorosa os administradores das empresas (...)".

Essa pluralidade de eventos causadores de incerteza sugere que o risco pode assumir diversos matizes o que, em outras palavras, significa que os agentes econômicos estão sujeitos a mais de uma modalidade de risco. Seguindo esta linha de raciocínio, DUARTE JUNIOR (2000: 2) argumenta que "Risco é um conceito multidimensional que cobre quatro grandes grupos: risco de mercado, risco operacional, risco de crédito e risco legal".

Uma operadora de cartão de crédito ou mesmo um banco convive com o risco de fraude com cartões magnéticos (ALMEIDA \& DUMONTIER, 1996: 53), sendo este um risco operacional. Esta mesma instituição corre o risco de crédito, isto é, de não receber do seu cliente o pagamento pelo crédito concedido. Mesmo uma bolsa de valores corre o risco de crédito se não acompanhar de maneira diligente a capacidade financeira dos comitentes operando no pregão em honrar seus compromissos. Uma empresa importadora, por sua vez, fica à mercê das oscilações no regime de câmbio, isto é, a referida empresa está sujeita ao risco cambial o qual é uma variante do risco de mercado, e também está sujeita a alterações no regime tarifário dos produtos importados, logo está sujeita também a um risco legal. Naturalmente, outros agentes econômicos, afora as corporações, estão sujeitos a situações de risco. Talvez o exemplo mais prosaico seja o risco que as pessoas físicas correm de serem demitidas ou de terem seu poder de compra reduzido por conta da inflação. 
Estes simples exemplos ilustram o fato de que o risco é parte inseparável das atividades humanas, sejam elas quais forem.

No campo das finanças, a noção de risco e seu gerenciamento assumem particular relevo.

As conseqüências do ineficaz gerenciamento de risco de uma empresa nãofinanceira podem custar a sobrevivência da instituição em questão, sem contar que seus clientes, fornecedores e colaboradores também sofrem com os efeitos advindos da interrupção das atividades da empresa.

Com efeito, as conseqüências do inadequado gerenciamento de risco nas instituições financeiras atingem a sociedade de maneira mais contundente. Um banco de varejo que tenha se exposto em demasia ao risco e que venha a ser liquidado extrajudicialmente pelo Banco Central pode colocar a perder a totalidade das aplicações de seus clientes. Esta perda de alguns clientes tem o potencial de ameaçar a confiança da população em todo o sistema bancário do país.

As atividades bancárias, apesar de serem potencialmente muito lucrativas, são também, segundo MISHKIN (2000: 154), “(...) perigosas porque tornam mais fácil e rápido para as instituições financeiras e seus funcionários fazerem apostas enormes".

Tais instituições têm a capacidade de assumir grandes posições nos mercados de títulos de dívidas, no mercado cambial e no mercado de derivativos, os quais têm um apelo muito forte dado o potencial de grandes ganhos. Isto faz com que haja um grande incentivo para se correr grandes riscos.

Exemplos de ocasiões em que a excessiva exposição ao risco acarretou grandes prejuízos e até mesmo custou a vida da instituição ameaçando a confiança da população em todo o sistema não faltam, tanto no mercado externo como no Brasil. Talvez o caso mais emblemático tenha ocorrido em 1995 envolvendo o Barings, um banco inglês com mais de duzentos anos de existência, o qual foi à bancarrota por falta de supervisão nas operações realizadas pela filial em Singapura. Em 1995 o Banco Daiwa foi proibido de operar nos Estados Unidos depois que um funcionário da agência de Nova Iorque foi capaz de encobrir perdas de mais de um bilhão de dólares por mais de onze anos. Neste caso, além do banco Daiwa ter tido prejuízos que ultrapassaram um bilhão de dólares e 
ter sido proibido de operar nos Estados Unidos, ele recebeu uma multa de US\$ 340 milhões da autoridade reguladora americana. No Brasil, o Banco Marka foi à bancarrota em 1999 por causa de sua excessiva exposição no mercado de dólar.

\subsubsection{Acordo da Basiléia e a Supervisão Bancária}

As instituições de regulação bancária dos países desenvolvidos, cientes dos riscos assumidos pelas instituições financeiras e da necessidade de se estabelecer limites e padrões para operação bancária no que se refere ao gerenciamento de risco, formaram o Comitê da Basiléia.

O Comitê é formado pelos bancos centrais e instituições de supervisão ou regulamentação bancária dos países industrializados. Seus membros se encontram a cada três meses no BIS (Bank for International Settlements) de modo a estabelecerem linhas gerais para a política de supervisão bancária. Os princípios fundamentais são transformados em documentos, os quais sugerem medidas que devem ser seguidas pela instituição local de supervisão bancária de cada país membro bem como pelas instituições financeiras que compõem o sistema financeiro de cada país.

O BIS, por sua vez, é uma organização internacional que fomenta a cooperação monetária e financeira entre seus membros e serve como banco dos bancos centrais dos países que o compõem. Adicionalmente, o BIS funciona como um fórum para a promoção de discussões sobre o processo de decisão nos bancos centrais, um centro para pesquisa econômica e monetária e contra-parte em algumas operações realizadas por bancos centrais. Afora ceder suas instalações e apoio necessários para as reuniões do Comitê da Basiléia, o BIS não participa no processo de estabelecimento da política sugerida pelo Comitê da Basiléia.

Em 15 de Julho de 1988, um marco na busca da estabilidade financeira dos países foi alcançado com o Acordo da Basiléia, fruto dos trabalhos do Comitê da Basiléia cujos signatários eram os países que compunham o Grupo dos Dez (G-10).

Nesse evento, por intermédio de seus respectivos Bancos Centrais, Bélgica, Canadá, França, Alemanha, Itália, Japão, Holanda, Suécia, Reino Unido e Estados Unidos anunciaram o acordo que resultaria na convergência internacional no que diz respeito à supervisão, regulamentação e adequação dos bancos a certos parâmetros. Por 
esse acordo, os bancos centrais dos países que compunham o G-10 teriam que aplicar as recomendações contidas no documento por eles assinado até o ano de 1992.

Segundo JORION (1997: 44) e FABOZZI (1997: 592), o propósito principal do Acordo da Basiléia era prover padrões mínimos de exigência de capital para os bancos comerciais de modo que eles se resguardassem contra o risco de crédito. Esta iniciativa, por conseguinte, visou estabelecer as bases para um sistema financeiro sólido e confiável. O controle sugerido valia-se da razão de Cooke, a qual cobre exclusivamente o risco creditício. A razão de Cooke recomenda que o capital seja igual a pelo menos $8 \%$ dos ativos do banco, ponderados pelo risco. Todavia, a interpretação do capital é mais ampla do que a definição usual do valor patrimonial, uma vez que seu objetivo é proteger depósitos dos aplicadores do banco.

O Acordo de 1988 consistia de duas seções principais as quais contemplavam a definição de capital e os pesos atribuídos a riscos incorridos pelos bancos. Adicionalmente, o documento continha quatro anexos. Recentemente, cinco emendas foram feitas ao acordo original.

Seguindo as recomendações contidas no Acordo Basiléia, a autoridade monetária brasileira, na figura do Banco Central e o Conselho Monetário Nacional-CMN, ao qual o Banco Central se subordina, intensificaram a emissão de normativos que regulam e padronizam o gerenciamento do risco por parte das instituições financeiras atuando no país. Vale salientar que o Banco Central do Brasil está revestido de autoridade para supervisionar e fiscalizar as instituições que compõem o sistema financeiro nacional por intermédio da Lei $n^{\circ}$. 6.024/74, de 13/03/1974, podendo inclusive intervir e liquidar extrajudicialmente instituições financeiras privadas e públicas não controladas pela União Federal.

Inspiradas pelas recomendações advindas do Acordo da Basiléia, as limitações estabelecidas pelo Banco Central no tocante às exposições ao risco das carteiras de investimento das instituições financeiras adquiriram maior importância face o novo padrão monetário instituído no Brasil no segundo semestre de 1994. Após essa data, os índices nominais de inflação apresentaram acentuada queda, o que provocou uma sensível redução nos ganhos de floating por parte dos bancos. 
Segundo MATHIAS \& SIQUEIRA (1996: 19), esses ganhos foram reduzidos da ordem de US\$10 bilhões para menos de US\$500 milhões, obrigando os bancos a procurarem fontes alternativas de receitas. Já a partir do segundo semestre de 1994, os bancos começaram a expandir suas carteiras de empréstimos, aumentando suas exposições ao risco. Isto sem falar no aumento da exposição ao risco cambial a que os bancos ficaram sujeitos por longo período por causa da sobrevalorização do Real em relação ao Dólar norte-americano.

\subsubsection{As Novas Recomendações do Acordo da Basiléia e o Valor em Risco - VaR}

Foi visto que o Acordo da Basiléia de 1988 estava calcado na exigência de capital mínimo visando unicamente mitigar o risco de crédito, relevando o risco de mercado.

Segundo DUARTE JUNIOR (2000: 2), o risco de mercado “(...) pode ser definido como uma medida da incerteza relacionada aos retornos esperados de um investimento em decorrência de variações em fatores de mercado como taxas de juros, taxas de câmbio, preços de commodities e ações."

Portanto, fazia-se necessário estabelecer uma metodologia que contemplasse esta modalidade de risco. Concomitantemente, o Comitê da Basiléia reconheceu que já existiam em algumas instituições financeiras mecanismos de monitoramento de risco muito mais sofisticados que aqueles recomendados pelo Acordo de 1988. JORION (1997: 50) ressalta que em Abril de 1995 os bancos centrais implicitamente reconheciam que os modelos de gerenciamento de risco utilizados por muitos bancos estavam num estágio muito mais avançado que qualquer corpo regulatório poderia propor.

Enfim, o conjunto de propostas publicado em Abril de 1993 pelo Comitê da Basiléia aperfeiçoou o primeiro conjunto de medidas prudenciais que datava de 1988 ao recomendar uma nova ferramenta de gerenciamento do risco chamada de Valor em Risco ou simplesmente VaR, acrônimo para Value-at-Risk.

As novas recomendações do Comitê da Basiléia sugeriam que o VaR total de um banco seria obtido pela soma do VaR dos portfólios expostos a quatro tipos de 
modalidade de risco, quais sejam: risco cambial, risco de taxa de juros, risco na variação dos preços de commodities e das ações. Em suma, as novas recomendações visavam a mensuração do risco de mercado, algo que representava uma grande melhoria em relação às antigas medidas prudenciais recomendadas pelo Acordo de 1988, calcadas no Índice de Cooke.

O VaR, segundo JORION (1997: xiii), nada mais é que um método de avaliação de risco que utiliza técnicas estatísticas básicas. O VaR fornece como resposta a pior perda possível dentro de um intervalo de tempo e dado um intervalo de confiança, estando o mercado nas suas condições normais. Por exemplo, um banco que afirme que o VaR de um dia de sua carteira de investimentos é de $\mathrm{R} \$ 4.000 .000,00$ para um nível de confiança de $99 \%$ quer dizer que, sob condições normais de mercado, existe 1 chance em 100 de o banco incorrer numa perda de mais de $\mathrm{R} \$ 4.000 .000,00$ no prazo de um dia.

Portanto, uma grande vantagem do VaR é que ele sumariza em um único número a exposição total de uma instituição ao risco de mercado. Eis o motivo pelo qual o VaR está rapidamente se tornando uma ferramenta essencial para se quantificar de maneira bastante clara a exposição ao risco.

O referido autor, com o objetivo de ilustrar como o VaR consegue ser uma medida concisa e, ao mesmo tempo, carregar bastante informação, cita o caso em que o J.P. Morgan revelou no seu relatório anual de 1994 que o seu VaR diário era, em média, US\$ 15.000.000,00 a um nível de confiança de 95\%, deixando para seus acionistas evidente o grau de risco incorrido pela instituição.

\subsubsection{Dificuldades no Cômputo do Valor em Risco - VaR}

Ocorre que, apesar do VaR utilizar ferramentas básicas de estatística, o seu cálculo para uma carteira de investimentos pode se tornar bastante trabalhoso.

Para se ter idéia do grau de dificuldade envolvido no cálculo do VaR de uma carteira de investimentos, vale lembrar que JORION (1997: 149) afirma que as matrizes utilizadas para o cálculo do VaR aumentam geometricamente com o número de ativos que compõem a carteira.

Ora, tem-se o seguinte problema: 
Por um lado, é de suma importância para qualquer empresa, independentemente do seu ramo de atividade, a criação de mecanismos que possam auxiliar a mensuração do risco. Para as empresas financeiras em particular, torna-se imperativo que elas se adeqüem ao arcabouço de normas instituído pelo Banco Central e pelo Acordo da Basiléia, os quais incluem a monitoração do risco de mercado pelo VaR.

Por outro lado, o cálculo do VaR pode se tornar uma tarefa não trivial. Em alguns casos, adotar a metodologia tradicional para seu cálculo pode inviabilizar sua utilização.

Este conjunto de contingências é um terreno fértil para que os estudiosos pesquisem metodologias mais simples para o cálculo do VaR.

\subsection{Justificativa do Tema}

Uma vez explicitada a situação problema, o autor do trabalho busca contribuir com o tema aprofundando o estudo de uma metodologia mais simples para o cálculo do risco por intermédio do $\mathrm{VaR}$, e que ao mesmo tempo esteja em conformidade com as regras estabelecidas pelo Banco Central e pelo Comitê da Basiléia.

A metodologia utilizada neste trabalho para o cálculo do VaR foi desenvolvida por NIFFIKEER et al. (2000: 1903-1932), os quais decompuseram a curva de juros de títulos por intermédio da metodologia desenvolvida por LITTERMAN \& SCHEINKMAN (1988: 54-61).

A metodologia desenvolvida por NIFFIKEER et al. (2000: 1903-1932) foi empregada por eles na Inglaterra para o cálculo do $\mathrm{VaR}$ de carteiras de investimento compostas por swaps de taxas de juros e de moedas fornecendo, segundo os autores, resultados satisfatórios.

Esta dissertação pretende contribuir para o estado da arte na área de gerenciamento de risco na medida em que modifica uma modelagem desenvolvida para o cálculo do Valor em Risco de uma carteira de swaps tornando-a apta para calcular o Valor em Risco de uma carteira de renda fixa. Isto é, NIFFIKEER et al. (2000: 19031932) propuseram um modelo alternativo para o cálculo do VaR de uma carteira de swaps. O presente estudo adapta o modelo de NIFFIKEER et al. (2000: 1903-1932) de forma que o mesmo, com algumas alterações, seja capaz de calcular o VaR de uma carteira de renda fixa. 
Adicionalmente, poder-se-á averiguar se uma metodologia inicialmente desenvolvida e testada em mercados estáveis é capaz de fornecer uma medida de risco de boa qualidade considerando um ambiente marcado pela instabilidade, característica distintiva do mercado nacional.

Em outras palavras, resta a dúvida se esta metodologia alternativa para se estimar o VaR fornece bons resultados para títulos de renda fixa brasileiros dadas as particularidades do mercado doméstico, como a alta volatilidade, por exemplo.

\subsection{Objetivo do Trabalho}

O objetivo do trabalho é, partindo da metodologia NIFFIKEER et al. (2000: 19031932), a qual se baseia nos estudos LITTERMAN \& SCHEINKMAN (1988: 54-61), propor uma metodologia para o cálculo do VaR de uma carteira de renda fixa e testá-la para um caso particular de uma carteira de títulos públicos federais brasileiros.

A aplicação do back-testing responderá à questão se o VaR obtido pelo método alternativo é uma boa medida do risco.

LITTERMAN \& SCHEINKMAN (1988: 54-61), doravante denominados LS (1988: 54-61), estabeleceram uma metodologia para decompor a curva de juros de títulos da dívida norte-americana em fatores que explicam $97 \%$ da variabilidade da curva de juros.

NIFFIKEER et al. (2000: 1903-1932), doravante denominados NHF (2000: $1903-$ 1932), partindo do modelo desenvolvido por LS (1988: 54-61), apresentaram um modelo simplificado para o cálculo do VaR de uma carteira de swaps.

O presente trabalho introduzirá algumas modificações na metodologia de NHF (2000: 1903-1932) de modo que se possa calcular de maneira simplificada o VaR de uma carteira de títulos de renda fixa composta por títulos públicos federais brasileiros de diferentes vencimentos.

Conforme já foi explanado, as modificações a serem introduzidas decorrem do fato do modelo NHF (2000: 1903-1932) se preocupar com o cálculo do VaR de carteiras de swaps de taxas de juros enquanto que este trabalho objetiva encontrar o VaR de uma carteira de renda fixa. 
Os títulos a serem empregados neste estudo serão da modalidade Letra do Tesouro Nacional - LTN, emitida pela Secretaria do Tesouro Nacional e possui rendimento prefixado definido pelo deságio sobre o valor do principal, cujo funcionamento será abordado na revisão bibliográfica.

Dentre os quatro tipos de risco que o Comitê da Basiléia sugere que sejam calculados, o modelo ora apresentado objetiva fornecer uma estimativa para o VaR de um portfólio de investimentos sujeitos a risco de flutuações na taxa de juros, a qual constitui uma modalidade do risco de mercado.

As demais modalidade de risco devem ser submetidas a outros tratamentos, os quais fogem ao escopo deste trabalho.

\subsection{Pergunta de Pesquisa}

A pergunta de pesquisa é:

É possível afirmar que o VaR calculado a partir das metodologias apresentadas por LS (1988: 54-61) e NHF (2000: 1903-1932), adaptadas pelo presente trabalho para o cômputo do VaR de uma carteira de renda fixa, é uma medida adequada do risco de uma particular carteira composta por títulos públicos federais brasileiros?

O pergunta acima considerará uma carteira de títulos de renda fixa composta por Letras do Tesouro Nacional de diferentes vencimentos e considerando o período de 01/06/2001 até 31/10/2001.

\subsection{Metodologia do Trabalho}

Segundo LAKATOS (1991: 68), o ponto de partida para uma pesquisa é um problema. Seguindo esta linha de raciocínio, o ponto de partida para o presente trabalho é a necessidade de se mensurar o risco por intermédio do VaR de uma maneira simplificada. Utilizar-se-á o VaR pelos motivos anteriormente expostos e, em especial, pelo fato do Banco Central do Brasil exigir que as instituições financeiras o façam.

Ainda segundo o referido autor, o crescimento do conhecimento conduz os velhos problemas para novos por intermédio de conjecturas e refutações. Sob esta ótica, podese dizer que o cálculo do VaR pelos caminhos tradicionais carrega considerado grau de 
complexidade computacional, ensejando que estudiosos proponham novas metodologias que consigam calculá-lo de maneira mais simples. A conjectura, neste ponto, é saber se tais metodologias funcionam no mercado brasileiro de títulos de renda fixa.

Ora, a passagem dos velhos problemas para os novos por intermédio de novas suposições e argumentações, tal como sugere LAKATOS (1991: 68), requer que uma metodologia seja adotada de forma que se diferencie a simples intuição da ciência. (TEIXEIRA, 1999: 10)

ECO (1995: 59), por seu turno, diz que:

... a metodologia, apesar de instrumental, é condição necessária para competência científica. Como pesquisa, a metodologia significa a produção crítica e auto-crítica de caminhos alternativos, bem como a indagação sobre os caminhos vigentes e passados.

Yin (1989: 17) diz que existem três pontos a serem analisados para a escolha de uma metodologia de pesquisa, quais sejam: (i) o tipo de problema a ser pesquisado; (ii) o grau de controle que o investigador possui sobre os eventos presentes e (iii) a característica do foco da pesquisa, isto é, se baseada em eventos contemporâneos ou eventos históricos.

Do ponto de vista metodológico, este estudo se valerá de um estudo de caso, baseado em eventos contemporâneos, de uma particular carteira de títulos de renda fixa para se testar os modelos pesquisados.

Saliente-se que não se deseja obter a generalização analítica ou a validação dos modelos estudados. Deseja-se sim testar um caso particular, porém de grande aplicação na realidade financeira do Brasil, e assim contribuir para o estoque de estudos envolvendo modelos simplificados para o cômputo do Valor em Risco.

Quanto ao plano de trabalho, tem-se que:

- Serão colhidas e tabeladas as cotações dos títulos públicos federais negociados no mercado secundário. Estas cotações são obtidas por intermédio do sítio na Internet do Banco do Central do Brasil; 
- Utilizar-se-á a metodologia LS (1988: 54-61) adaptada por NHF (2000: 19031932) para se decompor a curva de juros dos títulos em estudo;

- O modelo NHF (2000: 1903-1932) para o cálculo do VaR de uma carteira de swaps deverá ser adaptado para o cálculo do VaR de uma carteira de renda fixa;

- Calcula-se o VaR da carteira de renda fixa composta por LTNs utilizando a abordagem tradicional do VaR paramétrico pelo método das variânciascovariâncias e pelo método de dois fatores proposto por NHF (2000: 19031932) e modificado pelo presente estudo de forma a se adequar o modelo à carteira de renda fixa.

- A análise dos modelos será operacionalizada por intermédio de back-testing o qual, segundo JORION (1997: 85), é uma metodologia recomendada pelo Comitê da Basiléia como um meio de verificar a acurácia do VaR obtido.

\subsection{Descrição dos Capítulos}

O capítulo 1 procura contextualizar os temas abordados bem como deixar claro o objetivo do trabalho.

O capítulo 2 contém a revisão bibliográfica dos temas pertinentes ao presente trabalho, tais como mercado de títulos de renda fixa e sua respectiva avaliação de risco, avaliação de risco de carteira de títulos e, ainda, o conceito de valor em risco e suas diferentes abordagens.

O capítulo 3 será reservado para a explanação das metodologias para a decomposição da curva de juros em fatores e o cálculo do VaR utilizando a referida decomposição. Neste capítulo, o modelo de fatores e a metodologia simplificada para o cálculo do VaR de uma carteira de renda fixa serão deduzidos partindo-se do modelo originalmente concebido por NHF (2000: 1903-1932) para o cálculo do valor em risco de swaps de juros. Ainda no capítulo 3 serão apresentadas aos variáveis de interesse, as simplificações introduzidas e os cuidados metodológicos que deverão ser atentados no momento da aplicação dos modelos.

O capítulo 4 evidenciará a aplicação da metodologia de decomposição da curva de 
juros para uma determinada carteira de títulos públicos federais brasileiros. Uma vez que as curvas de juros tenham sido decompostas, o VaR pela metodologia simplificada será calculado para a carteira de títulos em questão, sempre observando os cuidados metodológicos apresentados no capítulo anterior. Ainda neste capítulo, o VaR paramétrico obtido pela metodologia tradicional utilizando a matriz de covariâncias e o back-testing serão determinados de forma que se tenha mais elementos para se realizar a análise e discussão dos resultados encontrados, as quais também farão parte do capítulo 4.

O capítulo 5 abrigará a discussão das limitações da pesquisa, as limitações dos modelos propostos e as dificuldades no estabelecimento de parâmetros inerentes aos modelos propostos.

As considerações finais constarão do capítulo 6. Por intermédio deste capítulo, será possível averiguar que os objetivos traçados no capítulo introdutório foram perseguidos e alcançados e que o problema de pesquisa foi respondido de maneira satisfatória. Ainda neste capítulo, serão apresentadas as lacunas no conhecimento que ainda podem ser explorados e que sejam afins aos temas envolvidos nesta dissertação. 


\section{Capítulo 2: Os Títulos de Renda Fixa e o VaR}

A revisão bibliográfica está divida em dois grandes temas.

O primeiro deles é a discussão dos principais aspectos atinentes aos títulos de renda fixa.

O segundo se refere justamente à ferramenta de mensuração de risco conhecida como Valor em Risco (VaR) aplicada a instrumentos de renda fixa.

\subsection{Características dos Títulos de Renda Fixa}

\subsubsection{Definição}

A caracterização dos títulos de renda fixa, em geral, faz referência ao conceito de fluxo de caixa. VIEIRA SOBRINHO (1984: 42) afirma que "Fluxo de caixa de uma empresa pode ser entendido como uma sucessão de recebimentos ou pagamentos, em dinheiro, previstos para determinado período de tempo".

Segundo BODIE et al. (2000: 279), um título de renda fixa é uma reinvindicação sobre um fluxo de caixa periódico e especificado. O emissor do título se obriga a fazer pagamentos especificados ao detentor do título em datas especificadas. Isto significa que ativos de renda fixa ou obrigações de renda fixa conferem aos seus titulares o direito sobre um fluxo de caixa especificado. Uma obrigação é um título emitido em função da tomada de um empréstimo. O devedor emite uma obrigação conferindo determinados direitos a quem vier comprá-la. Uma vez adquirida por um comprador, o mesmo passa a ser detentor do título e credor de quem o emitiu. A incerteza que cerca os fluxos de caixa prometidos ao detentor do título é mínima, contanto que o emissor do título seja suficientemente merecedor de crédito.

WESTON \& BRIGHAM (2000: 252) afirmam que “(..) um título é nota promissória de longo prazo emitida por uma empresa ou unidade governamental". E ilustram da seguinte maneira:

Por exemplo, em 2 de Janeiro de 1993, a Allied Foods Products tomou emprestado \$ 50 milhões vendendo 50.000 títulos individuais a $\$ 1.000$ cada 
um. A Allied recebeu os $\$ 50$ milhões e prometeu aos detentores dos títulos pagar juros anuais e repagar os $\$ 50$ milhões em uma data específica.

FABOZZI (2000: 1) utiliza a expressão bônus para se referir aos títulos de renda fixa. Este autor apresenta a seguinte definição:

Um bônus é um instrumento de dívida que requer que o emissor (também denominado devedor ou tomador do empréstimo) pague ao credor ou investidor a quantia tomada acrescida de juros no decorrer de um período de tempo predeterminado. Um bônus típico ("simples") emitido nos EUA especifica (1) uma data fixa na qual vence o valor tomado (o principal) e (2) o valor contratual dos juros, que normalmente é pago a cada seis meses. A data em que o principal deverá ser pago é denominada de data de vencimento. Supondo-se que o emitente não se torne inadimplente nem resgate a emissão antes da data de vencimento, um investidor que detenha este bônus até a data de vencimento assegura um padrão conhecido de fluxo de caixa.

ANDREZO \& LIMA (1999: 4) apresentam a seguinte definição:

O mercado de renda fixa caracteriza-se pelo conhecimento do ganho futuro, em termos nominais (taxa pré ou pós-fixada), enquanto, no mercado de renda variável, o ganho somente será conhecido na data da venda do papel. Não obstante, devemos reconhecer que, no mercado de renda fixa, um eventual ganho nominal, considerado na compra do título, pode não se concretizar e, até mesmo, transformar-se em perda, em termos reais, devido às condições do mercado durante o período, como pode ocorrer no caso de uma elevação das taxas de juros do mercado.

\subsubsection{Classificação dos Títulos quanto aos Emissores}

Conforme HAUGEN (1986: 9), títulos de renda fixa são emitidos por governos e por firmas privadas.

Os governos emitem títulos para financiar déficits orçamentários, os quais ocorrem quando as receitas são superadas pelas despesas. Esses títulos são emitidos pelo governo em seus níveis federal, estadual e municipal. Ainda segundo o referido autor, pelo fato do governo ter a faculdade de emitir dinheiro, os títulos de renda fixa do governo federal não estão sujeitos a default. Os títulos dos governos estadual e 
municipal têm seu respaldo na capacidade do governo de arrecadar por intermédio de impostos.

Para FABOZZI (1997: 3), uma das características importantes de um título de renda fixa é quanto à natureza de seu emissor. Cada emissor apresenta características bastantes distintivas. Uma primeira grande divisão que pode ser feita quanto à natureza dos emissores dos instrumentos de renda fixa é que os mesmos podem ser emitidos por instituições públicas e privadas. No âmbito do mercado norte-americano, os três maiores emissores de títulos são as corporações domésticas, os governos municipais e o governo federal, incluindo suas agências.

Dentre as instituições privadas, não apenas as financeiras estão autorizadas a emitir títulos de renda fixa. Empresas industriais, comerciais e de serviços podem emitir determinadas modalidades de títulos. GITMAN (1997: 474) afirma que:

Um título privado é um certificado indicando que uma empresa tomou emprestado certa quantia de dinheiro de uma instituição ou um investidor e promete reembolsá-la numa data futura, sob termos claramente definidos.

Dentre os instrumentos de renda fixa de emissão privada, destacam-se os Certificados de Depósito Bancário (CDB), os Recibos de Depósito Bancário (RDB), os bonds corporativos, as debêntures, os commercial papers, eurôbonus, as Letras de Câmbio (LC), as Letras Hipotecárias (LH), alguns tipos de ações preferenciais, títulos conversíveis em ações, high yield bonds, etc.

ASSAF NETO (2000: 179), por sua vez, afirma que:

Bonds são títulos de renda fixa representativos de contratações de empréstimos pela empresas, os quais prometem pagar a seus investidores determinado fluxo futuro de rendimentos. Esses papéis nada mais são do que notas promissórias emitidas sem garantias reais que pagam juros periódicos a seus proprietários, ou determinado montante fixo no final do prazo de emissão.

Ainda segundo ASSAF NETO (2000: 83):

As debêntures são títulos de crédito emitidos por sociedades anônimas, tendo por garantia seus ativos. Os recursos provenientes de sua emissão são destinados ao financiamento do capital de giro e capital fixo das empresas. Da 
mesma forma que as ações, as operações com debêntures são normatizadas pela Comissão de Valores Mobiliários -CVM.

E acrescenta na mesma página que:

As letras de câmbio são emitidas (sacadas) pelos financiados dos contratos de crédito, sendo aceitas pelas instituições financeiras participantes da operação. Posteriormente ao aceite, a letra de câmbio é vendida a investidores por meio dos mecanismos de intermediação do mercado financeiro.

\subsubsection{Classificação dos Títulos quanto à Maturidade}

Segundo FABOZZI (1997: 4), uma característica chave de um título é o seu termto-maturity, isto é, o período de tempo, geralmente expresso em anos, durante o qual o tomador do empréstimo prometeu honrar os compromissos assumidos. A maturity de um título é a data na qual a dívida será saldada pelo devedor. Nesta data, o devedor pagará o valor principal ou valor de face ao doador do empréstimo. Deve-se ressaltar que as expressões term-to-maturity e maturity não são sinônimos. A maturidade ou maturity expressa a data na qual todas as obrigações e direitos decorrentes do título cessarão. O term-to-maturity do título denota a idéia do tempo remanescente até a maturidade do título. Ainda segundo o referido autor, a maturidade de um título é essencial por muitos motivos.

O primeiro deles é que a maturidade indica a expectativa de vida do instrumento de renda fixa ou o número de períodos durante o qual o detentor do papel espera receber pagamentos intermediários de juros. Ainda que o título não pague juros intermediários, a maturidade expressa o intervalo de tempo entre a data atual e a data que o devedor prometeu pagar o valor de face ou principal.

O segundo motivo é que o rendimento ou yield do título, cujo conceito será discutido no tópico 2.1.13, depende substancialmente de sua maturidade. Mais especificamente, considerando um determinado momento no tempo, o yield de um título de longo prazo poderá ser maior, menor ou igual ao yield oferecido num título de curto prazo. 
O terceiro motivo é que a volatilidade o preço de um título está intimamente ligada à maturidade do título. Mudanças nos níveis dos juros do mercado afetam de maneira mais contundente títulos de longo prazo que títulos de prazos mais curtos.

Além dos conceitos de term-to-maturity e maturity, EMERY \& FINNERTY (1997: 133) apresentam o conceito de original maturity que consiste na vida do título no momento de sua emissão.

Outro conceito relacionado ao mercado de títulos chama-se call provision, pelo qual o emissor possui o direito (opção) de liquidar a dívida antes de sua maturidade ao pagar o call price.

Segundo FABOZZI (1997: 5), a maioria dos títulos privados são classificados como term-bonds, isto é, títulos com termo previsto contratualmente para determinada data futura. Contudo, muitas corporações emitem títulos conferindo ao seu emissor algo chamado de call privilege, que consiste numa cláusula contratual que permite ao emissor resgatar o título antes de sua maturidade. WESTON \& BRIGHAM (2000: 253) chamam esta cláusula dentro do contrato de Cláusula de Resgate. Segundo os referidos autores

A maioria dos títulos tem uma cláusula pela qual o emitente pode liquidá-los antes do vencimento. Essa característica é chamada de cláusula de resgate (...). Se um título é resgatável e se as taxas de juros na economia declinam, então a companhia pode vender uma nova emissão de título de baixas taxas de juros e usar o dinheiro para pagar a velha emissão de altas taxas de juros, precisamente da forma pela qual um proprietário imobiliário pode refinanciar uma hipoteca.

EMERY \& FINNERTY (1997: 133) fazem uma diferenciação entre títulos cujo valor emprestado é pago de uma só vez na sua maturidade e os demais onde o pagamento do valor emprestado ocorre em prestações. Os títulos que requerem pagamento do principal na maturidade são chamados de bullet maturity enquanto que os títulos em que o principal é pago em prestações são chamados de sinking fund. Este pagamento de principal na maturidade que caracterizam os títulos bullet maturity são chamados de balloon payment. 


\subsubsection{Sistemas de Pagamentos}

GITMAN (1997: 166) afirma que "Uma anuidade é uma série de fluxos de caixa anuais e iguais" e que "A série mista de fluxos de caixa não reflete um padrão préestabelecido, enquanto que ... uma anuidade é um modelo de fluxos de caixa anuais e iguais".

Contudo, não necessariamente uma anuidade implica série de pagamentos com periodicidade anual. WESTON \& BRIGHAM (2000: 214) definem anuidade como: “(...) uma série de pagamentos iguais realizados em intervalos fixos durante um número especificado de períodos". E acrescentam que:

(...) se os pagamentos são realizados no final de cada período, como ocorre normalmente, são chamados de anuidades ordinárias, ou diferidas. Se os pagamentos são feitos no começo de cada período, são anuidades antecipadas.

FABOZZI (2000: 19) apresenta uma definição similar do que vem a ser um fluxo periódico e igual ao argumentar que "Quando o primeiro investimento ocorrer daqui a um período, é conhecido como anuidade ordinária”.

Um conceito afim é a série uniforme. SAMANEZ (1999: 97) afirma que:

Uma série uniforme é uma seqüência de pagamentos ou recebimentos iguais efetuados a intervalos de tempo iguais. Os vencimentos dos termos de uma série uniforme podem ocorrer no final de cada período (termos postecipados), no início (termos antecipados), ou ao término de um período de carência (termos diferidos).

VIEIRA SOBRINHO (1984: 44) afirma que "As séries de pagamentos podem ser definidas como uma sucessão de pagamentos ou recebimentos $V_{1}, V_{2}, V_{3} \ldots V_{n}$, e com vencimentos sucessivos $t_{1}, t_{2}, t_{3} \ldots t_{n}$." Percebe-se, portanto, que se $V_{l}=V_{2}=V_{3} \ldots$ $=V_{n}$ tem-se uma anuidade ou uma série uniforme. Caso contrário, tem-se uma série mista ou uma série irregular.

Pelas definições anteriores, percebe-se que as anuidades ou séries uniformes possuem horizonte de tempo finito e que também não há o pagamento do principal no final. 
Com efeito, existem séries uniformes que possuem horizonte de tempo infinito, as quais são chamadas de perpetuidades.

SAMANEZ (1999: 99) assevera que "Existe uma situação que interessa analisar, denominada série perpétua de pagamentos, ou simplesmente perpetuidade. Ela ocorre quando o número de termos da série tende ao infinito".

Em suma, é possível agrupar os principais tipos de fluxos de caixa nas seguintes modalidades:

- Série Uniforme ou Anuidade Ordinária:

Figura 1: Fluxo de Caixa de uma Anuidade Ordinária

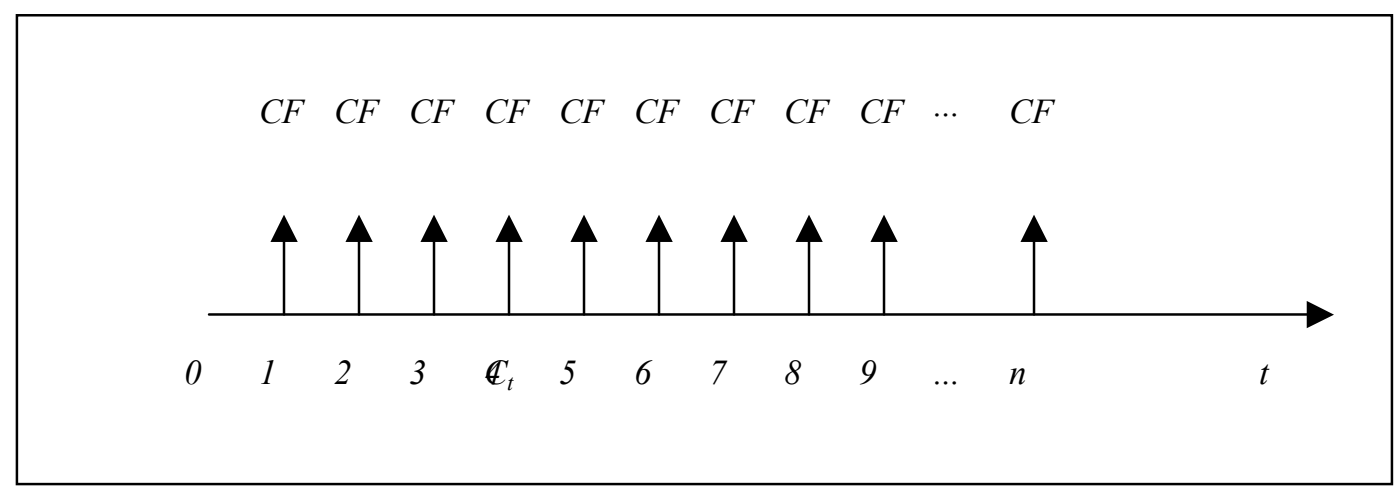

- Série Uniforme ou Anuidade Antecipada:

Figura 2: Fluxo de Caixa de uma Anuidade Antecipada

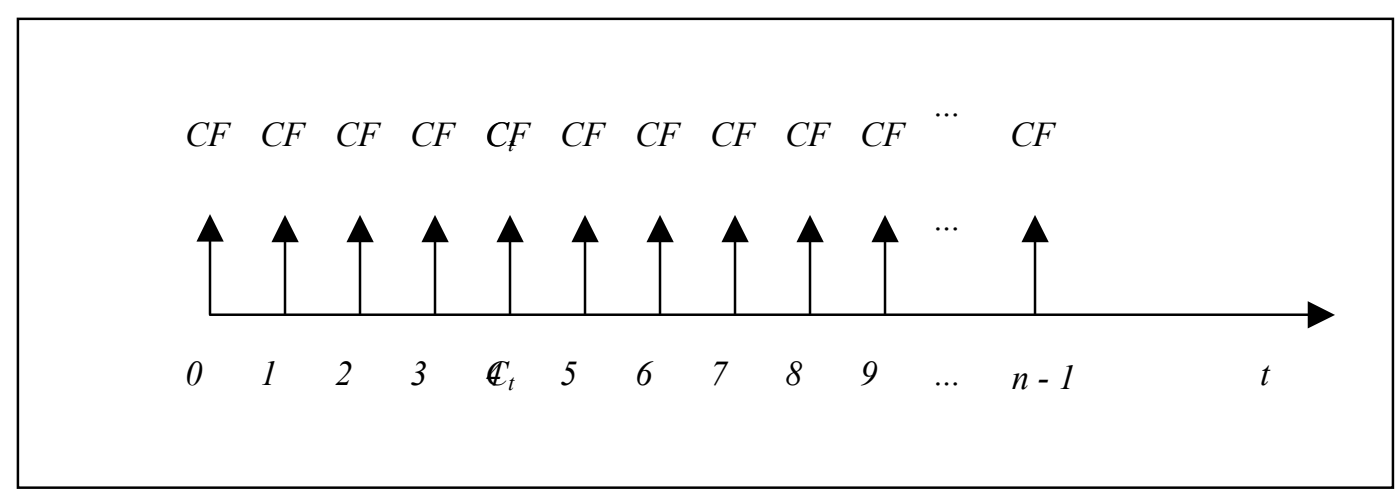

- Série Mista ou Irregular:

Figura 3: Fluxo de Caixa de uma Série Irregular

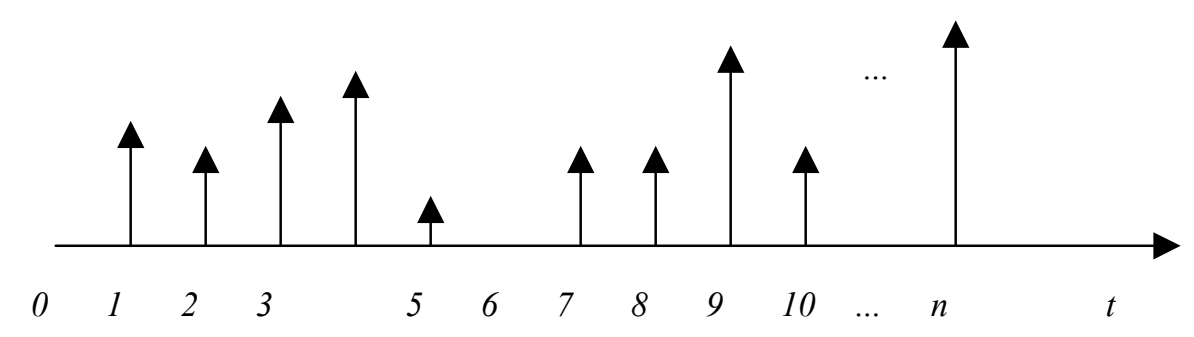


- Perpetuidade:

Figura 4: Fluxo de Caixa de uma Perpetuidade

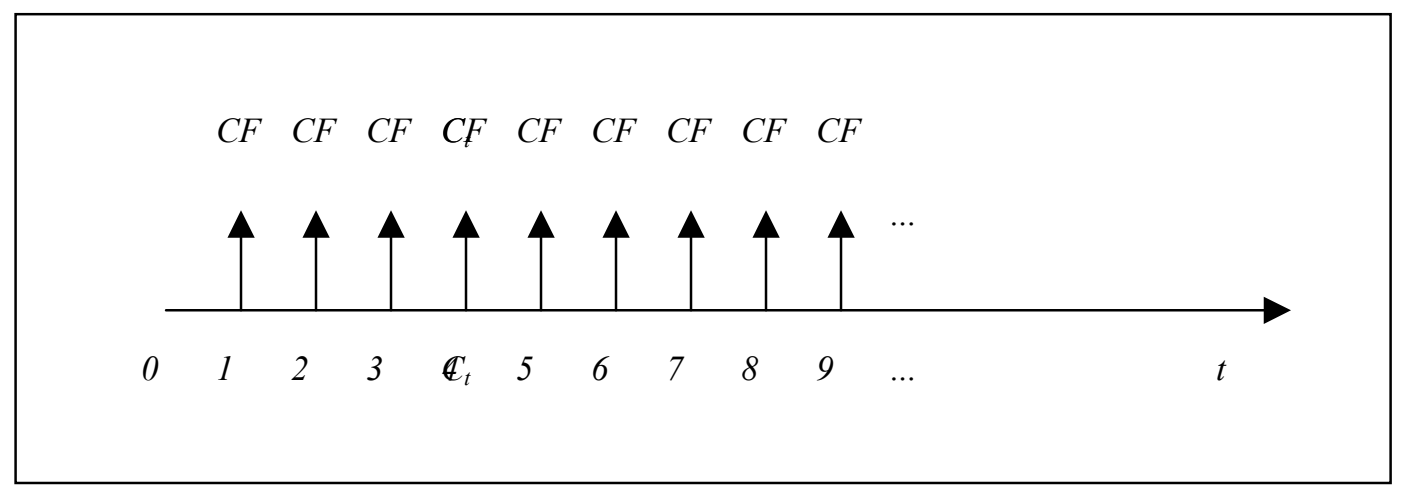

Os títulos de renda fixa também podem ser classificados de acordo com os fluxos de caixa gerados, isto é, de acordo com as características da sucessão de pagamentos ou recebimentos.

Antes de adentrar nos tipos mais comuns de séries de pagamentos, deve-se salientar os conceitos de amortização e juros dentro do contexto de reembolso de um empréstimo. Segundo SAMANEZ (2001: 169), tem-se que:

O processo de reembolso de um empréstimo consiste em efetuar pagamentos periódicos (prestações) de modo a liquidar o débito. Essas prestações consistem de duas parcelas: a amortização (devolução do principal emprestado), e os juros (serviço da dívida) correspondentes aos saldos do empréstimo ainda não reembolsado.

Os tipos mais comuns de séries de pagamentos são:

- Pagamento Único: Para CASAROTTO FILHO \& KOPITTKE (1998: 76), o Sistema de Pagamento Único é tal que "O tomador simplesmente paga os juros e amortiza o principal, tudo no final do empréstimo".

Sob a ótica desta modalidade de sistema de pagamento, supondo um investidor que decida adquirir um título, um Treasury Bill americano, por exemplo, o qual promete pagar $\$ 1.000$ ao fim de três anos a uma taxa de $4 \%$ ao ano, este investidor desembolsará a seguinte quantia para adquirir o referido título: 


$$
P V=\frac{1.000}{(1+0,04)^{3}}=\$ 889
$$

Por conseguinte, o fluxo de caixa do investidor, considerando o sistema de pagamento único, será o seguinte:

Figura 5: Fluxo de Caixa do Investidor

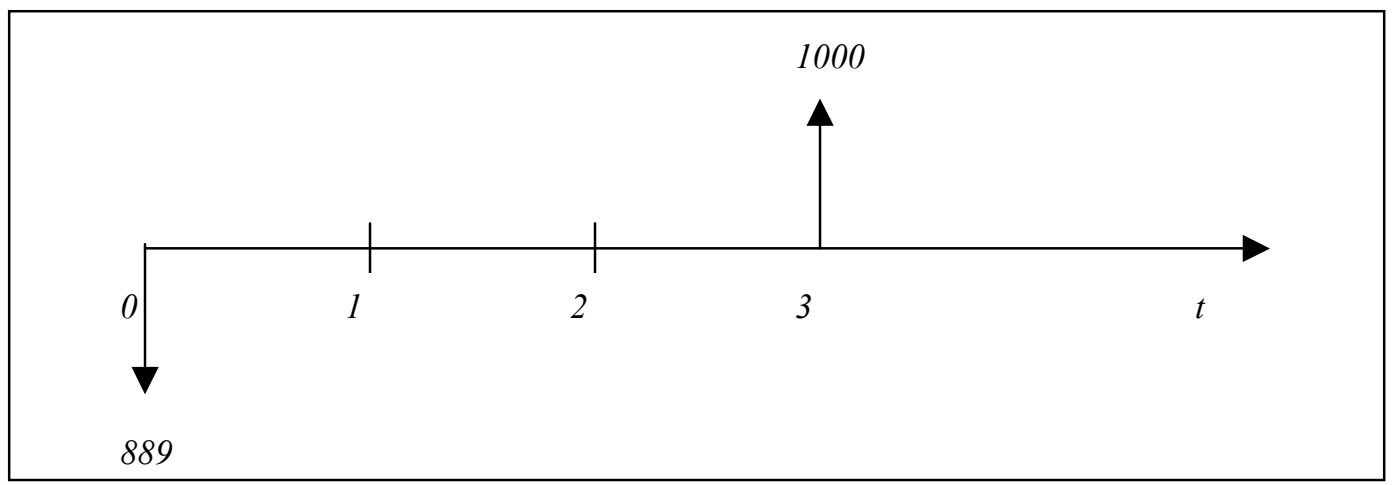

Pode-se perceber por este sistema de pagamento que o valor presente da obrigação nada mais é que o valor futuro descontado a uma taxa de juros conveniente. Por esta razão, os títulos de renda fixa que se sujeitam a este sistema de pagamento são chamados de títulos de desconto (discount bond) ou títulos de cupom zero. A denominação cupom zero advém do fato de não ocorrer pagamentos intermediários de juros.

É possível que o título mais negociado desta categoria seja justamente o Treasury Bill norte-americano.

- Sistema Americano: Em relação ao Sistema Americano, o esquema de amortização é tal que o principal é restituído por meio de uma parcela única ao final da operação. Os juros podem ser pagos periodicamente (mais comum), ou capitalizados e pagos juntamente com o principal no fim do prazo acertado. Isto é, por intermédio do Sistema de Amortização Americano o pagamento do principal é feito de uma só vez, no final do período do empréstimo, sendo que os juros são pagos periodicamente e, eventualmente, podem ser capitalizados e pagos de uma só vez, juntamente com o principal (tudo depende do acordo entre as partes interessadas).

- Sistema Price: VIEIRA SOBRINHO (1984: 138) afirma que: 
(...) o Sistema Francês de Amortização é mais conhecido no Brasil como "Sistema da Tabela Price ou simplesmente, Tabela Price. De acordo com o Professor Mário Geraldo Pereira, a denominação Tabela Price se deve ao nome do matemático, filósofo e teólogo inglês Richard Price, que viveu no Século XVIII e que incorporou a teoria dos juros compostos às amortizações de empréstimos (ou financiamentos). A denominação Sistema Francês, pelo autor citado, deve-se ao fato de esse sistema ter-se efetivamente desenvolvido na França, no Século XIX. O Sistema Francês consiste em um plano de amortização de uma dívida em prestações periódicas, iguais e sucessivas, dentro do conceito de termos vencidos, em que o valor de cada prestação, ou pagamento, é composto por duas parcelas distintas: uma de juros e outra de capital (chamada amortização).

Os empréstimos para o financiamento da casa própria no Brasil empregam intensivamente este sistema de amortização. Do ponto de vista prático, neste sistema, o mutuário obriga-se a devolver o principal mais os juros em prestações iguais e periódicas.

Ele também é o mais utilizado pelas instituições financeiras e pelo comércio em geral. Como os juros incidem sobre o saldo devedor que por sua vez decresce na medida em que as prestações são pagas, estes são decrescentes e, conseqüentemente, as amortizações do principal são crescentes.

- Sistema de Amortização Constante (SAC): O referido autor lembra que o nome deste sistema:

(...) deriva da sua principal característica, ou seja, as amortizações periódicas são todas iguais ou constantes (no Sistema Francês, as amortizações crescem exponencialmente à medida que o prazo aumenta). É um sistema de fundamental importância no Brasil, principalmente devido à sua ampla utilização pelo Sistema Financeiro da Habitação, nas operações de financiamento para aquisição de casa própria. O SAC consiste em um plano de amortização de uma dívida em prestações periódicas, sucessivas e decrescentes em progressão aritmética, dentro do conceito de termos vencidos, em que o valor de cada prestação é composto por uma parcela de juros e outra parcela de capital (ou amortização) (...). A parcela de capital é obtida dividindo-se o valor do empréstimo (ou financiamento) pelo número de prestações, enquanto o valor 
da parcela de juros é determinado multiplicando-se a taxa de juros pelo saldo devedor existente no período imediatamente anterior.

- Sistema de Amortização Misto (SAM): O sistema de amortização misto foi criado pelo antigo Banco Nacional da Habitação (BNH) em 1979. O SAM é obtido calculando-se uma média aritmética simples das prestações do mesmo valor financiado aplicando-se o Sistema de Prestações Constantes, isto é, Sistema Price, e o Sistema de Amortizações Constantes. Por conseguinte, os valores correspondentes à amortização e juros do SAM também são obtidos por intermédio das respectivas médias aritméticas.

Naturalmente podem ser criados outros sistemas adequando as necessidades de doadores e tomadores de recursos tais como série gradiente, sistema de parcelas intermediárias de amortização, por exemplo.

\subsubsection{Construção dos Fluxos Conforme as Taxas sejam Pré-fixadas, Pós-} fixadas ou Flutuantes

Os fluxos de caixa associados aos títulos de renda fixa podem ser pré-fixados, pós-fixados ou flutuantes., sendo que os mesmos serão tratados a seguir.

\subsubsection{Fluxos Construídos com Taxas Pré-fixadas e o Sistema de Amortização Francês}

Os títulos pré-fixados caracterizam-se por terem uma taxa de juros fixada no início da operação. Nestas circunstâncias, o titular já sabe exatamente a quantia que receberá em cada período.

Supondo um empréstimo de $\$ 100$ por 11 períodos e taxa de juros igual a $1,6231 \%$ por período, tem-se que a prestação que amortiza a dívida considerando o Sistema Francês é \$10. A relação matemática que relaciona taxa de juros, principal, prestação e número de prestações para o sistema de prestações iguais é dado por:

$$
P=\frac{P M T \times\left[(1+r)^{N}-1\right]}{(1+r)^{N} \times r}
$$

Sendo que: 
$P: \quad$ Principal emprestado;

$r: \quad$ Taxa de juros;

$N$ : Número de prestações;

PMT: Prestação.

Neste caso, o fluxo de caixa do credor consiste de uma saída de caixa no valor de $\$ 100$ no instante zero correspondente à concessão do empréstimo seguido de 11 recebimentos iguais e sucessivos no valor de $\$ 10$, tal como evidencia o fluxo abaixo:

Figura 6: Fluxo de Caixa do Credor

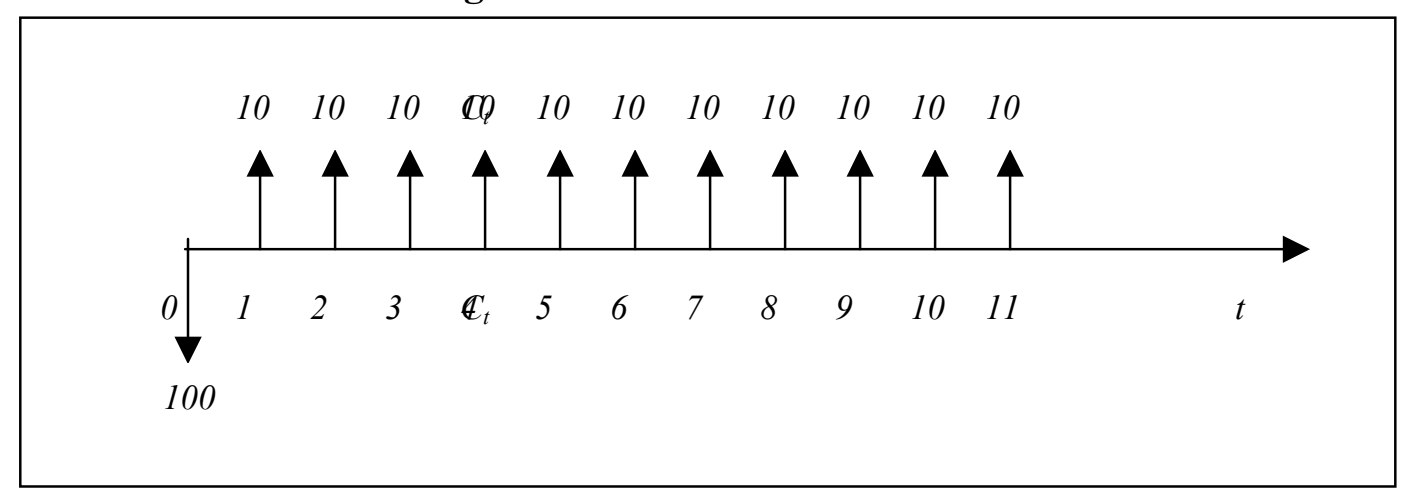

GITMAN (1997: 472) afirma que os pagamentos iguais, em geral, amortizam integralmente o principal e os juros durante toda a vida do empréstimo, tal como foi evidenciado anteriormente.

Mais uma vez, deve ficar evidente o fato de não haver pagamento de principal ao final do empréstimo uma vez que prestações carregavam consigo a parcela correspondente à amortização do principal.

O mercado de títulos norte-americano costuma designar de sinking fund o mecanismo pelo qual uma firma paga o principal em prestações, ao invés de se quitar o principal de uma só vez.

Segundo EMERY \& FINERTY (1997: 770), a vantagem de se ter um sinking fund é que o credor consegue monitorar a capacidade de pagamento por parte do devedor. Isto é, o credor não precisa aguardar até a maturidade do título para saber se o devedor terá capacidade de pagar o principal. Adicionalmente, o sinking fund reduz a vida 
efetiva do título o que, por conseguinte, reduz o risco do título. $\mathrm{O}$ conceito de vida efetiva do título consta no tópico de duration deste trabalho.

\subsubsection{Fluxos Construídos com Taxas Pré-fixadas e Sistema de Amortização Americano}

Considerando o caso de empréstimos cujas prestações são iguais e periódicas, acrescidas de pagamento de soma no vencimento, tem-se que se as prestações corresponderem apenas aos juros, o pagamento no final do empréstimo corresponderá ao principal, o que caracteriza o Sistema Americano de Pagamentos.

O principal também é chamado de valor de face ou valor nominal.

Sendo assim, considerando um empréstimo no valor de $\$ 100$ e juros de $10 \%$ ao período, o fluxo de caixa do credor será caracterizado por uma saída de caixa no valor de $\$ 100$ no instante zero, seguido de entradas de caixa no valor correspondente aos juros, isto é, $\$ 10$, e no vencimento da obrigação, além dos juros, o credor recebe o principal:

Figura 7: Fluxo de Caixa. Sistema de Amortização Americano

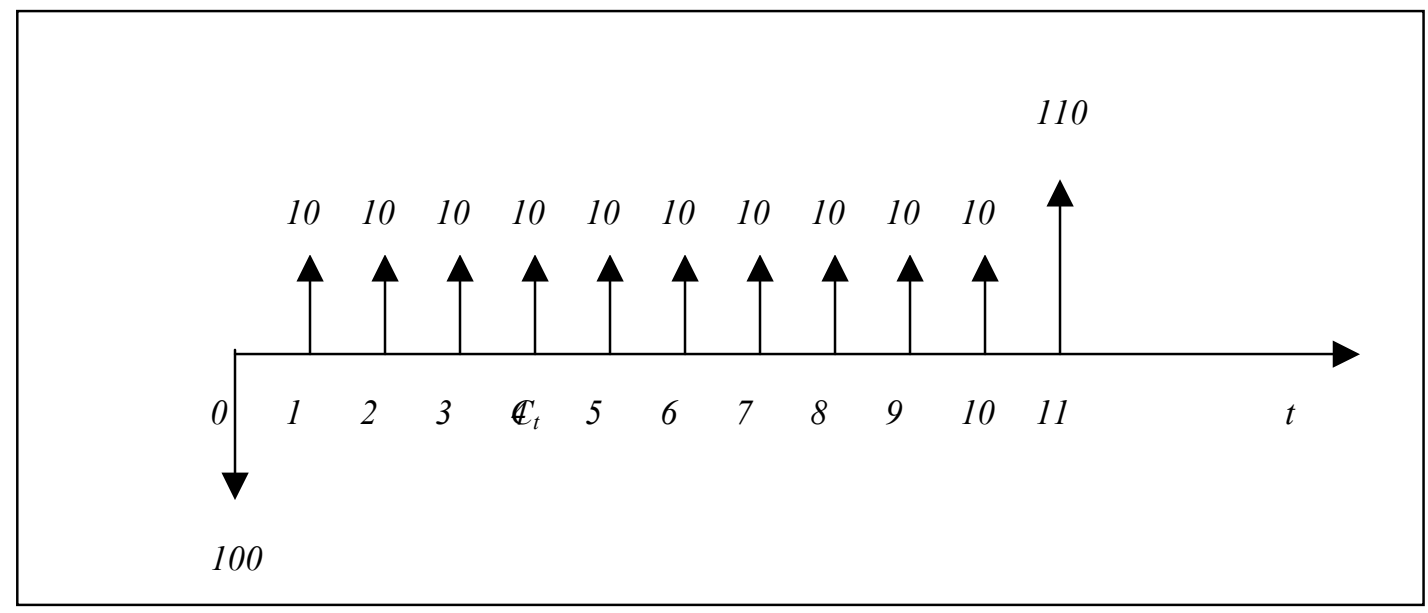

É importante notar que na situação anterior, independentemente do número de parcelas, o último pagamento necessariamente corresponderá aos juros acrescidos do principal. 


\subsubsection{O Sistema de Pagamento de Cupom}

Segundo FABOZZI (1997: 5), o cupom de um título corresponde ao pagamento periódico de juros efetuado pelo emissor ao detentor do título durante a vida deste último. O cupom é obtido multiplicando-se a taxa do cupom pelo principal ou pelo valor de face ou pelo valor ao par. Considerando um valor de face ou valor nominal deste título seja de $\$ 100$, percebe-se que o cupom é de $10 \%$ do principal de $\$ 100$. Considerando o fluxo de caixa anterior, e conforme já foi salientado, percebe-se que último fluxo de caixa representado pelo valor de $\$ 110$ consiste justamente no pagamento do valor de face ou valor nominal de $\$ 100$, acrescido de $\$ 10$ de cupom.

Conforme EMERY \& FINERTY (1997: 770), o pagamento do cupom é o termo financeiro que a linguagem corrente chama de pagamento de juros pactuados. Ainda segundo esses autores, a maioria das corporações emitem títulos que pagam cupom semi-anualmente, isto é, quando uma firma emite um título de cupom, o mesmo paga juros semestrais.

Entrementes, existem também as obrigações zero cupom, conhecidas no mercado brasileiro de títulos de cupom zero e apelidadas de título careca pelo fato desta modalidade de obrigação não oferecer pagamentos intermediários ao seu detentor.

Nesse caso, os titulares recebem o valor de face no vencimento, mas não recebem nenhum pagamento de juros até então, eis o motivo da obrigação ser chamada de cupom zero. Estas obrigações são vendidas no mercado por um preço abaixo do seu valor de face, conforme afirma WESTON \& BRIGHAM (2000: 793):

\footnotetext{
Alguns títulos não pagam juros, mas são oferecidos a um desconto substancial abaixo dos valores ao par. Assim, proporcionam valorização de capital ao invés de renda de juros. Esses papéis são chamados de títulos sem cupom de juros (ou de cupom zero) ou chamados de títulos de desconto de emissão original (DEOs). As empresas passaram a utilizar esses títulos de forma considerável pela primeira vez em 1981.
}

Porém, é possível que um título de cupom zero seja vendido ao par. Segundo FABOZZI (1997: 6), o atrativo para estes títulos é que, no vencimento, o titular recebe o principal acrescido de juros. Segundo o referido autor, embora o Tesouro norte americano não emita títulos de cupom zero com uma maturidade superior a um ano, 
títulos de cupom zero e com maturidade superior a um ano foram criados por instituições a partir de títulos do governo americano com prazo superior a um ano. Merril Lynch foi a primeira a fazer isto com a criação dos Treasury Investment Growth Receipts (TIGRs) em Agosto de 1982. Os títulos de cupom zero mais famosos são aqueles criados por dealers de títulos públicos federais americanos sob o nome de Separate Trading of Registered Interest and Principal Securities (STRIPS). Além destes tipos, existem títulos que pagam taxa de cupom que aumenta ao passar do tempo. Estes títulos são denominados de step-up notes uma vez que a taxa de cupom dá passos crescentes ao passar do tempo.

\subsubsection{Fluxos Construídos com Séries Irregulares de Pagamentos}

Porém, não necessariamente o valor recebido deve ser constante para caracterizar uma renda fixa, isto é, mesmo um título que prometa pagar fluxo de caixa irregular é considerado uma renda fixa, tal como evidencia o fluxo abaixo:

\section{Figura 8: Fluxo de Caixa Irregular}

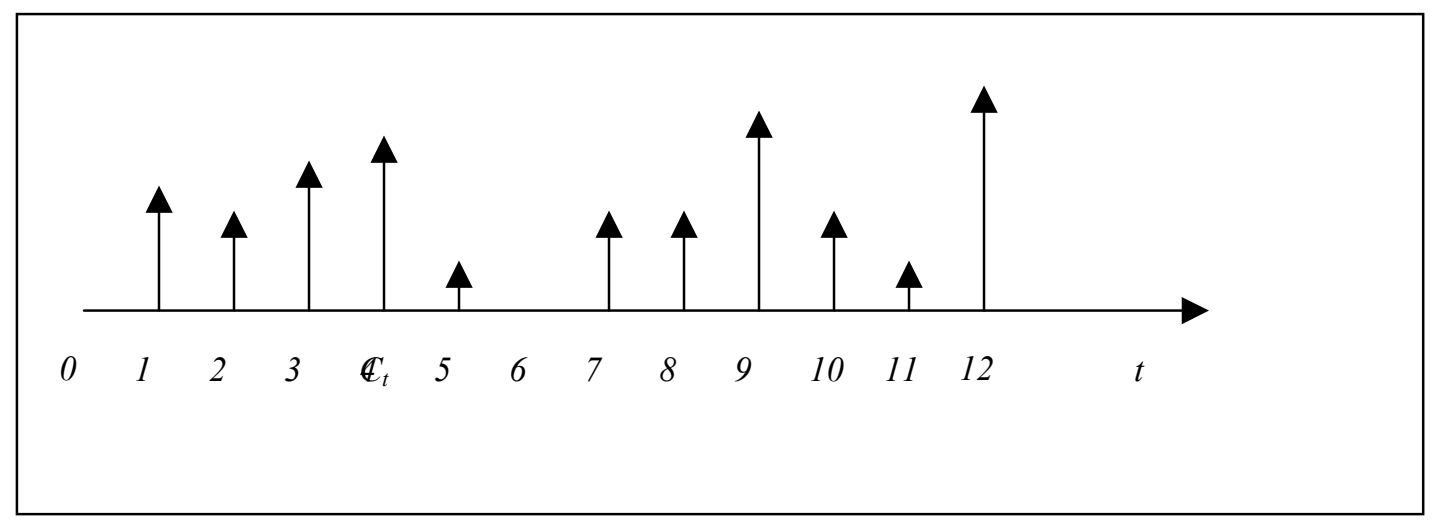

WESTON \& BRIGHAM (2000: 221) afirmam que:

A definição de anuidade inclui a expressão quantia constante - em outras palavras, as anuidades envolvem pagamentos que são iguais em cada período. Embora muitas decisões financeiras envolvam pagamentos constantes, algumas decisões importantes envolvem fluxos de caixa desiguais ou não constantes. 


\subsubsection{Fluxos Construídos com Taxas Pós-fixadas}

É provável que o primeiro instrumento de renda fixa com rentabilidade pósfixada de relevância no mercado brasileiro tenha sido as Obrigações Reajustáveis do Tesouro Nacional - ORTN, de emissão federal e que rendiam juros mais correção monetária.

A ORTN foi instituída em 1964 pela Lei nº 4.357/64, marcando a introdução da correção monetária no Brasil, sendo extinta em 1986 pelo Decreto-Lei n 2.283 e substituída pela Obrigação do Tesouro Nacional (OTN) naquele mesmo ano por ocasião do Decreto-Lei $\mathrm{n}^{\circ}$ 2.284/86.

Segundo VIEIRA SOBRINHO (1984: 188), as ORTN são:

(...) títulos ao portador, emitidos pelo Tesouro Nacional com prazos de 2 e 5 anos, com juros pagos semestralmente à razão de $6 \%$ e $8 \%$ ao ano, respectivamente. (...) as ORTN rendem correção monetária paga no vencimento do título, mais juros pagos semestralmente, calculados à razão de $0,5 \%$ ou $0,667 \%$ ao mês (conforme o título tenha prazo de emissão de 2 ou 5 anos) sobre o valor nominal das ORTN correspondentes a cada mês do semestre. (...) a partir de janeiro de 1980 , as ORTN, tanto as de 2 anos como as de 5 anos de prazo, passaram a ser emitidas nos dias 15 de cada mês; antes dessa data, a emissão poderia ser feita em qualquer dia. $\mathrm{O}$ ano considerado é o ano civil.

O referido autor discute um caso no qual é requerido o cálculo do juro semestral pago ao detentor de uma ORTN emitida no dia 15-12-1979 com cinco anos de prazo. Com tais informações, as seguintes considerações devem ser feitas:

- Uma vez que o prazo é de cinco anos, o juro a ser pago pela ORTN corresponderá a $\frac{8}{12} \%$ ao mês;

- Os juros semestrais podem ser recebidos a partir do primeiro dia útil do mês de pagamento, salvo a última parcela, que deve ser recebida juntamente com o valor corrigido da ORTN no dia do seu vencimento;

- Como a ORTN foi emitida em 15-12-1979, o primeiro pagamento de juro semestral ocorrerá no primeiro dia útil de junho de 1980; 
Considerando as informações acima e conhecendo-se o valor da ORTN nas datas de interesse, pode-se construir o fluxo dado pela Tabela 1:

\section{Tabela 1: Fluxo de Caixa de uma ORTN}

\begin{tabular}{lrr}
\hline Data & Valor da ORTN & Juros \\
\hline $15 / 12 / 79$ & 468,71 & 3,12 \\
\hline $15 / 01 / 80$ & 487,83 & 3,25 \\
\hline $15 / 02 / 80$ & 508,33 & 3,39 \\
\hline $15 / 03 / 80$ & 527,14 & 3,51 \\
\hline $15 / 04 / 80$ & 546,64 & 3,64 \\
\hline $15 / 05 / 80$ & 566,86 & 3,78 \\
\hline & & \\
\hline Total & & 20,70 \\
\hline
\end{tabular}

Portanto, no primeiro dia útil do mês de junho de 1980, o detentor de uma ORTN recebeu a quantia de $\$ 20,70$, na moeda da época, referentes ao pagamento de juros.

Atualmente, os fluxos pós-fixados construídos no Brasil são atrelados a outras taxas pós-fixadas, mesmo porque, conforme foi salientado, a ORTN foi extinta em 1986. O restante deste tópico dedica-se a discutir essas outras taxas.

As instituições financeiras que atuam no mercado interbancário realizam diariamente operações de trocas de disponibilidades de recursos, as quais são registradas e liquidadas financeiramente através da CETIP - Central de Custódia e Liquidação Financeira de Títulos -, mediante crédito ou débito nas contas de reservas bancárias no Banco Central, sendo que a sensibilização das reservas ocorre no dia útil subseqüente ao da operação.

Do universo de empréstimos desta natureza e que durem um dia, a CETIP calcula uma média das taxas de juros ponderadas pelos volumes das operações, a qual é divulgada diariamente no final de cada dia útil. Esta taxa média diária obtida pela metodologia anterior chama-se de DI over, acrônimo para Deposito Interfinanceiro com prazo de um dia útil. Usualmente, o DI over é conhecido como taxa do CDI.

No caso brasileiro, um fluxo atrelado ao CDI, que é uma taxa pós-fixada, pode ser construído diariamente na medida em que a CETIP divulga a taxa do CDI. Neste particular, a divulgação da taxa do CDI diário ocorre no final do dia a que ela se refere.

Uma típica obrigação de renda fixa brasileira, como uma debênture, paga cupom 
semestral. É comum no mercado brasileiro que a taxa do cupom de uma debênture seja a acumulação no período de um semestre da taxa diária do CDI, ou um percentual do CDI.

Nesta linha de raciocínio, considerando uma debênture com valor de face R\$ 1.000.000,00, que prometa pagar cupom semestral equivalente a $100 \%$ do CDI e que o CDI acumulado neste período seja de 10,45\%, tem-se que o cupom semestral será de:

$$
\text { Cupom }=0,1045 * 1.000 .000=\mathrm{R} \$ 104.500,00
$$

Ainda no caso brasileiro, fluxos podem ser construídos com outras taxas pósfixadas como a TR, TBF, IGP-M e Selic, entre outras.

Deve-se notar que conquanto a TR, a Selic, a TBF e outros índices sejam divulgados diariamente, existem indexadores para a construção de fluxos pós-fixados que são divulgados com periodicidade mensal, tal como ocorre com o IGP-M.

\subsubsection{Fluxos Construídos com Taxas Flutuantes}

Em contraste com os títulos que pagam cupom fixo ou mesmo os step-ups, existem títulos denominados de floating-rate bonds ou títulos de taxa flutuante.

FABOZZI (2000: 5) comenta que os títulos atrelados a taxas flutuantes possuem:

(...) taxas de juros que são reajustadas periodicamente de acordo com um benchmark predeterminado. Embora a taxa de cupom da maioria dos bônus de taxas flutuantes seja reajustada com base em algum índice financeiro, há algumas emissões para as quais o benchmark para taxa de cupom é um índice não-financeiro, como o preço de um commodity. Em segundo lugar, enquanto o cupom de bônus de taxas de juros normalmente sobe quando o benchmark sobe e cai quando o benchmark cai, há emissões em que a taxa de juro do cupom se comporta de maneira inversa em relação às mudanças nas taxas de juros. Tais emissões são denominadas flutuantes inversas (inverse floaters) e investidores institucionais as utilizam como instrumentos de hedging.

No ambiente internacional, uma das taxas flutuantes mais empregadas nos negócios é a London Interbank Offered Rate, conhecida como LIBOR, compilada e divulgada diariamente pela British Bankers Association. 
A LIBOR é cotada em maturidades que vão de um mês até um ano e, além de funcionar como um indicativo dos juros de curto prazo, é considerada por BREALEY \& MYERS (1998: 360) “(...) a taxa de juro em dólares a que os principais bancos internacionais de Londres emprestam dinheiro uns aos outros". Isto não quer dizer que a LIBOR seja cotada exclusivamente em relação ao dólar americano, na verdade, a LIBOR é cotada nas moedas GBP (libra esterlina), CAD (dólar canadense), EUR (euro), USD (dólar americano), AUD (dólar australiano), YEN (ien japonês), CHF (franco suíço). Quando a moeda a que LIBOR se refere for omitida, subtende-se que a mesma é cotada em relação ao dólar americano.

Tabela 2: Taxas vigentes da LIBOR em 30/01/2002

\begin{tabular}{|l|c|}
\hline & Taxa anual em 30/01/2002 \\
\hline LIBOR de 1 mês & 1,830 \\
\hline LIBOR de 3 meses & 1,870 \\
\hline LIBOR de 6 meses & 2,020 \\
\hline LIBOR de 1 ano & 2,500 \\
\hline
\end{tabular}

Fonte: http://www.bankrate.com

Existem taxas flutuantes similares à LIBOR, como a Paris Interbank Offered Rate - PIBOR, Tokyo Interbank Offered Rate - TIBOR, Euro Interbank Offered Rate Euribor. Contudo, nenhuma delas tem a relevância da LIBOR.

Outra taxa flutuante de bastante interesse é a prime rate, taxa que vigora nos Estados Unidos para empréstimos concedidos para empresas consideradas de baixo risco de crédito, como as blue chips.

No mercado internacional, o floater é um instrumento de renda fixa cujo cupom ou taxa de juros é periodicamente ajustado de acordo com o patamar de uma taxa flutuante como a LIBOR ou a prime rate, sendo que os exemplos mais comuns desses instrumentos de renda fixa são as floating rate notes e os floating rate certificates of deposits. 
Considerando o cenário nacional, a Taxa de Juros de Longo Prazo, conhecida como TJLP é a taxa de juros flutuante mais usual sendo que a mesma é fixada pelo Conselho Monetário Nacional e vigora durante três meses. Nas resoluções emitidas pelo Banco Central, ao divulgar o novo patamar da TJLP, ele explica que a fixação levou em consideração a inflação projetada para os próximos doze meses acrescida de prêmio pelo risco. A TJLP é utilizada de maneira bastante intensa como custo para os empréstimos concedidos pelo BNDES.

É interessante notar que em operações de renda fixa envolvendo taxas flutuantes, as partes conhecem o atual patamar da taxa e sabem também até que data a taxa flutuante vigorará antes de ser ajustada. No caso da taxa pós-fixada, o fluxo só é conhecido quando o nível da taxa for divulgado.

\subsubsection{O Retorno e o Preço dos Títulos de Renda Fixa}

FABOZZI (2000: 26) afirma que:

O preço de qualquer instrumento financeiro é igual ao valor presente dos fluxos de caixa esperados do instrumento financeiro. Portanto, para se determinar o preço são necessárias: 1) Uma estimativa dos fluxos de caixa esperados. 2) Uma estimativa do rendimento adequado exigido.

E acrescenta que "O retorno exigido é determinado pela investigação dos retornos oferecidos por bônus comparáveis no mercado".

Conforme BERNSTEIN \& DAMODARAN (1998: 187), três dados de entrada são necessários para se avaliar qualquer ativo: (1) o fluxo de caixa esperado, (2) o timing do fluxo de caixa e (3) a taxa de desconto que seja apropriada ao grau de risco dos fluxos de caixa. E acrescentam que este modelo de avaliação é genérico o suficiente para se aplicar a qualquer tipo de ativo. Sob esta visão, um título de renda fixa tem seu preço dado pela seguinte formulação geral:

$$
P=\sum_{t=1}^{T} \frac{C_{t}}{(1+r)^{t}}
$$

Sendo que:

$$
\text { P: } \quad \text { Preço do título; }
$$



$t: \quad$ tempo;
$C_{t}: \quad$ fluxo de caixa no instante $t$;
$r: \quad$ taxa de juros.

Ainda segundo os referidos autores, partindo de uma perspectiva que vise a avaliação de ativos, um título livre de risco e de cupom zero, o qual proporciona apenas um fluxo de caixa no seu vencimento, representa o ativo mais fácil de ser avaliado. Para este ativo, a taxa de desconto apropriada é a taxa livre de risco. Nestas condições, o preço deste título resume-se a:

$$
P=\frac{F}{\left(1+r_{f}\right)^{t}}
$$

Sendo que:

$$
\begin{aligned}
& F: \quad \text { Valor de face do título; } \\
& r_{f} \quad \text { Taxa livre de risco; }
\end{aligned}
$$

Pode-se introduzir uma complexidade adicional ao considerar um título livre de risco e que pague cupom numa periodicidade determinada. Segundo BERNSTEIN \& DAMODARAN (1998: 197), este título pode ser visualizado como uma coleção títulos de cupom zero e cada um deles pode ser avaliado de maneira similar o que conduz ao seguinte resultado:

$$
P=\sum_{t=1}^{N} \frac{\text { Cupom }}{\left(1+r_{f}\right)^{t}}+\frac{F}{\left(1+r_{f}\right)^{N}}
$$

Deve-se notar que a taxa de desconto deve estar numa unidade compatível com a unidade de tempo utilizada na variável $t$. Ademais, a taxa de desconto utilizada deve ser obtida por intermédio de uma curva de juros conveniente.

Supondo um caso no qual um bônus com prazo de 20 anos com uma taxa de cupom de $10 \%$ ao ano ou $5 \%$ ao semestre e que possui valor de face igual a $\$ 1.000$ deva ter seu preço calculado. 
Naturalmente, o fluxo de caixa com estas características apresenta o seguinte perfil:

Figura 9: Fluxo de Caixa

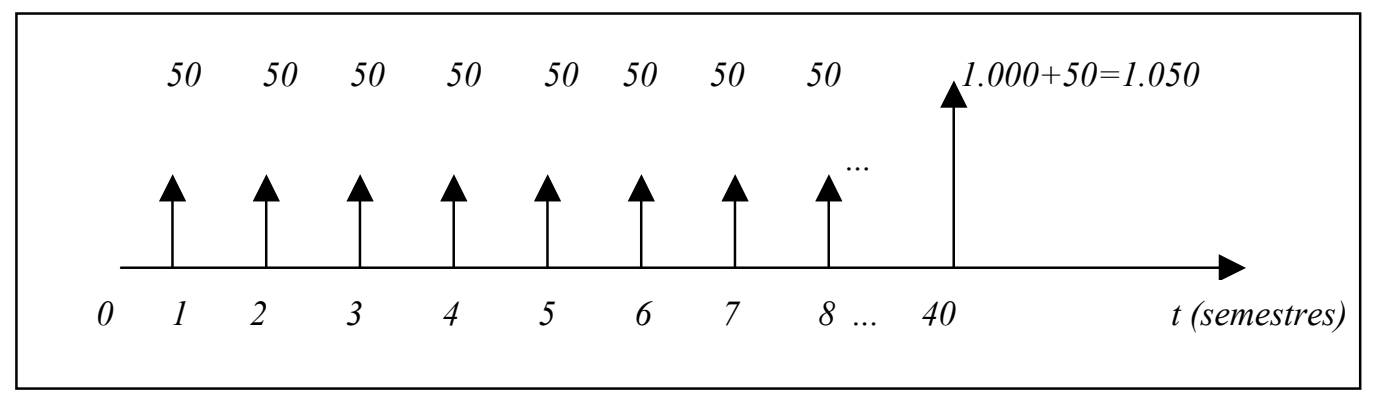

Considerando que a taxa básica vigorando na economia no momento da negociação deste título seja de $11 \%$ ao ano, tem-se que a taxa básica ao semestre é dada por:

$$
r_{\text {semestral }}=\frac{11}{2}=5,5 \%
$$

Admitindo ainda que este título seja de baixo risco, é razoável considerar que a taxa de rendimento exigida por potenciais investidores coincida com a taxa básica da economia, ou seja, $5,5 \%$ ao semestre.

Nestas circunstâncias, tem-se que o preço desta obrigação é dado por:

$$
P=\sum_{t=1}^{T} \frac{C_{t}}{\left(1+r_{\text {semestral }}\right)^{t}}=\sum_{t=1}^{39} \frac{50}{(1+0,055)^{t}}+\frac{1.050}{(1+0,055)^{40}}=802,306+117,46=\$ 919,77
$$

BERNSTEIN \& DAMODARAN (1998: 197) afirmam que o próximo passo na avaliação de ativos é se desfazer da premissa de que o título em análise não tenha risco de default. Segundo os referidos autores, para títulos que possuem risco embutido, a estrutura básica de avaliação permanece inalterada. A modificação residiria na taxa de desconto utilizada, a qual deverá ser maior que a taxa livre de risco.

Caso a taxa de desconto seja maior, o preço do título cairá. Caso contrário, isto é, se a taxa de desconto for menor, o título será mais caro. Sobre esta questão, FABOZZI (2000: 32) afirma que: 
Uma propriedade fundamental de um bônus é que seu preço muda no sentido oposto da mudança no retorno exigido. A razão disto é que o preço do bônus é o valor presente dos fluxos de caixa. À medida que o retorno exigido aumenta, o valor presente dos fluxos de caixa decresce: daí a diminuição de preço. O oposto é verdadeiro quando o retorno exigido decresce: o valor presente dos fluxos de caixa aumenta e, portanto, o preço do bônus aumenta.

A curva de possíveis preços do título em questão, de acordo com o patamar da taxa de desconto, é dado pela Figura 10:

Figura 10: Evolução do Preço de Acordo com a Taxa de Desconto

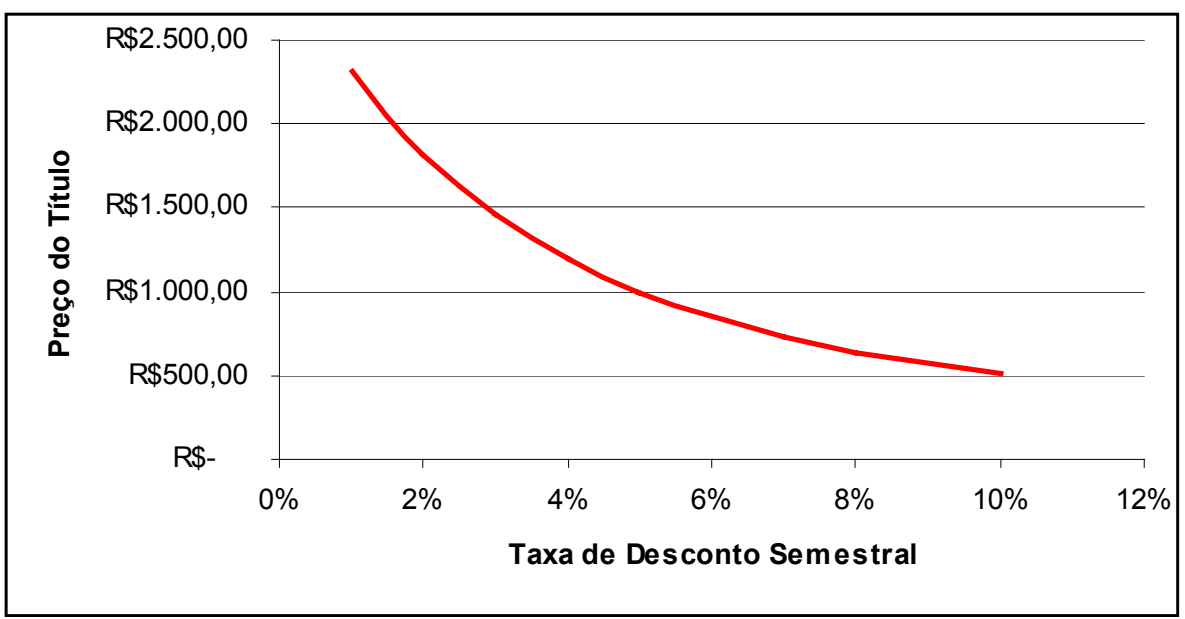

Percebe-se do gráfico que, quando a taxa de desconto é exatamente igual à taxa do cupom, o preço do título é igual ao seu valor de face ou principal.

Ainda que o título não possua pagamentos intermediários de cupom, a curva do valor presente em relação à taxa de desconto continuará a ter o formato exponencial.

O retorno e o preço de um título de renda fixa são variáveis que estão interrelacionadas. Corroborando este argumento, ROGÊ FERREIRA \& ANDRADE (1999: 61) asseveram que o retorno de um título de renda fixa é proporcionado pelos juros pagos por este título e por alterações no seu preço à vista.

Para BODIE et al. (2000: 316), tem-se que:

(...)em um mercado competitivo, todos os títulos precisam oferecer taxas esperadas de retorno justas aos investidores. Se uma obrigação for emitida com um cupom de $8 \%$ quando os rendimentos competitivos são de $8 \%$, ela será 
vendida pelo valor nominal. Se a taxa de mercado subir para $9 \%$, no entanto, quem compraria uma obrigação com cupom de $8 \%$ pelo valor nominal? O preço da obrigação precisa cair até que o seu retorno esperado aumente para o nível competitivo de $9 \%$. De maneira oposta, se a taxa de mercado cair para $7 \%$, o cupom de $8 \%$ da obrigação é atraente, em comparação aos rendimentos sobre investimentos alternativos. Os investidores que estão ansiosos por aquele retorno reagirão fazendo ofertas de preços das obrigações que estão acima de seu valor nominal, até que a taxa total de retorno caia para a taxa de mercado.

Quando um investidor paga por um título um preço superior ao seu valor de face, diz-se que o título foi comprado com ágio. Por outro lado, quando um título de renda fixa é adquirido por um preço inferior ao seu valor de face, diz-se que o mesmo foi adquirido com deságio. Quando um título de renda fixa é adquirido por seu valor de face, diz-se que mesmo foi comprado ao par.

FABOZZI (2000: 33) argumenta de maneira similar à BODIE et al. ao dizer que:

À medida que os retornos dos mercados mudam, a única variável que pode mudar para compensar um investidor pelo novo retorno exigido no mercado é o preço do bônus. Quando a taxa de cupom for igual ao retorno exigido, o preço do bônus será igual ao seu valor ao par ... Quando os retornos do mercado se elevam acima da taxa do cupom num determinado ponto no tempo, o preço do bônus se ajusta para que o investidor possa realizar algum juro adicional. Se assim não o fosse, os investidores não comprariam a emissão por oferecer um retorno abaixo do de mercado; a falta de demanda resultante faria com que o preço caísse e, assim, com que o retorno do bônus aumentasse. É assim que o preço do bônus cai abaixo de seu valor ao par.

FABOZZI (2000: 34) finaliza o raciocínio ao dizer que “(...) um bônus cujo preço está acima de seu valor ao par está sendo vendido com prêmio. O relacionamento entre a taxa do cupom, o retorno exigido e o preço podem ser resumidos como segue":

- Se a taxa do cupom for menor que o retorno exigido, o preço da obrigação será menor que o valor ao par, portanto a obrigação em questão é um bônus com desconto. 
- Se a taxa do cupom for igual ao retorno exigido, o preço da obrigação será igual ao valor ao par, portanto a obrigação em questão é um bônus vendido ao par;

- Se a taxa do cupom for maior que o retorno exigido, o preço da obrigação será maior que o valor ao par, portanto a obrigação em questão é um bônus com prêmio.

WESTON \& BRIGHAM (2000: 260) reafirmam as relações entre taxa de cupom, retorno exigido e preço do título da seguinte maneira:

1. Sempre que a taxa de juros corrente, $\mathrm{k}_{\mathrm{d}}$, é igual à taxa de cupom, um título será vendido a seu valor ao par. Normalmente, a taxa de cupom é estabelecida no mesmo nível da taxa de juros corrente quando um título é emitido, de forma que inicialmente é vendido ao par.

2. As taxas de juros de fato mudam com o tempo, mas a taxa de cupom permanece fixa depois que o título foi emitido. Sempre que a taxa de juros corrente for maior do que a taxa de cupom, o preço do título cairá abaixo do seu valor ao par. Esse título é chamado de título de desconto.

3. Sempre que a taxa de juros corrente é inferior à taxa de cupom, o preço de um título vai se elevar acima de seu valor ao par. Esse título é chamado de título de prêmio.

4. Assim, um aumento nas taxas de juros fará que o preço de um título a pagar caia, enquanto um declínio nas taxas fará com que ele se eleve.

5. O valor de mercado de um título sempre vai se aproximar de seu valor ao par à medida que a data de vencimento se aproxime, desde que a empresa não vá à falência.

O referido autor complementa asseverarando que os titulares das obrigações de renda fixa podem se sujeitar a perdas ou ganhos de capital de acordo com o movimento das taxas de juros.

EMERY \& FINNERTY (1997: 773) afirmam que a maioria dos emissores de títulos de cupom estabelece uma taxa de cupom de tal forma que o título tenha seu preço correspondente ao valor ao par. Contudo, custos de transação assimétricos ou 
informações assimétricas podem tornar vantajoso para um emissor colocar a taxa de cupom abaixo da taxa de mercado.

Uma idéia errônea que se tem sobre os títulos de renda fixa é imaginar que os ganhos ou perdas nesta modalidade de investimento são fixos. Na verdade, os títulos de renda fixa são obrigações cujos ganhos são variáveis e são função de uma série de fatores, particularmente do comportamento das taxas de juros.

\subsubsection{Medidas de Rentabilidade de um Título}

ASSAF NETO (2000: 180) afirma que:

O conceito de Yield to Maturity - YTM reflete o rendimento (yield) efetivo dos títulos de renda fixa até seu vencimento (maturity). A determinação do YTM considera o preço de mercado do título e os fluxos de rendimentos associados, eqüivalendo sua metodologia exatamente à medida da taxa interna de retorno (IRR). A IRR é a taxa de desconto que iguala, em determinada data, entradas e saídas previstas de caixa de um investimento. Comparando o resultado do IRR com o custo de capital, é tomada a decisão econômica do investimento. Se a rentabilidade oferecida (IRR) for maior ou igual à remuneração exigida pelos proprietários do capital, a proposta é aceita, sendo rejeitada quando a IRR for inferior ao retorno desejado.

A idéia do YTM fica mais evidente quando se tem um fluxo de caixa préestabelecido, inclusive com seu preço fixado, e se deseja encontrar a taxa de remuneração que o comprador obterá se o título for adquirido e mantido até o seu vencimento. WESTON \& BRIGHAM (2000: 261) apresentam uma situação na qual é oferecido um título que vence em 14 anos, pagando cupom anual de 15\% sobre um valor de face de $\$ 1.000$ e que custa $\$ 1.368,31$. Um título como este apresentaria o fluxo de caixa dado pela Figura 11: 




Pelo fluxo de caixa dado pela Figura 11, tem-se que a taxa do cupom é de $15 \%$ pagos anualmente e que o YTM é de $10 \%$ ao ano. Um investidor com um custo de capital inferior à $10 \%$ ao ano ficaria inclinado a adquirir o título por $\$ 1.368,31$ uma vez que seu capital seria remunerado à taxa de $10 \%$ ao ano.

Naturalmente, não se pode confundir o conceito de rendimento (yield), o qual, consoante a explicação precedente, equivale à taxa interna de retorno, também conhecida como TIR ou IRR, com o conceito de cupom, o qual, conforme visto no tópico 2.1.8, corresponde ao pagamento periódico de juros efetuado pelo emissor ao detentor do título durante a vida deste último sendo que o cupom é obtido multiplicando-se a taxa do cupom pelo principal ou pelo valor de face ou pelo valor ao par. (FABOZZI, 1997: 5)

Ainda considerando o fluxo dado pela Figura 11, apesar do detentor do título receber cupom anual de $15 \%$, seu capital é remunerado à taxa de $10 \%$ ao ano.

\subsection{Os Mercados de Títulos de Renda Fixa no Brasil}

Conquanto existam os títulos de renda fixa de emissão privada, o mercado de títulos de renda fixa nacional é marcado pela preponderância dos títulos públicos federais. 


\subsubsection{O Mercado de Títulos de Renda Fixa de Emissão Federal e o Mercado Aberto no Brasil}

Sob o ponto de vista histórico, o Mercado de Títulos de Renda Fixa no Brasil foi e continua sendo fortemente movido pelas operações que ocorrem no Mercado Aberto (Open Market).

Para CHIESA (1983: 9), as operações do Mercado Aberto:

(...) constituem-se na política de compra e venda de títulos financeiros por parte do Banco Central, como autoridade monetária, tendo por objetivo o ajustamento, a qualquer instante das condições de liquidez da economia e ordenar a estrutura das taxas de juros, tanto do mercado monetário como no de capitais (...) praticam-se oficialmente no Brasil as operações de Mercado Aberto desde 1968, quando a gerência da Dívida Pública do Banco Central abriu sua carteira e deu início à condução das operações com títulos públicos federais (ORTN).

Há de se reconhecer que há quem considere que o início das operações no Mercado Aberto tenha ocorrido em 16/07/1964 por meio da Lei $n^{\circ}$. 4.357 que autorizava a emissão de ORTN com finalidade quase restrita à cobertura do déficit do Tesouro Nacional sem a necessidade de emissão de papel-moeda.

A razão de se considerar 1968 o ano que marcou o início do Mercado Aberto é o fato de que a partir desta data as negociações dos títulos ORTN adquiriram grande liquidez, algo que no passado não existia.

Uma evolução no Mercado Aberto deu-se em 29/01/1970 por intermédio do Decreto-Lei 1.079 que instituiu a Letra do Tesouro Nacional (LTN), um título vendido com desconto sobre o seu valor de face, a qual possuía vencimentos mais adequados ao mercado que as ORTNs. Nesse mesmo ano as LTNs passaram a ser vendidas no mercado semanalmente por intermédio dos agentes selecionados pelo Banco Central para negociação, os chamados dealers.

Quanto aos dealers, vale ressaltar que o Banco Central do Brasil, por intermédio da Circular n. ${ }^{\circ} 2.993$, de 14/07/2000, estabeleceu critérios de seleção das instituições credenciadas a operar com o Departamento de Operações do Mercado Aberto (DEMAB) bem como fixou em vinte e cinco o número de instituições financeiras credenciadas a operar com o DEMAB. As instituições ainda não credenciadas têm seu 
desempenho avaliado levando em conta a carteira própria e o volume de suas operações com o Banco Central e com os demais participantes do mercado. As instituições já credenciadas são avaliadas levando-se em conta o relacionamento com o DEMAB, entre outros critérios. Cabe às instituições credenciadas como dealers:

- manter cotação de negociabilidade para a compra e venda de três ou mais títulos de emissão do Banco Central e do Tesouro Nacional;

- apresentar freqüência em operações com títulos de emissão do Banco Central e do Tesouro Nacional de forma a dar liquidez a esses títulos;

- manter presença ativa e equilibrada no conjunto de operações realizadas pela mesa de operações do DEMAB;

- manter o Banco Central informado das ocorrências que afetem o equilíbrio e a liquidez do mercado financeiro;

- fornecer ao Banco Central, diariamente, informações sobre suas atividades operacionais que possibilitem avaliar a instituição de per si e sua participação relativa no mercado;

- conceder atenção prioritária às negociações de títulos do Banco Central, bem como aos contatos, de rotina ou especiais, mantidos com este Órgão.

O pleno funcionamento do Mercado Aberto nacional iniciou-se tardiamente, pois somente após a reforma bancária ocorrida em 1964 por intermédio da lei n. ${ }^{\circ} 4.595$ de 31/12/1964, é que o Banco Central do Brasil foi criado, e começou a funcionar em abril de 1965. Antes desta data, cabia ao Banco do Brasil as funções de Banco Central concomitantemente com suas funções de banco comercial.

A referida lei permitia que o Banco Central, sob certas circunstâncias, adquirisse títulos do Tesouro Nacional, ainda que para isso papel moeda tivesse que ser emitido. Com a promulgação da Constituição Federal em 1988 ficou vedado ao Banco Central conceder direta ou indiretamente empréstimos ao Tesouro Nacional e a qualquer instituição que não seja financeira; contudo a mesma constituição de 1988 permite que o Banco Central compre títulos do Tesouro Nacional com o objetivo de regular a oferta de moeda ou o patamar das taxas de juros. Ou seja, o Banco Central do Brasil não está 
totalmente impedido de financiar o Tesouro Nacional, algo que tem o potencial de mitigar o funcionamento do Mercado Aberto no Brasil.

Atualmente, existem basicamente dois grandes emissores de títulos públicos federais, o Banco Central-BACEN e a Secretaria do Tesouro Nacional-STN. O BACEN emite títulos com o objetivo de operacionalizar a Política Monetária doméstica enquanto que a STN emite seus papéis com o propósito de instrumentalizar a Política Orçamentária.

Tanto os papéis emitidos pelo BACEN como os do STN são emitidos e negociados por intermédio de uma câmara de compensação denominada SELIC, que é o Sistema Especial de Liquidação e Custódia criado em 1979 e administrado pelo próprio Banco Central. O SELIC permite que os títulos sejam negociados escrituralmente, sem a necessidade de se emitir um título físico, o que reduz significativamente os riscos envolvidos na operação. O SELIC constitui um marco na forma de liquidação financeira das operações de compra e venda de títulos públicos, pois até o seu advento, as liquidações eram feitas por intermédio da compensação bancária. Estas, a partir de 1979, passaram a ser realizadas na conta Reservas Bancárias que os bancos possuem no Banco Central, sendo que a liquidação passou a ser feita no mesmo dia que a transação de compra e venda tiver sido realizada. Adicionalmente, o SELIC permitiu que os títulos públicos passassem a funcionar como se fossem reservas bancárias, porém com a vantagem de permitir ao seu detentor remuneração diária. Ora, isto faz com que a instituição financeira opte por carregar títulos públicos a deter reserva, algo que enseja a liquidez do mercado de títulos de renda fixa constituído por papéis federais.

O SELIC, nos seus primórdios, conforme atesta GOMES de FARIA (2000: 81), caracterizava-se pelo fato de:

(...) só admitir um papel federal, a Letra do Tesouro Nacional (LTN), prefixada, emitida com prazo em número inteiro de semanas ou 365 dias cravados e negociada com taxas de desconto bancário (...). Hoje, há uma variedade muito grande de papéis negociados no SELIC, todos de responsabilidade de órgãos públicos, predominantemente federais: Banco Central do Brasil e Secretaria do Tesouro Nacional. 
Dentre os títulos emitidos pelo BACEN, destaca-se o Bônus do Banco Central (BBC), o qual caracteriza-se por ser um título de renda pré-fixada com deságio e emitido por um número inteiro de semanas. Suas emissões são realizadas por intermédio de leilões semanais, geralmente às terças-feiras e liquidados no dia útil imediatamente posterior.

$\mathrm{O}$ valor de face do título $\mathrm{BBC}$ é de $\mathrm{R} \$ 1.000,00$, sendo que o mesmo é negociado com base no seu valor presente. Em outras palavras, o título promete pagar ao seu detentor R\$ 1.000,00 no vencimento e é negociado pelo seu valor presente. Este valor presente chama-se Preço por Unidade a Receber, também denominado de PU do papel. Isto é, um investidor que adquira hoje um BBC por um PU de, digamos, $\mathrm{R} \$ 987,374589$ tem a promessa do BACEN de receber R $\$ 1.000,00$ no vencimento. Adicionalmente, o BACEN determina que o PU seja declarado com seis casas decimais após a vírgula.

Supondo um banco comercial que deseje adquirir 800 BBCs em um leilão que ocorrerá na próxima semana e que tenha vencimento em 87 dias úteis após o leilão, este banco apresentará oferta no leilão de um PU tal que produza uma taxa desejada, 19\% ao ano over, por exemplo.

Nessas circunstâncias, as partes envolvidas realizarão a seguinte aritmética:

$$
1000=P U \times(1+0,19)^{\frac{87}{252}} \Rightarrow P U=941,712447
$$

Caso a oferta seja aceita, a SELIC debitará da conta deste banco a quantia de 800 x $941,712447=\mathrm{R} \$ 753.369,96$ no dia do leilão e, no vencimento do papel, creditará o valor de $\mathrm{R} \$ 800.000,00$.

As Letras do Tesouro Nacional (LTN) são papéis caracterizados por serem títulos de renda pré-fixada com deságio, emitidas com vencimento para 6 ou 12 meses. $O$ valor de face de cada LTN é R\$1.000,00 e as mesmas são adquiridas por PU que representa um desconto em relação ao valor de face de maneira idêntica ao BBC.

Outro título de incontestável importância é a Nota do Tesouro Nacional-NTN, cuja colocação primária destina-se a prover o Tesouro Nacional de recursos para cobertura de déficits orçamentários ou antecipação de operações de crédito. Existem várias séries de NTN, cada uma de acordo com sua particularidade de prazo, taxa de 
juros e indexador. Dentre as séries, destacam-se os títulos NTN-C, NTN-D e NTN-H. A Nota do Tesouro Nacional, série C (NTN-C) é um título com a valorização do principal definida pela variação do IGP-M e pagamentos semestrais de juros, sendo que o Índice Geral de Preços - Mercado (IGP-M) é o índice de inflação calculado mensalmente pela Fundação Getúlio Vargas, com base na média ponderada do Índice de Preços por Atacado, do Índice de Preços ao Consumidor, e do Índice Nacional de Custo da Construção Civil -INCC. A NTN-D é um título atrelado à variação cambial mais juros. A NTN-H é um título atrelado à TR.

Uma recente inovação no mercado de títulos públicos federais deu-se em 2002, ano em que o Tesouro Nacional passou a oferecer ao pequeno investidor a oportunidade de comprar títulos públicos pela Internet. Esta inovação no mercado, chamada de Tesouro Direto, possibilitou que pessoas físicas adquirissem títulos públicos diretamente do Tesouro Nacional. Exigiu-se da pessoa interessada que a mesma fosse residente no Brasil, possuísse Cadastro de Pessoa Física-CPF e estivesse cadastrada em alguma das Instituições Financeiras habilitadas a operar no Tesouro Direto. Para que a operação se efetive, faz-se necessário que o interessado compre títulos por meio de Agentes de Custódias, instituições financeiras como Corretoras de Valores, Bancos Comerciais, Múltiplos ou de Investimento e Distribuidoras de Valores. O Agente de Custódia, autorizado pelo cliente, efetuará compras e vendas no Tesouro Direto bem como efetuará o serviço de guarda dos títulos de seus clientes. Estão disponíveis para compra os seguintes títulos: Letras Financeiras do Tesouro (LFT), Letras do Tesouro Nacional (LTN) e Notas do Tesouro Nacional, série C (NTN-C), sendo que, posteriormente, o Tesouro Nacional poderá disponibilizar outros títulos. No momento em que foi criado, este sistema permitiu que o interessado comprasse no mínimo 0,2 título (aproximadamente $\mathrm{R} \$ 200,00$ ) e no máximo $\mathrm{R} \$ 200.000,00$ por mês. A liquidez dos títulos é garantida pelo fato de o Tesouro Nacional recomprar todas as quartas-feiras os títulos vendidos no Tesouro Direto.

\subsection{As Carteiras de Títulos no Brasil}

As carteiras de títulos de renda fixa no Brasil são constituídas fortemente por títulos de renda fixa emitidos pelo governo federal e por títulos de renda fixa de emissão privada. 
Dentre as carteiras de títulos que se valem da renda fixa, não se pode deixar de mencionar a indústria de fundos.

RUSSO (2000), fazendo referência a um estudo que abrangeu um período de dois anos, de maio de 1998 até abril de 2000 assevera que:

A indústria de fundos de investimento no Brasil está concentrada no segmento de renda fixa. Dos cerca de $R \$ 220$ bilhões depositados em fundos, hoje, $R \$ 200$ bilhões aproximadamente estão nesse segmento e $R \$ 20$ bilhões em carteiras de renda variável.

Os títulos que podem compor algumas modalidades de fundos de investimento autorizados a funcionar pelo Banco Central são, por força de normatização do próprio poder regulador, justamente de emissão do Banco Central e da Secretaria do Tesouro Nacional. Isto é, o Banco Central do Brasil, por intermédio da Circular 2.958, de 06/01/2000, determinou que os fundos de investimento financeiro podem ser identificados como referenciados em indicador de desempenho, de acordo com a estrutura dos ativos financeiros que compõem a carteira de investimento, desde que atendidas cumulativamente as seguintes condições:

I -tenham no mínimo $80 \%$ de seu patrimônio líquido representado, isolada ou cumulativamente, por (i) títulos de emissão do Tesouro Nacional e/ou do Banco Central do Brasil, (ii) títulos e valores mobiliários de renda fixa cujo emissor esteja classificado na categoria baixo risco de crédito, com certificado de agência de risco estabelecida no país;

II - estipulem que 95\%, no mínimo, da carteira seja composta por ativos financeiros ou modalidades operacionais de forma a acompanhar direta ou indiretamente, a variação do indicador de desempenho escolhido;

III - restrinjam a atuação nos mercados de derivativos a realização de operações com o objetivo de proteger posições detidas à vista, até o limite dessas.

\subsection{Avaliação de Risco nas Carteiras de Títulos de Renda Fixa}

Segundo BERNSTEIN \& DAMODARAN (1998: 81), as fontes mais comuns de risco em investimentos são as exposições a mudanças em taxas de juros. 
Segundo FRANCIS (1980: 207), o risco de taxa de juros pode ser definido como flutuações nos preços de um título causados por mudanças nas taxas de juros associadas com o título em questão. Desta forma, os títulos com altos níveis de risco embutidos nas taxas de juros experimentarão maiores mudanças nos seus preços que aqueles títulos com menores parcelas de risco embutidas nas taxas de desconto.

Nesta linha de raciocínio ROGÉ FERREIRA \& ANDRADE (1999: 61) asseveram que a mudança no preço à vista de um título de renda fixa podem ser provocadas por:

a) passagem do tempo: nesse caso, a mudança no preço também não constitui fonte de incerteza para o investidor, visto que tal alteração pode perfeitamente ser calculada e antecipada.

b) alteração nas taxas de juros: deslocamento na yield curve implicam alterações na taxa de desconto dos retornos futuros do título, alterando seu valor presente. Como na maioria das vezes modificações nas taxas de juros não podem ser antecipadas pelos agentes econômicos, é exatamente nesse fator que reside a maior parte do risco relacionado aos títulos de renda fixa.

DIXIT \& PINDYCK (1994: 49) afirmam que a incerteza na taxa de juros pode ter o efeito de alterar o retorno de um investimento. Estes autores complementam o raciocínio ao dizerem que:

(...) supondo que um investimento forneça uma perpetuidade que pague $\$ 1$ por ano para sempre. O valor presente desta perpetuidade é $\$ 1 / \mathrm{r}$, sendo $\mathrm{r}$ a taxa de juros. Se $r=10$ por cento, o valor é $\$ 1 / 0,1=\$ 10$. Supondo que haja incerteza acerca do valor de $r$, sendo que há $50 \%$ de chances de $r=5 \%$ e $50 \%$ de chances para $r=15 \%$, então a esperança de $r$ é igual a $10 \%$. Então, o valor esperado da perpetuidade é $0,5 *(1 / 0,05)+0,5 *(1 / 0,15)=\$ 13,33>\$ 10$. Isto faz o investimento mais atrativo e aumenta o incentivo em adquiri-lo.

BODIE et al. (2000: 316) afirmam que enquanto as taxas de juros variam, os detentores de títulos de renda fixa realizam ganhos e perdas de capital. São justamente estes ganhos e perdas que fazem com que os investimentos de renda fixa apresentem risco.

Mesmo que os pagamentos do cupom e do principal estejam garantidos, há risco embutido nestes tipos de obrigações. 
Segundo STIGUM \& ROBINSON (1996: 209), o risco associado aos instrumentos de renda fixa surge por causa das incertezas atinentes às taxas de juros e pelos fatores que modelam a forma da curva de juros.

Portanto, a variação das taxas de juros do mercado afeta o valor das carteiras compostas por títulos de renda fixa. Pode-se dizer que o preço das obrigações está sujeita às mudanças nas taxas de juros. Isto é, os ativos de renda fixa são sensíveis às mudanças nos juros.

MALKIEL (1962), citado por BODIE et al. (2000: 317), estabeleceu cinco relacionamentos bem conhecidos de precificação de títulos de renda fixa:

- Os preços e os rendimentos de obrigações são inversamente relacionados: com um aumento nos rendimentos, os preços das obrigações caem; com uma queda nos rendimentos, eles sobem;

- Um aumento no rendimento até o vencimento de uma obrigação resulta em uma queda de preço menor do que o aumento no preço associado com uma queda de igual magnitude no rendimento;

- Os preços de obrigações de longo prazo tendem a ser mais sensíveis às mudanças nas taxas de juros do que os de curto prazo;

- O risco das taxas de juros é inversamente relacionado à taxa de cupom da obrigação. Os preços de obrigações com cupons altos são menos sensíveis às mudanças nas taxas de juros do que os de cupons mais baixos.

Ainda que se tenha em mente a análise qualitativa estabelecida por Malkiel, faz-se necessário quantificar a sensibilidade do preço do ativo de renda fixa para variações nas taxas de juros.

Corroborando este raciocínio, DERMAN (1996: 4) assevera que no universo da renda fixa, abordagens teóricas foram ensejadas pelo choque nos preços dos títulos de renda fixa originados pelas variações bruscas das taxas de juros no final da década de setenta. 
Ainda segundo o referido autor, técnicas como a duration, convexidade e outras medidas de sensibilidade ao risco cresceram em sofisticação e popularidade e, portanto, devem ser abordadas.

\subsubsection{A Duration}

Segundo LEVY \& SARNAT (1984: 52), o tempo que resta para um título vencer e o seu titular receber o valor de face recebe o nome de maturidade da obrigação. É comum pensar que títulos com a mesma maturidade tenham características similares no que tange ao risco das flutuações dos seus preços. Na prática, contudo, isto não é verdade pois, ainda que os títulos tenham maturidades iguais, o padrão de pagamento de juros pode diferir sensivelmente entre os mesmos.

BODIE et al. (2000: 318) afirmam que:

Para lidar com o conceito de vencimento de uma obrigação que faz muitos pagamentos, precisamos de uma medida do vencimento médio dos fluxos de caixa prometidos da obrigação, para servir como uma estatística de resumo do vencimento efetivo da obrigação. Esta medida também deve nos dar alguma informação sobre a sensibilidade da obrigação às mudanças nas taxas de juros (...).

A partir de um estudo do National Bureau of Economic Research datado de 1938, Frederick Macauley estabeleceu uma relação conhecida como duration. A duration é a média ponderada dos prazos de vencimentos de cada pagamento que o título confere. Cada prazo de vencimento é ponderado pelo valor presente de seu respectivo pagamento.

Considerando o fluxo abaixo, percebe-se que o mesmo confere ao seu titular dez pagamentos em dez vencimentos. Para cada prazo de vencimento $t$, seu respectivo fluxo de caixa $C_{t}$ será trazido a valor presente. A soma dos dez produtos (valor presente de $C_{t}$ vezes $t$ ) será dividida pela soma dos valores presentes de $C_{t}$, o que fornecerá a duration do fluxo. 


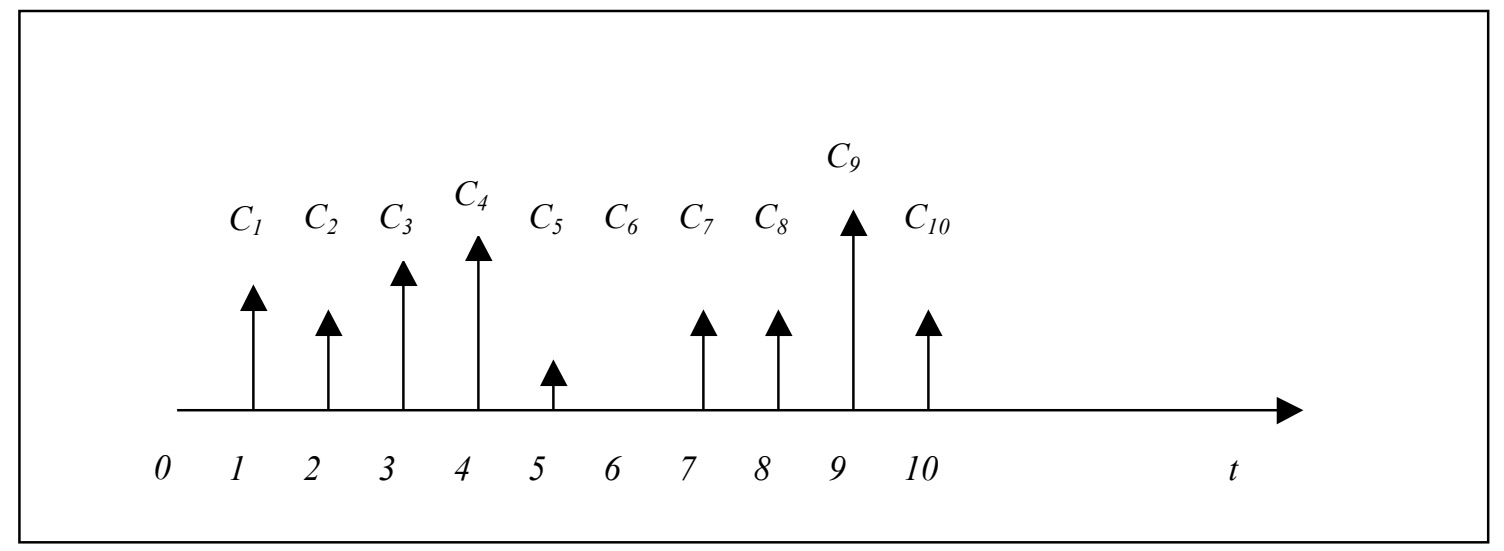

Colocando o raciocínio acima em termos matemáticos, tem-se que a duration é dada por:

$$
D=\frac{\sum_{t=1}^{T} \frac{C_{t}}{(1+r)^{t}} \times t}{\sum_{t=1}^{T} \frac{C_{t}}{(1+r)^{t}}}
$$

Sendo que:

D: duration;

$t: \quad$ tempo;

$C_{t}$ : $\quad$ fluxo de caixa no instante $t$;

$r$ taxa de juros.

Note que a parcela expressa por $\frac{C_{t}}{(1+r)^{t}}$ que está dentro das somatórias nada mais é que o valor presente de cada componente do fluxo de caixa.

Considerando as informações dadas na Tabela 3, o cálculo da duration para um título de valor de face $\$ 100 \mathrm{MM}$ emitido à taxa de cupom de $6 \%$ ao ano pode facilmente ser esquematizado da seguinte maneira: 
Tabela 3: Cálculo da Duration de um Título

\begin{tabular}{|c|c|c|c|c|}
\hline $\begin{array}{c}\text { Vencimento } \\
\text { (anos) }\end{array}$ & $\boldsymbol{C}_{\boldsymbol{t}}$ & $\begin{array}{r}\text { Taxa de } \\
\text { desconto }\end{array}$ & $\begin{array}{c}\text { Valor } \\
\text { Presente da } \\
\text { parcela } \boldsymbol{C}_{\boldsymbol{t}}\end{array}$ & $\begin{array}{c}\boldsymbol{t} \text { x Valor Presente } \\
\text { de } \boldsymbol{C}_{\boldsymbol{t}}\end{array}$ \\
\hline 1 & 6 & $6 \%$ & 5,66 & 5,66 \\
\hline 2 & 6 & $6 \%$ & 5,34 & 10,68 \\
\hline 3 & 6 & $6 \%$ & 5,04 & 15,11 \\
\hline 4 & 6 & $6 \%$ & 4,75 & 19,01 \\
\hline 5 & 106 & $6 \%$ & 79,21 & 396,05 \\
\hline Soma & & & 100 & 446,51 \\
\hline
\end{tabular}

Duration $=\frac{446,51}{100}=4,44651$ anos.

Segundo FABOZZI (1997: 86), é importante notar que para um título de cupom zero, a duration coincide com sua maturidade, o que corrobora o argumento de BODIE et al. (2000: 321) quando afirmam que "A duração de uma obrigação de cupom zero é igual ao seu tempo até o vencimento".

Essas assertivas podem ser visualizadas por intermédio do cálculo da duration para um título de valor de face $\$ 100 \mathrm{MM}$ e que não paga juros intermediários:

Tabela 4: Cálculo da Duration de um Título de Cupom Zero

\begin{tabular}{|c|c|c|c|c|}
\hline $\begin{array}{c}\text { Vencimento } \\
\text { (anos) }\end{array}$ & $C_{\boldsymbol{t}}$ & $\begin{array}{c}\text { Taxa de } \\
\text { desconto }\end{array}$ & $\begin{array}{c}\text { Valor } \\
\text { Presente da } \\
\text { parcela } C_{\boldsymbol{t}}\end{array}$ & $\begin{array}{c}\boldsymbol{t} \text { X Valor Presente } \\
\text { de } \boldsymbol{C}_{\boldsymbol{t}}\end{array}$ \\
\hline 1 & 0 & $6 \%$ & 0 & 0 \\
\hline 2 & 0 & $6 \%$ & 0 & 0 \\
\hline 3 & 0 & $6 \%$ & 0 & 0 \\
\hline
\end{tabular}




\begin{tabular}{|l|c|c|c|c|}
\hline 4 & 0 & $6 \%$ & 0 & 0 \\
\hline 5 & 100 & $6 \%$ & 74,73 & 373,63 \\
\hline Soma & & 74,73 & 373,63 \\
\hline \multicolumn{2}{|l}{} \\
\hline
\end{tabular}

A partir do conceito de duration, é possível deduzir um modelo simples para determinar a sensibilidade do valor presente da carteira de ativos de renda fixa para pequenas mudanças nas taxas de juros.

\subsubsection{A Sensibilidade do Preço e a Duration}

Conforme BENINGA (1997: 229), a duração é uma medida da sensibilidade do preço de um título para mudanças nas taxas de juros que descontam o fluxo. Isto é, segundo o referido autor, outra maneira de se visualizar a duration é considerá-la como a elasticidade preço do título em relação à taxa de juros, algo que explica porque a medida da duration pode ser utilizada para calcular a volatilidade do preço do título. Ademais, esta interpretação da duration faz com que a mesma seja freqüentemente utilizada como uma medida de risco do título.

A sensibilidade do preço do título para mudanças nas taxas de juros pode ser obtida calculando-se a derivada do valor presente de um fluxo de caixa dado por $P$ em relação à taxa de juros dada por $r$ :

$$
P=\sum_{t=1}^{T} \frac{C_{t}}{(1+r)^{t}}=\sum_{t=1}^{T} C_{t} \times(1+r)^{-t}
$$

A partir da equação do valor presente, pode-se obter sua derivada primeira em relação à taxa de juros:

$$
\frac{d P}{d r}=\sum_{t=1}^{T}\left[-C_{t} \times t \times(1+r)^{-t-1}\right]=\sum_{t=1}^{T} \frac{\left[-C_{t} \times t\right]}{(1+r)^{t+1}}=\frac{-1}{1+r} \times \sum_{t=1}^{T} \frac{C_{t} \times t}{(1+r)^{t}}
$$

Sabendo que a duration é dada por: 
$D=\frac{\sum_{t=1}^{T} \frac{C_{t}}{(1+r)^{t}} \times t}{P}$

Fazendo a devida substituição, tem-se que:

$\frac{d P}{d r}=\frac{-1}{1+r} \times D \times P$

Então, para uma variação infinitesimal $d r$ nas taxas de juros, o preço do título variará de $d P=\frac{-1}{1+r} \times D \times P \times d r$.

É comum entre os estudiosos de renda fixa utilizarem a equação anterior de forma ligeiramente diferente ao se introduzir o conceito de duration modificada dada por $D^{*}$. (BODIE et al., 2000: 320)

A duration modificada consiste em $D^{*}=\frac{D}{1+r}$.

Neste caso, tem-se que $d P=-D^{*} \times P \times d r$.

Vale lembrar que nos casos práticos em que as variações das taxas de juros não são infinitesimais, deve-se reescrever as relações anteriores da seguinte maneira:

- $\Delta P \approx \frac{-1}{1+r} \times D \times P \times \Delta r:$ sendo $\Delta P$ e $\Delta r$ variações discretas no preço do título e nas taxas de juros, respectivamente.

- $\Delta P \approx-D^{*} \times P \times \Delta r$ : sendo $\Delta P$ e $\Delta r$ variações discretas no preço do título e nas taxas de juros, respectivamente.

FABOZZI (2000: 85) lembra que como a duration modificada para todos os títulos é positiva, a equação anterior afirma que há uma relação antagônica entre variação percentual aproximada do preço do título e a variação da taxa de juros. Isto é um aumento nas taxas de juros implicará queda no preço do título e uma queda nas taxas de juros implicará aumento no preço do título. 
Conforme já foi evidenciado, um título de valor de face $\$ 100 \mathrm{MM}$, que paga juros de $6 \%$ ao ano implica duration de 4,46 anos, dada uma taxa de juros de $6 \%$ ao ano.

Se, contudo, a taxa de juros passar para $6,5 \%$ ao ano, este título deixará de valer \$100 MM e passará a valer:

Tabela 5: Cálculo da Duration de um Título

\begin{tabular}{|c|c|c|c|}
\hline $\begin{array}{c}\text { Vencimento } \\
\text { (anos) }\end{array}$ & $\boldsymbol{C}_{\boldsymbol{t}}$ & $\begin{array}{c}\text { Taxa de } \\
\text { desconto }\end{array}$ & $\begin{array}{c}\text { Valor Presente da } \\
\text { parcela } \boldsymbol{C}_{\boldsymbol{t}}\end{array}$ \\
\hline 1 & 6 & $6,5 \%$ & 5,63 \\
\hline 2 & 6 & $6,5 \%$ & 5,29 \\
\hline 3 & 6 & $6,5 \%$ & 4,97 \\
\hline 4 & 6 & $6,5 \%$ & 4,66 \\
\hline 5 & 106 & $6,5 \%$ & 77,36 \\
\hline \multicolumn{2}{|c|}{ SOMA do VP } \\
\hline
\end{tabular}

Contudo, ao se utilizar a duration, obtém-se os seguintes resultados:

$$
\Delta P \approx \frac{-1}{1+r} \times D \times P \times \Delta r \approx \frac{-1}{1+0,06} \times 4,46 \times 100 \times(0,065-0,06)=-2,103, \quad \text { o } \quad \text { que }
$$

significa dizer que a duration prevê uma queda de \$2,1226 MM no valor da carteira, o que resultaria num preço de $(100-2,103)=\$ 97,90 \mathrm{MM}$.

Deve ficar claro que os valores $\$ 97,92 \mathrm{MM}$ (valor real da carteira) e $\$ 97,90 \mathrm{MM}$ são muito próximos, o que significa dizer que neste caso a duration foi uma aproximação bastante razoável.

Note que esta aproximação é razoável para pequenas mudanças nas taxas de juros. Para variações não tão pequenas, a aproximação dada pela duration não é satisfatória. 


\subsubsection{A Duration e a Administração de Risco}

CARNEIRO \& CARNEIRO (2000: 24) afirmam que:

(...) a administração de carteiras de renda fixa no mercado brasileiro é feita, essencialmente, por meio da dimensão duration. A agenda básica desse mercado direcional é dominada por questões como: qual posição tomar (pós ou pré), qual o nível de duration e qual segmento da curva de juros a ser posicionado. Por exemplo, no caso dos mercados de juros da BM\&F (contratos DI e swap), essas questões são cruciais no momento da escolha da estratégia/contratos, integração, modularização e transparência do processo de investimento e da tomada de decisão.

Ainda que a duration seja um instrumento bastante utilizado na administração de risco para carteiras de renda fixa, a duration possui algumas limitações.

A duration só é válida para exposições sujeitas a pequenos movimentos na taxa de juros por causa da aproximação linear. (FABOZZI, 2000: 90-92)

A segunda limitação na utilização da duration é que a mesma só é válida para curvas de juros (yield curves) que se movimentem em paralelo uma vez que a dedução da sensibilidade do preço do título às variações das taxas de juros supõe o mesmo $d r$ para todos os vencimentos. Em outras palavras, o modelo de Macauley assume movimentos paralelos em toda a estrutura das taxas de juros.

Segundo JORION (1997: 123), a duration está limitada a processos estocásticos que possam ser explicados por modelos de um fator, o qual será analisado posteriormente.

Sob a ótica do presente estudo, modelos de um fator são aqueles que apenas conseguem captar variações no valor da carteira para mudanças paralelas nas curvas de juros, assunto que merecerá especial atenção no tópico 3.1. 


\subsubsection{A Convexidade}

A convexidade é uma medida de segunda ordem no que diz respeito aos efeitos no preço de um título ou carteira de títulos dada uma mudança no patamar dos juros.

Em outras palavras, a convexidade está associada à derivada segunda do Valor Presente do fluxo em relação aos juros.

A Convexidade é dada pela seguinte relação:

$$
C=\frac{1}{P \times(1+r)^{2}} \times \sum_{t=1}^{T}\left[P V\left(C_{t}\right) \times t \times(t+1)\right]
$$

Sendo que:

C: $\quad$ convexidade;

T: $\quad$ número de vencimentos do título;

$C_{t}$ : $\quad$ fluxo de caixa no instante $t$;

$P V\left(C_{t}\right)$ : fluxo de caixa do instante $t$ trazido a valor presente;

$r: \quad$ taxa de juros;

P: $\quad$ preço do título.

A importância da convexidade decorre do fato da duration não ser capaz de descrever satisfatoriamente a variação no preço do título para grandes mudanças nas taxas de juros.

Isto é, a convexidade é um refinamento no cálculo da variação de preço de um título dada a variação nos juros. Este refinamento é tanto mais importante quanto maior for a variação no patamar dos juros.

O cálculo da variação do preço considerando efeitos de segunda ordem pode ser obtido por intermédio da expansão de Taylor de mesma ordem, a qual é dada por: 


$$
\Delta P=\frac{d P}{d r} \times \Delta r+\frac{1}{2} \times \frac{d^{2} P}{d r^{2}} \times(\Delta r)^{2}
$$

No cálculo da duration foi visto que a primeira derivada de $P$ em relação à $r$ é dada por:

$$
\frac{d P}{d r}=\sum_{t=1}^{T}\left[-C_{t} \times t \times(1+r)^{-t-1}\right]=\sum_{t=1}^{T} \frac{\left[-C_{t} \times t\right]}{(1+r)^{t+1}}=\frac{-1}{1+r} \times \sum_{t=1}^{T} \frac{C_{t} \times t}{(1+r)^{t}}
$$

Realizando as devidas transformações, tem-se que:

$$
\frac{d P}{d r}=\frac{-1}{1+r} \times \frac{\left(\sum_{t=1}^{T} \frac{C_{t} \times t}{(1+r)^{t}}\right) \times P}{P}=\frac{-1}{1+r} \times D \times P
$$

Por conseguinte, a segunda derivada de $P$ em relação a $r$ é dada por:

$$
\frac{d^{2} P}{d r^{2}}=\sum_{t=1}^{T}\left[C_{t} \times t \times(t+1) \times(1+r)^{-t-2}\right]=\frac{1}{(1+r)^{2}} \times \sum_{t=1}^{T} \frac{C_{t} \times t \times(t+1)}{(1+r)^{t}}
$$

Esta última relação pode ser simplificada para:

$$
\frac{d^{2} P}{d r^{2}}=\frac{\left(\frac{1}{(1+r)^{2}} \times \sum_{t=1}^{T} \frac{C_{t} \times t \times(t+1)}{(1+r)^{t}}\right) \times P}{P}=C \times P
$$

Relembrando que $\frac{d P}{d r}=\frac{-1}{1+r} \times D \times P$ e que $\frac{d^{2} P}{d r^{2}}=C \times P$, então, por intermédio da expansão de Taylor tem-se que:

$$
\Delta P=\left(\frac{-1}{1+r} \times D \times P\right) \times \Delta r+\frac{1}{2} \times(C \times P) \times(\Delta r)^{2}
$$

De maneira a evidenciar a utilização da convexidade, serão aproveitados os dados do item 2.4.1 através do qual foi exemplificado o conceito de duration: 
Tabela 6: Cálculo da Convexidade de um Título

\begin{tabular}{|c|c|c|c|c|}
\hline $\begin{array}{c}\text { Vencimento } \\
\text { (anos) }\end{array}$ & $\mathbf{C t}$ & $\begin{array}{c}\text { Taxa de } \\
\text { desconto }\end{array}$ & $\mathbf{V P}(\mathbf{C t})$ & $\mathbf{t}$ vezes (t+1) vezes VP(Ct) \\
\hline $\mathbf{1}$ & 6 & $6,00 \%$ & 5,6604 & 11,3208 \\
\hline $\mathbf{2}$ & 6 & $6,00 \%$ & 5,3399 & 32,0399 \\
\hline $\mathbf{3}$ & 6 & $6,00 \%$ & 5,0377 & 60,4526 \\
\hline $\mathbf{4}$ & 6 & $6,00 \%$ & 4,7525 & 235,0512 \\
\hline $\mathbf{5}$ & 106 & $6,00 \%$ & 79,2093 & 2575,1454 \\
\hline Soma & & 100 & 100 & 2810 \\
\hline
\end{tabular}

Em 2.4.1, foi visto que a duration do fluxo acima é de 4,4651 anos.

Relembrando que a convexidade é dada por $C=\frac{1}{P \times(1+r)^{2}} \times \sum_{t=1}^{T}\left[P V\left(C_{t}\right) \times t \times(t+1)\right]$, obtém-se para o fluxo acima a convexidade $C$ $=22,9187$.

Se, contudo, a taxa de juros passar para $6,5 \%$ ao ano, este título deixará de valer \$100 MM e passará a valer \$97,92 MM, conforme já foi calculado no item 2.4.2.

Ao se utilizar apenas a duration como medida de sensibilidade, obtém-se o valor \$97,90 MM como novo preço do título.

Utilizando a duration e a convexidade, chega-se ao seguinte valor para a variação no preço da carteira para uma mudança na taxa de juros de $6,0 \%$ ao ano para $6,5 \%$ ao ano:

$$
\Delta P \approx\left(\frac{-1}{1+r} \times D \times P\right) \times \Delta r+\frac{1}{2} \times(C \times P) \times(\Delta r)^{2}
$$




$$
\Delta P \approx\left(\frac{-1}{1+0,06} \times 4,46 \times 100\right) \times(0,065-0,06)+\frac{1}{2} \times(22,92 \times 100) \times(0,065-0,06)^{2}=-2,07
$$

, o que significa dizer que a duration e a convexidade prevêem uma queda de \$2,07MM no valor da carteira, o que resultaria num preço de $(100-2,07)=\$ 97,92 \mathrm{MM}$.

Vê-se, portanto, que a inclusão da convexidade ao modelo aumentou sensivelmente a acurácia da previsão. 


\subsection{O Valor em Risco (VaR)}

BENNINGA \& WIENER (1998: 1) afirmam que o "Valor em Risco (VaR) mede a pior perda esperada dentro de condições normais de mercado em um intervalo de tempo específico, dado um intervalo de confiança".

Esses mesmos autores citam um documento do J.P. Morgan segundo o qual o "VaR responde a questão: quanto eu posso perder com $\mathrm{x} \%$ de probabilidade em um intervalo de tempo pré-estabelecido". E acrescentam: "Supondo que o gestor de um portfólio de investimentos encontre um VaR igual a $\$ 1.000 .000$ a 1\%. Isto significa que há apenas 1 chance em 100 que a perda de um dia seja maior que \$1.000.000, considerando o mercado em condições normais". (BENNINGA \& WIENER, 1998: 1)

Para JORION (1997: 86), “...VAR summarizes the expected maximum loss (worst loss) over a target horizon within a given confidence interval".

Isto é, o “(...) o VaR sintetiza a máxima perda esperada dentro de um intervalo de tempo e dado um intervalo de confiança”.

Das definições acima, percebe-se, portanto, que o horizonte de tempo no qual a perda pode ocorrer $(T)$ e o intervalo de confiança $(1-\alpha)$, sendo $\alpha$ a significância, são os dois parâmetros principais a serem escolhidos.

A escolha desses dois parâmetros depende do objetivo que se tem dentro da monitoração do risco.

Para BENNINGA \& WIENER (1998: 1), o horizonte de tempo pode diferir de algumas horas para uma mesa de negociação de um banco de investimento, chegando a um ano para um fundo de pensão. Quando o objetivo é satisfazer exigências regulatórias, tal como ocorre com os bancos, a significância é tipicamente bem pequena, $1 \%$ por exemplo. Para um controle gerencial interno, uma companhia calcula o seu grau de exposição ao risco utilizando significâncias maiores, como 5\%, por exemplo.

BENNINGA \& WIENER (1998: 1) apresentam uma situação na qual um gerente de portfólio administra uma carteira de investimentos composta por um ativo. O retorno deste ativo possui distribuição normal, a média dos retornos é igual a $10 \%$ ao ano e o desvio padrão dos retornos anuais é 30\%. O valor do portfólio hoje é de \$100 MM. É 
desejável que o gerente tenha à disposição as seguintes informações: (i) qual é a distribuição do valor do portfólio dentro de um ano; (ii) qual a probabilidade de se perder \$20 MM ou mais dentro de um ano, isto é, qual é a probabilidade do valor final do portfólio ser igual ou inferior a $\$ 80 \mathrm{MM}$; (iii) com $1 \%$ de probabilidade, qual é a máxima perda dentro de um ano, isto é, qual é o VaR a 1\% considerando o horizonte de tempo igual a um ano.

Vale salientar que referidos autores escreveram de maneira inapropriada que desejam saber com $1 \%$ de probabilidade qual a máxima perda dentro de um ano. $\mathrm{Na}$ verdade, eles desejam conhecer a máxima perda com $99 \%$ de probabilidade. Isto é, se a análise for realizada em 100 dias, no máximo, em apenas 1 dia a perda verificada poderá ultrapassar a estimativa do Valor em Risco calculado.

i - Claro está que dentro de um ano o valor esperado para o portfólio é de \$ 110 MM com um desvio padrão de 30\%. Estes dados conduzem à seguinte distribuição normal:

\section{Figura 13: Distribuição Normal}

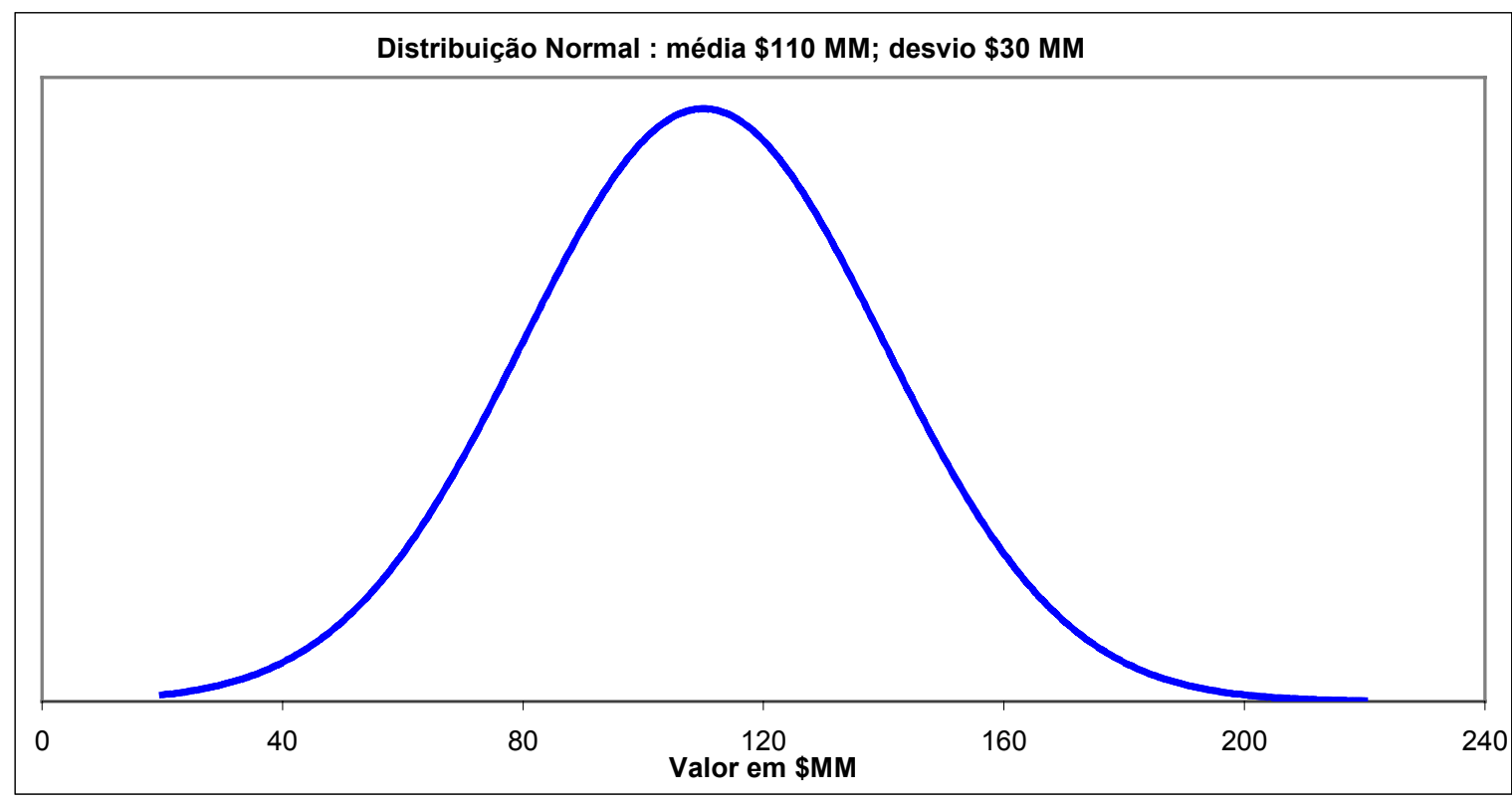

ii - A probabilidade de perda maior ou igual a \$20 MM é dada pela área à esquerda do quantil correspondente ao valor final de \$80 MM, conforme evidencia a distribuição abaixo: 
Figura 14: Distribuição Normal

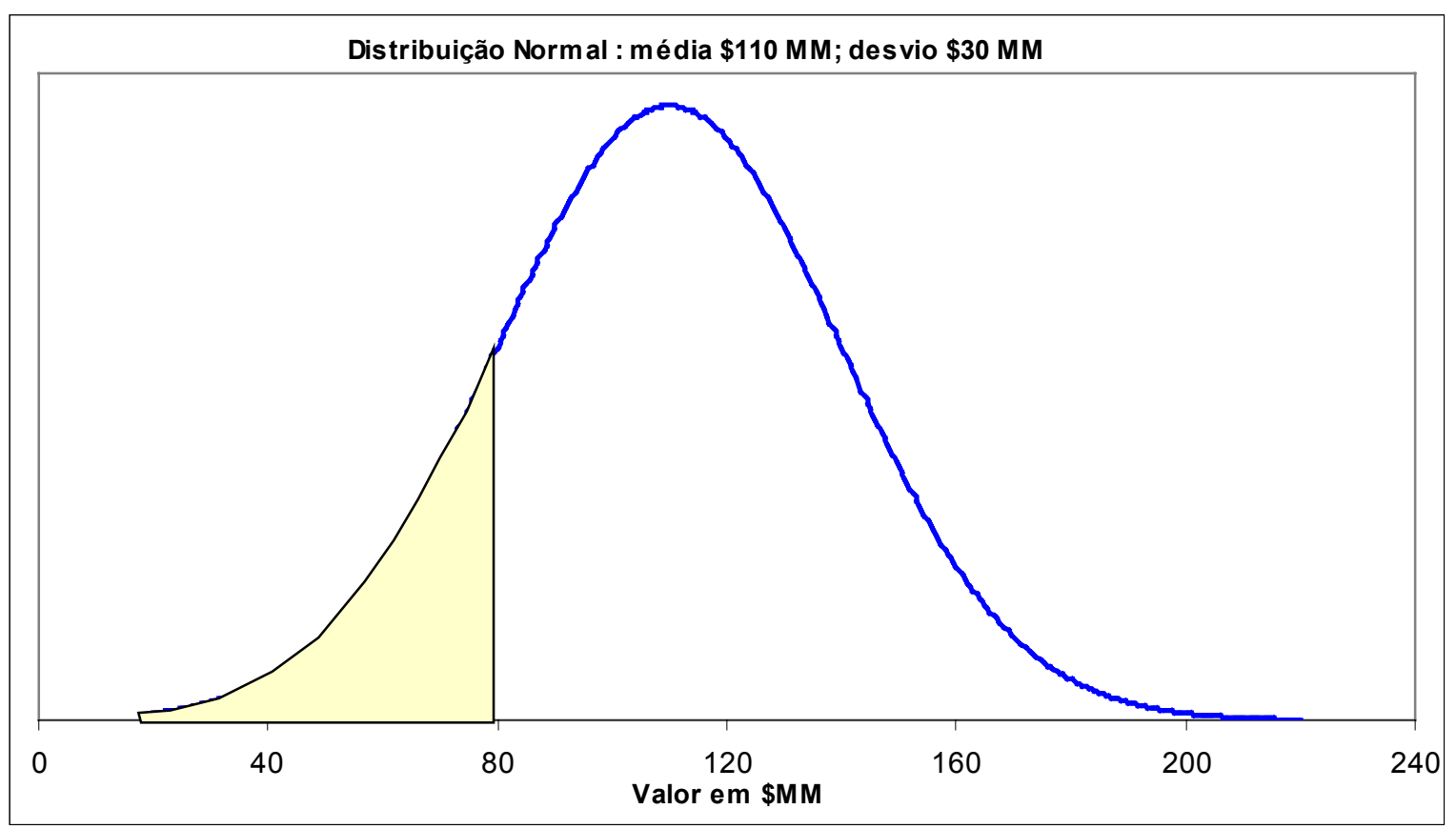

Uma vez que a área da região hachurada é igual à aproximadamente $16 \%$, fica evidente que a probabilidade do valor do portfólio ser igual ou menor a $\$ 80 \mathrm{MM}$ é de $16 \%$.

iii - Com 99\% de probabilidade, a máxima perda dentro de um ano, isto é, o VaR a $99 \%$ considerando o horizonte de tempo igual a um ano, pode ser obtido a partir do quantil cuja área à esquerda seja igual a $1 \%$. 
Figura 15: Distribuição Normal

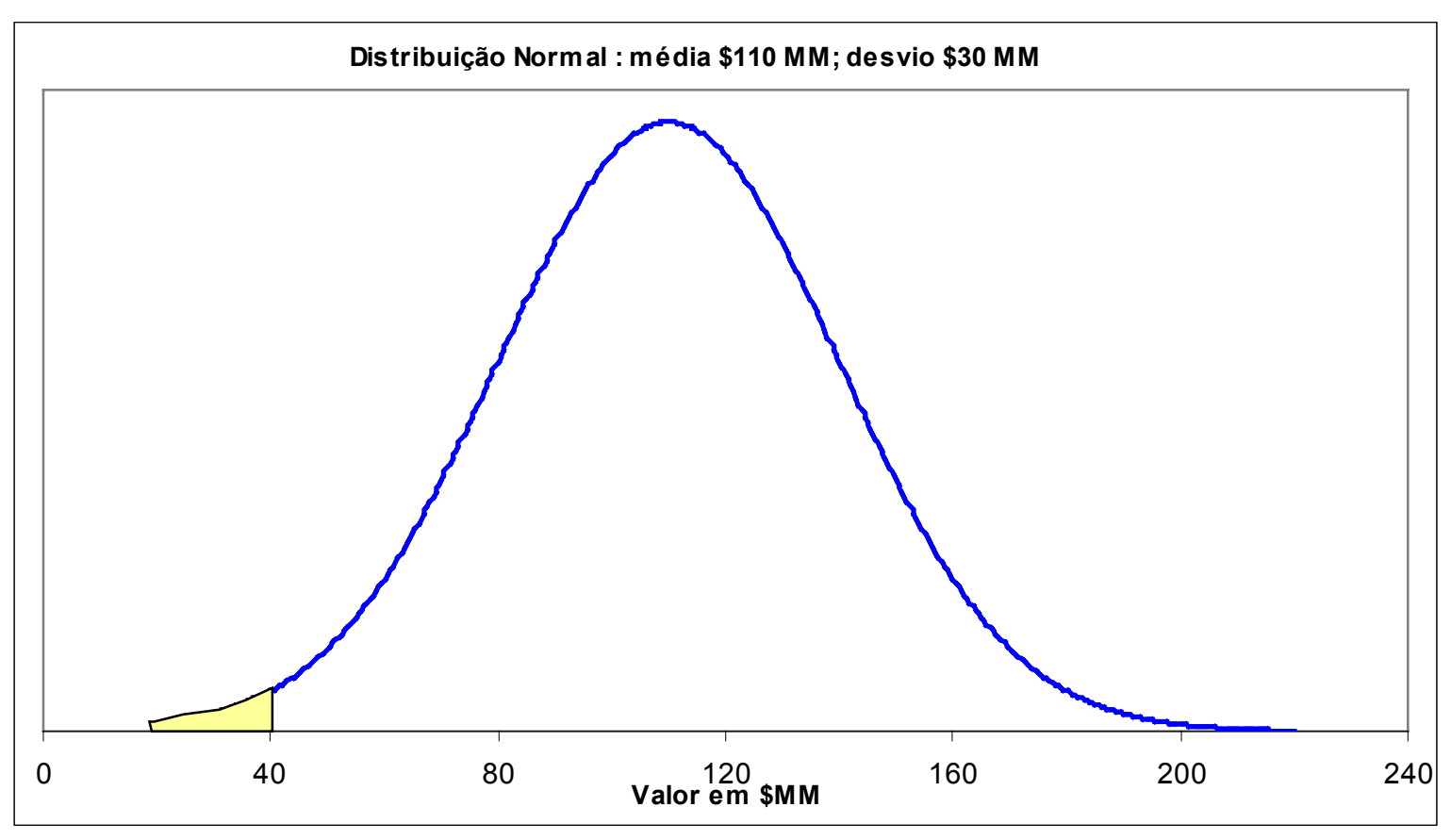

A região hachurada tem área igual a 1\%. O quantil que delimita esta área é dado pelo valor $\$ 40,21 \mathrm{MM}$.

Portanto, a probabilidade do valor do portfólio ao cabo de um ano ser igual ou inferior a $\$ 40,21 \mathrm{MM}$ é de $1 \%$.

Isto quer dizer que o valor em risco $(\mathrm{VaR})$ para o quantil 1\% é igual a (100 40,21) $=\$ 59,79 \mathrm{MM}$.

É interessante notar que no cálculo efetuado acima, o VaR encontrado com $99 \%$ de nível de confiança foi de $\$ 59,79 \mathrm{MM}$, valor que corresponde à diferença entre o valor presente do investimento igual a $\$ 100 \mathrm{MM}$ e o valor futuro $\$ 40,21 \mathrm{MM}$ obtido ao se impor que sua área à esquerda deveria ser $1 \%$. Deve ser salientado que neste caso há comparação de valores monetários em momentos distintos do tempo, o que fere o conceito de valor do dinheiro no tempo.

Logo, cabe argumentar que o VaR a 99\% deveria ser de \$69,79 correspondentes à diferença entre o valor futuro esperado \$110 MM e o valor futuro \$40,21 MM. (JORION,1997: 87-88) 
Em síntese, há de se atentar para estas particularidades ao se analisar as estimativas do VaR posto que as mesmas podem estar comparando o valor investido ou o valor futuro esperado com o valor futuro correspondente ao quantil cuja área à esquerda forneça o nível de confiança desejado.

\subsubsection{Metodologias para o Cálculo do Valor em Risco (VaR)}

O grande emprego da técnica de Valor em Risco nos últimos anos pelas instituições financeiras e pelos órgãos de regulação, conjugados com o intensivo estudo a que foi objeto no meio acadêmico evidenciaram algumas metodologias para o cálculo do VaR que se mostraram mais eficientes, as quais serão vistas a seguir:

\section{- VaR por Intermédio da Duration:}

A duration está intimamente ligada ao Valor em Risco para pequenas mudanças nas taxas de juros.

Supondo uma carteira de R\$ 100 MM com duration modificada igual a 4,5 anos e sabendo que nos últimos anos apenas $5 \%$ dos aumentos na taxa de juros diárias foram superiores a $0,38 \%$, pode-se dizer que:

A pior perda esperada para o horizonte de um dia útil com nível de confiança de $5 \%$ é igual a 4,5 x $100 \mathrm{MM}$ x 0,0038=R\$1,71 MM.

Isso quer dizer que em 100 dias úteis, em não mais que 5 dias espera-se ter uma perda maior que R\$ 1,71 MM, o que é a mesma coisa que dizer que em 95\% do tempo a perda no período de um dia útil será inferior a R\$1,71 MM.

Ou seja, o Valor em Risco para um ativo com as características apresentadas é de R\$ 1,71 MM, ou ainda que o $\operatorname{VaR}(95 \%)$ é igual a $\mathrm{R} \$ 1,71 \mathrm{MM}$ para o horizonte de tempo de um dia útil.

\section{- VaR por Simulação Histórica:}

No item 2.5 foi vista uma situação na qual pôde-se estimar o VaR de um ativo com risco a partir de seus retornos históricos, os quais possuíam distribuição normal.

Não obstante, aquele mesmo raciocínio, salvo algumas alterações, pode ser 
replicado para se estimar o VaR de um ativo cuja distribuição de retornos não siga um modelo conhecido.

Para se replicar o esquema descrito em 2.5 para uma distribuição não paramétrica bastará conhecer os retornos históricos deste ativo.

Para efeito de ilustração, serão considerados os retornos diários do IBOVESPA de Julho de 1994 até Junho de 1999.

Nesse período, a média dos retornos diários foi igual a $0,07351 \%$, sendo que distribuição dos retornos encontra-se na Figura 16:

\section{Figura 16: Histograma}

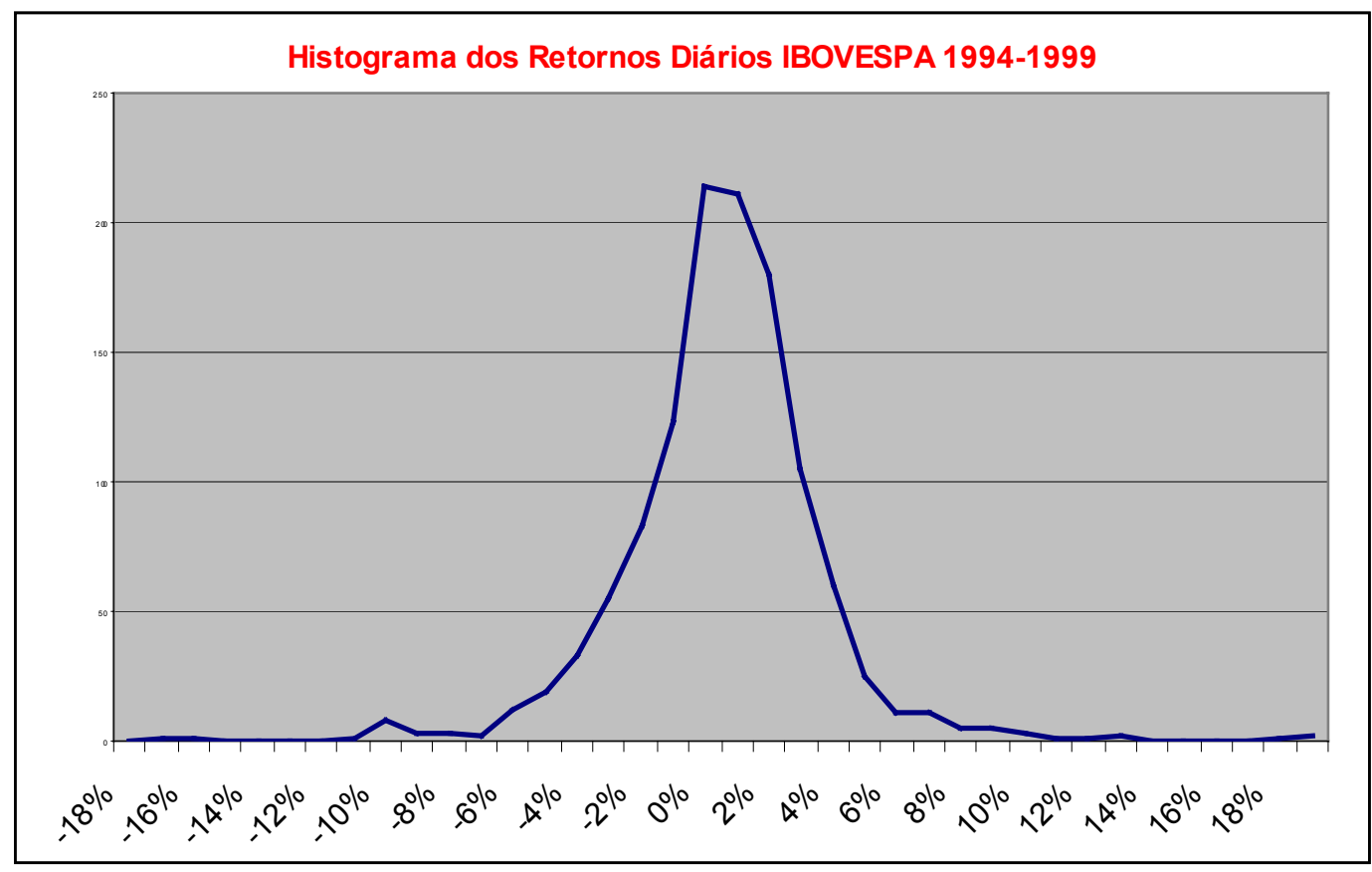

Note que o gráfico anterior não pode ser considerado como o de uma distribuição normal.

Em vista disto, a análise a ser seguir deverá prescindir de suposições quanto à distribuição dos retornos.

A partir dos retornos históricos do IBOVESPA, pôde-se determinar que o quantil dado por $-4,77 \%$ separa os $5 \%$ piores retornos diários. 
Figura 17: Histograma

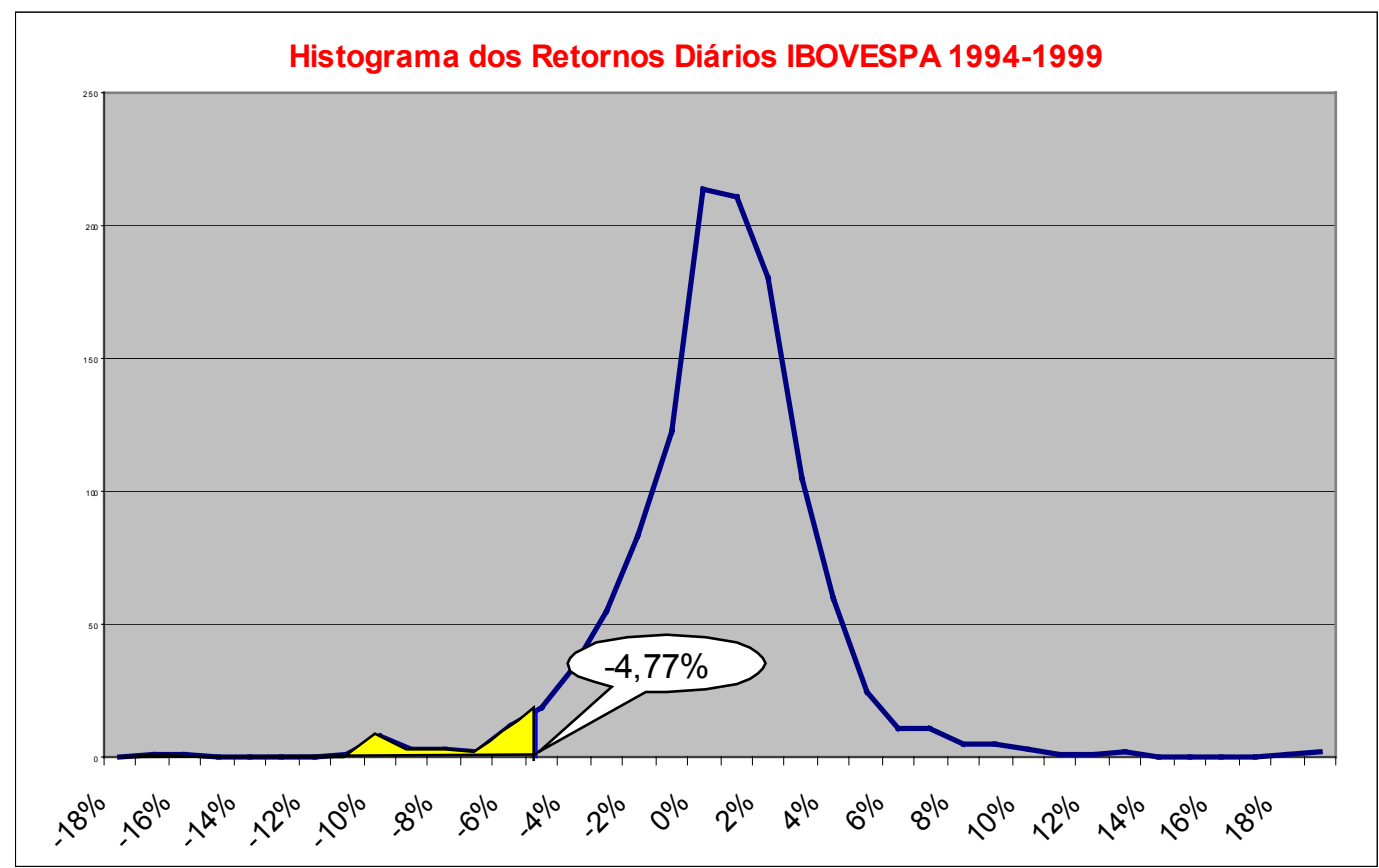

Considerando que ao cabo da análise anterior, isto é, Junho de 1999, invista-se R\$100 MM nas ações que compõem o índice Bovespa e, sabendo que retorno médio diário calculado foi de $0,07351 \%$, o valor esperado da carteira para o dia seguinte seria de $\mathrm{R} \$ 100,07351 \mathrm{MM}$.

Por outro lado, uma vez que o quantil $-4,77 \%$ delimita os $5 \%$ piores retornos diários, haveria 5 chances em 100 para que o valor da carteira caísse mais que 4,77\% de um dia para outro. Se este fosse o caso, a carteira passaria a valer R\$ 95,23 MM.

Sob essas circunstâncias, esperar-se-ia um valor da carteira de R\$100,07351 MM enquanto que o valor observado seria de $\mathrm{R} \$ 95,23 \mathrm{MM}$, logo o VaR para o horizonte de tempo de um dia, com um nível de confiança de 95\%, seria de $(100,07351-95,23)=\mathrm{R} \$$ 4,84351 MM.

Quando se diz que o nível de confiança do VaR diário é de 95\%, deve-se entender que em não mais que 5\% dos dias estudados a perda observada será maior que o VaR calculado.

Outro comentário que se faz necessário é sobre o tamanho da janela de tempo a partir da qual os dados serão coletados. Foi utilizada uma janela arbitrária com pouco 
menos que 1.200 dias úteis. Não há na literatura consultada fórmula para se determinar o tamanho da janela a se utilizada. Pode-se utilizar uma janela de 20, 60, 120 ou mais dias úteis, dependendo do bom senso e da experiência do analista para se determinar o tamanho apropriado.

\section{- VaR Paramétrico para Um Ativo:}

O cômputo do Valor em Risco pode ser consideravelmente simplificado se a distribuição dos retornos for considerada normal.

Sob essas circunstâncias, diz-se que o VaR é paramétrico pois pode ser obtido diretamente do desvio padrão e de um fator multiplicativo que dependerá do nível de confiança desejado. Qualifica-se o VaR de paramétrico pois sua estimação requer apenas o cálculo do parâmetro desvio padrão. Cabe ressaltar que o VaR é paramétrico não porque os retornos advêm de uma distribuição normal e sim porque pode ser obtido a partir de qualquer função cumulativa de probabilidade cuja incerteza possa ser expressa pelo desvio padrão.

De modo a se deduzir o VaR paramétrico de um ativo não derivativo, será considerada determinada modalidade de investimento por certo prazo e com rentabilidade dada por $\widetilde{i}$, sendo esta uma variável aleatória de média $\bar{i}$ e desvio padrão $\sigma_{i}$. Assume-se que $\bar{i}$ e $\sigma_{i}$ possam ser calculados a partir de valores históricos conhecidos.

Figura 18: Fluxo de Caixa

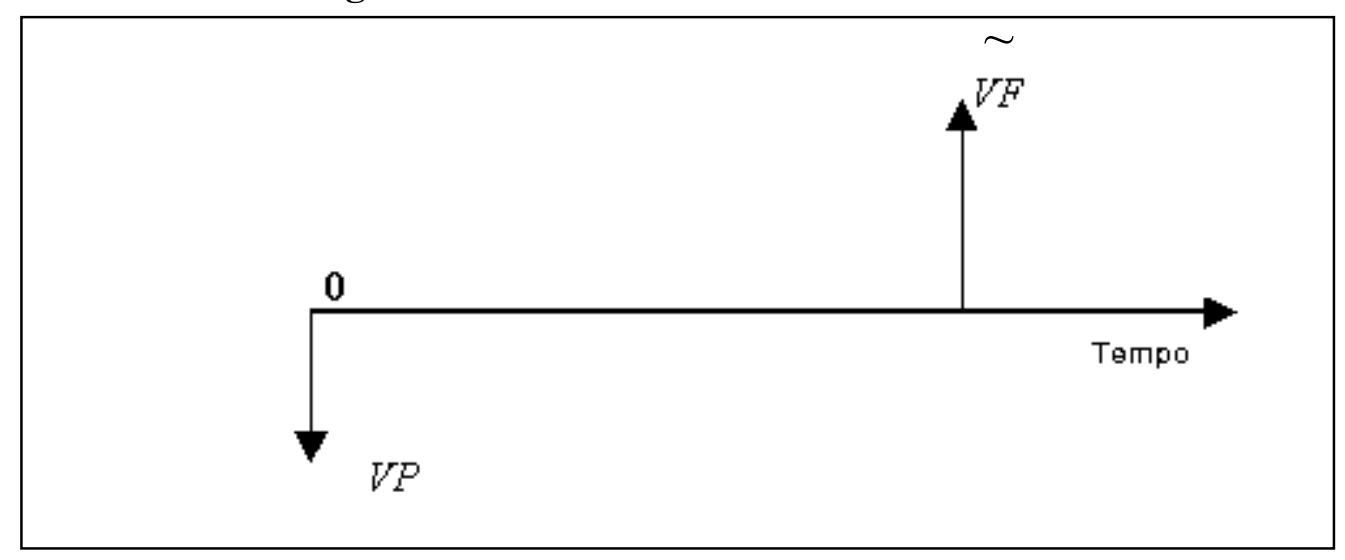

Sabendo-se que $V P$ é o valor presente de um investimento e $V F$ o seu respectivo valor futuro, tem-se que: 


$$
V F=V P \times(1+\tilde{i})
$$

De maneira a se conhecer os possíveis valores futuros que um investimento hoje produzirá futuramente, basta conhecer o valor esperado de $V \widetilde{F}$ e seu respectivo desvio padrão.

A esperança de $\widetilde{V F}$, designada por $\mu_{V F}$, é calculada da seguinte maneira:

$$
\left.E(\widetilde{V F})=\mu_{V F}=E[P V \times(1+\tilde{i})]=E[P V+P V \times \tilde{i})\right]=P V+P V \times \bar{i}
$$

A variância de $\widetilde{V F}$, expressa por $\sigma_{V F}^{2}$, pode ser obtida da seguinte forma:

$$
\sigma_{V F}^{2}=\operatorname{Variância}[P V \times(1+\tilde{i})]=\operatorname{Variância}[P V+P V \times \tilde{i}]=P V^{2} \times \sigma_{i}^{2}
$$

Portanto, o desvio padrão de $\widetilde{T F}$, expresso por $\sigma_{V F}$, é dado por:

$$
\sigma_{V F}=P V \times \sigma_{i}
$$

Uma vez calculado o desvio padrão de $\widetilde{\sim}$, é o momento de se obter o Valor em Risco de $V F$.

Assumindo a abordagem para o VaR como paramétrica, é conhecida a função cumulativa de probabilidade associada a $V F$.

Logo, existe um fator multiplicativo dado por CI que multiplicado pelo desvio padrão $\sigma_{V F}$ fornece área à esquerda de $\mu_{V F}-C I \times \sigma_{V F}$, igual à significância desejada.

Por exemplo, para uma distribuição normal, tem-se que:

- Deve-se multiplicar o desvio padrão por 1,645 para que a área à esquerda de $\mu_{V F}-1,645 \times \sigma_{V F}$ seja igual a $5 \%$;

- Deve-se multiplicar o desvio padrão por 1,960 para que a área à esquerda de $\mu_{V F}-1,960 \times \sigma_{V F}$ seja igual a $2,5 \%$;

- Deve-se multiplicar o desvio padrão por 2,327 para que a área à esquerda de 
$\mu_{V F}-2,327 \times \sigma_{V F}$ seja igual a $1 \%$;

Portanto, com o auxílio de uma tabela, sabe-se exatamente o fator CI a se multiplicar por $\sigma_{V F}$ de maneira a se obter o nível de confiança desejado.

Figura 19: Distribuição Normal

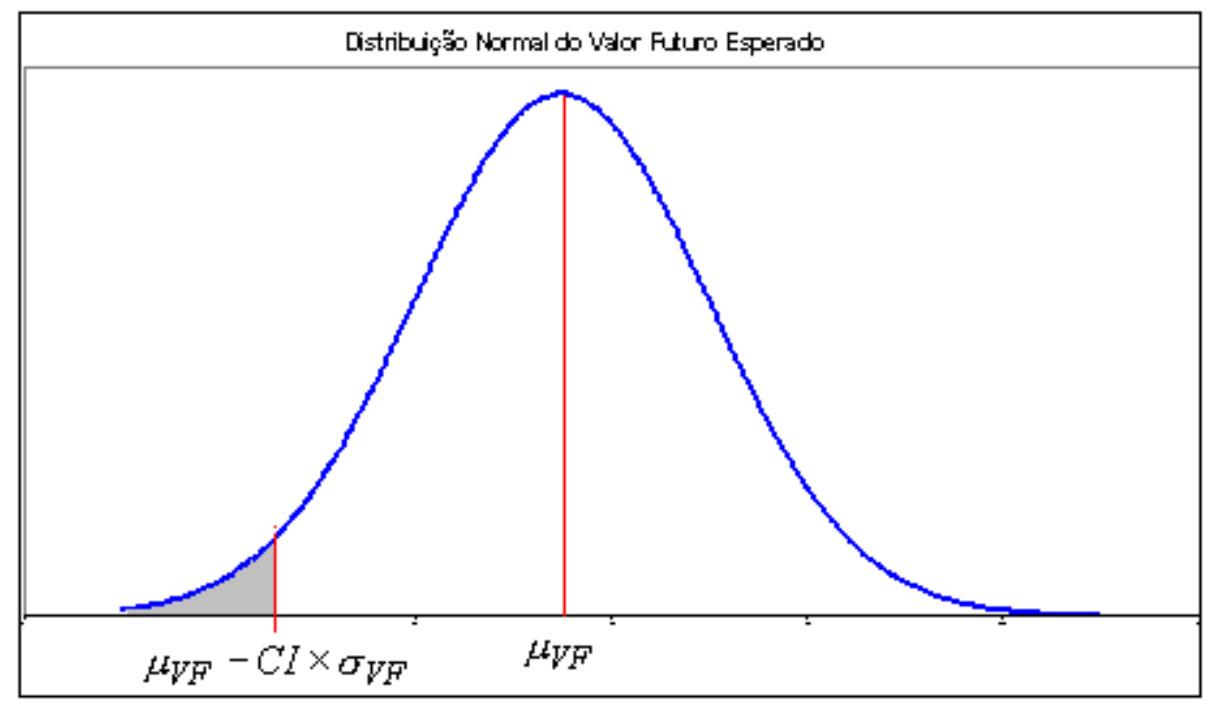

Ora, face ao exposto tem-se que:

- A área à esquerda de $\mu_{V F}-C I \times \sigma_{V F}$ é igual à significância desejada. Em outras palavras, a probabilidade do Valor Futuro ser inferior a $\mu_{V F}-C I \times \sigma_{V F}$ é igual à significância desejada;

- O VaR é justamente a diferença entre o Valor Futuro esperado dado por $\mu_{V F} \mathrm{e}$ o Valor Futuro que delimite área à esquerda igual à significância desejada.

Portanto, tem-se que o VaR para determinado nível de confiança é dado por:

$V a R=\mu_{V F}-\left(\mu_{V F}-C I \times \sigma_{V F}\right)=C I \times \sigma_{V F}$

Por conseguinte, tem-se que:

$V a R=C I \times \sigma_{V F}=C I \times V P \times \sigma_{i}$ 
A título de ilustração, será empregada a relação acima para que seja recalculado o VaR a 99\% de um investimento de $\$ 100 \mathrm{MM}$ que possui retorno médio de $10 \%$ e desvio padrão de $30 \%$.

$V a R=C I \times V P \times \sigma_{i}=2,327 \times 100 \times 0,3=69,8 M M$, valor que coincide com o VaR obtido em 2.5.

- VaR Paramétrico para uma Carteira de Ativos pelo Método da VariânciaCovariância:

Já foi demonstrado que o VaR paramétrico para um ativo não derivativo é dado pela seguinte relação:

$$
V a R_{C I, \text { periodo }}=C I \times V P \times \sigma
$$

Sendo que:

- $\quad$ CI nível de confiança ou coeficiente correspondente ao quantil fixado;

- $\quad V P$ é o valor inicial investido;

- Sigma é o desvio padrão do fator de risco, cujo conceito será analisado no tópico posterior;

O VaR de uma carteira de $N$ ativos não derivativos é dado pela seguinte relação:

$$
V a R_{C}=\sqrt{\left[V R_{1} \ldots V a R_{N}\right]\left[\begin{array}{ccc}
\rho_{11} & \cdots & \rho_{1 N} \\
\vdots & \vdots & \vdots \\
\rho_{N 1} & \cdots & \rho_{N N}
\end{array}\right]\left[\begin{array}{c}
V a R_{1} \\
\vdots \\
V a R_{N}
\end{array}\right]}
$$

Sabendo-se que:

$$
\begin{aligned}
& -\quad V a R i=C I \times \sigma_{i} \times V P_{i} \\
& -\quad V a R_{j}=C I \times \sigma_{j} \times V P_{j} \\
& -\quad \rho_{i j}=\frac{\operatorname{Cov}(i, j)}{\sigma i \times \sigma_{j}}
\end{aligned}
$$


Efetuando-se os produtos matriciais, obtém-se:

$$
V a R_{C}=C I \times \sqrt{\sum_{i=1}^{N} \sum_{j=1}^{N} \operatorname{cov}(i, j) \times V P_{i} \times V P_{j}}
$$

Sabendo que $\operatorname{cov}(i, j)$ é a covariância dos fatores de risco $F R$, cujo conceito será explicado a diante, pode-se reescrever a relação anterior da seguinte maneira:

$$
V a R_{C}=C I \times \sqrt{\sum_{i=1}^{N} \sum_{j=1}^{N} \operatorname{cov}(F R i, F R j) \times V P_{i} \times V P_{j}} .
$$

Por conseguinte, tem-se que o VaR de uma carteira de $N$ ativos não derivativos é dado por:

$$
V a R_{C}=C I \times \sqrt{\sum_{i=1}^{N} \sum_{j=1}^{N} \operatorname{cov}(F R i, F R j) \times V P_{i} \times V P_{j}}
$$

Esta modelagem para o VaR será de substantiva importância para os objetivos do presente estudo uma vez que é a partir dela que se desenvolverá a dedução do método de dois fatores para o cômputo do Valor em Risco de uma carteira de ativos.

\subsubsection{Comentários Quanto ao Cálculo das Covariâncias dos Fatores de Risco FR de uma Carteira de Ações}

No tópico anterior foi visto que o cálculo do Valor em Risco de um ativo ou de uma carteira de ativos requer o cômputo das covariâncias dos fatores de risco denominados de FR.

Se o ativo em análise for uma ação ou uma carteira de ações, o fator de risco consistirá nos retornos periódicos, por exemplo, diários, que cada ação experimentou.

Isto quer dizer que dadas as cotações históricas de, digamos, três ações $\mathrm{A}, \mathrm{B}$ e C, poder-se-á construir a Tabela 7: 
Tabela 7: Cotações Históricas

\begin{tabular}{|c|c|c|c|}
\hline Data & Cotação da Ação A & Cotação da Ação B & Cotação da Ação C \\
\hline $\mathbf{d}_{\mathbf{0}}$ & $\$ 23,0$ & $\$ 3,1$ & $\$ 7,0$ \\
\hline $\mathbf{d}_{-1}$ & $\$ 24,0$ & $\$ 2,6$ & $\$ 7,0$ \\
\hline $\mathbf{d}_{-2}$ & $\$ 22,9$ & $\$ 2,4$ & $\$ 7,1$ \\
\hline $\mathbf{d}_{-3}$ & $\$ 23,3$ & $\$ 3,1$ & $\$ 7,2$ \\
\hline $\mathbf{d}_{-4}$ & $\$ 22,8$ & $\$ 2,5$ & $\$ 6,5$ \\
\hline $\mathbf{d}_{-5}$ & $\$ 23,5$ & $\$ 3,2$ & $\$ 7,1$ \\
\hline $\mathbf{d}_{-6}$ & $\$ 23,9$ & $\$ 3,1$ & $\$ 7,1$ \\
\hline $\mathbf{d}_{-7}$ & $\$ 23,7$ & $\$ 3,0$ & $\$ 7,0$ \\
\hline $\mathbf{d}_{-8}$ & $\$ 23,4$ & $\$ 2,8$ & $\$ 6,8$ \\
\hline $\mathbf{d}_{-9}$ & $\$ 23,6$ & $\$ 2,6$ & $\$ 6,6$ \\
\hline
\end{tabular}

A tabela anterior evidencia as cotações históricas de três ações A, B e C. O dia em que a análise é feita é representado por $\mathrm{d}_{0}$. A construção da tabela supra visou incluir na análise o dia atual bem como as nove cotações mais recentes.

Uma vez que se dispõe das cotações das ações, faz-se necessário calcular os retornos logarítmicos diários de cada uma delas dado por:

$$
\begin{aligned}
& r e t_{a \zeta \tilde{a} o}^{t}=\ln \left(\frac{\cot a c ̧ \tilde{a} o_{t}}{\cot a c ̧ \tilde{a} o_{t-1}}\right) \text {. Sendo que: } \\
& \text { - } r e t_{\text {ação }}^{t} \text { é o retorno logarítmico da ação entre os instantes } t \text {-1 e } t \text {. }
\end{aligned}
$$

Portanto, para a ação $A$, o retorno observado em $\mathrm{d}_{0}$ é dado por: $r e t_{A}^{0}=\ln \left(\frac{23}{24}\right)=-4,256 \%$. Seguindo este raciocínio é possível montar a Tabela 8 :

Tabela 8: Cotações Históricas

\begin{tabular}{|c|r|r|r|}
\hline Data & Retorno da Ação A & Retorno da Ação B & Retorno da Ação C \\
\hline $\mathbf{d}_{\mathbf{0}}$ & $-4,256 \%$ & $17,589 \%$ & $0,000 \%$ \\
\hline $\mathbf{d}_{-1}$ & $4,692 \%$ & $8,004 \%$ & $-1,418 \%$ \\
\hline $\mathbf{d}_{-2}$ & $-1,732 \%$ & $-25,593 \%$ & $-1,399 \%$ \\
\hline $\mathbf{d}_{-3}$ & $2,169 \%$ & $21,511 \%$ & $10,228 \%$ \\
\hline $\mathbf{d}_{-4}$ & $-3,024 \%$ & $-24,686 \%$ & $-8,829 \%$ \\
\hline $\mathbf{d}_{-5}$ & $-1,688 \%$ & $3,175 \%$ & $0,000 \%$ \\
\hline $\mathbf{d}_{-6}$ & $0,840 \%$ & $3,279 \%$ & $1,418 \%$ \\
\hline $\mathbf{d}_{-7}$ & $1,274 \%$ & $6,899 \%$ & $2,899 \%$ \\
\hline $\mathbf{d}_{-8}$ & $-0,851 \%$ & $7,411 \%$ & $2,985 \%$ \\
\hline $\mathbf{d}_{-9}$ & - & - & - \\
\hline
\end{tabular}


Logo, o Valor em Risco de uma hipotética carteira constituída das ações A, B, C é dado por:

$V a R_{95 \%, \text { lia }}=1,645 \times \sqrt{\begin{array}{l}V P_{A}^{2} \times \sigma_{A}^{2}+V P_{B}^{2} \times \sigma_{B}^{2}+V P_{C}^{2} \times \sigma_{C}^{2}+2 \times V P_{A} \times V P_{B} \times \sigma_{A, B}+2 \times V P_{A} \times V P_{C} \times \sigma_{A, C}+ \\ 2 \times V P_{B} \times V P_{C} \times \sigma_{B, C}\end{array}}$

Sendo que:

- $V P_{A}, V P_{B}, V P_{C}$ são os preços de mercado na data em que a análise é feita, $\mathbf{d}_{0}$ no caso, das ações A, B e C, respectivamente;

- $\sigma_{A}^{2}, \sigma_{B}^{2}$ e $\sigma_{C}^{2}$ são as variâncias das taxas de retorno logarítmicos das ações A, B e C, respectivamente;

- $\sigma_{A, B}, \sigma_{A, C}, \sigma_{B, C}$ são as covariâncias entre as taxas de retorno logarítmicas das ações A e B; A e C; B e C, respectivamente;

O passo seguinte consiste nos cálculos das covariâncias e variâncias dos retornos das ações, seguido do respectivo cálculo do Valor em Risco da carteira de ações, o qual não traz dificuldades maiores.

No entanto, quando se considera o Valor em Risco de uma carteira de títulos de renda fixa surgem dificuldades adicionais, as quais são tratadas a seguir.

\subsubsection{Comentários Quanto ao Cálculo das Covariâncias dos Fatores de Risco FR de uma Carteira de Títulos de Renda Fixa Pré-fixada}

A título de ilustração, deve-se considerar o fluxo a seguir no qual estão evidenciados os títulos $F_{1}, F_{2}$ e $F_{5}$ vencendo em 1, 2 e 5 anos, respectivamente.

\section{Figura 20: Fluxo de Caixa}

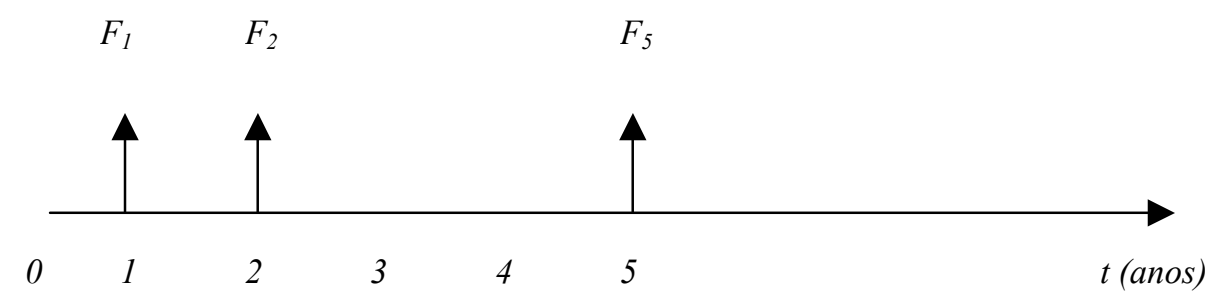


Supondo que se objetive calcular o Valor em Risco da carteira constituída pelo conjunto de títulos de renda fixa evidenciado pelo fluxo anterior e que seja conhecida a estrutura temporal das taxas de juros observadas na data $t=0$, é possível calcular os valores presentes dos títulos da seguinte maneira:

- Valor presente do título 1 é igual a $V P_{1}=\frac{F_{1}}{1+r_{1}}$

- Valor presente do título 2 é igual a $V P_{2}=\frac{F_{2}}{1+r_{2}}$

- Valor presente do título 5 é igual a $V P_{5}=\frac{F_{5}}{1+r_{5}}$

- $\mathrm{r}_{1}, \mathrm{r}_{2}$ e $\mathrm{r}_{5}$ são taxas ao período obtidas da estrutura temporal das taxas de juros;

Sob essas condições, a estimativa do VaR95\%, 1 dia para a carteira de títulos de renda fixa será dada por:

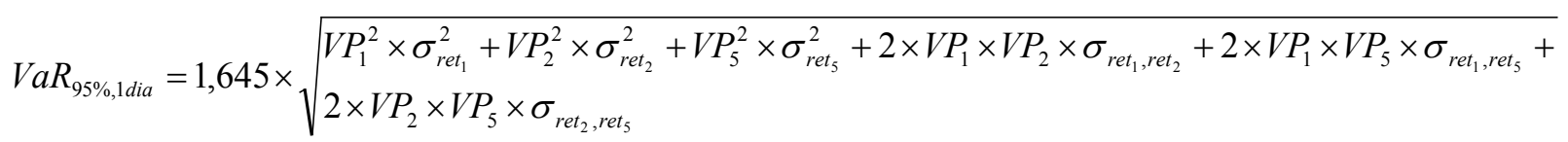

Onde ret $_{1}$, ret ${ }_{2}$ e ret 5 são as taxas por um período unitário de tempo, em geral um dia, sendo que os cômputos de suas respectivas covariâncias e desvios serão objeto de estudo nos parágrafos que se seguem.

A forma mais comum de se estudar os desvios é feita com base nos dados históricos observados, sendo que tais dados são utilizados para a construção da estrutura temporal das taxas de juros.

Desta maneira, assumindo que a data da análise seja dada por $t=0$, serão consideradas as estruturas temporais de taxas de juros para as datas $t=-1, t=-2, \ldots, t=$ $-n$. Isto é, se o analista quiser calcular hoje o Valor em Risco de uma carteira de títulos de renda fixa com títulos de prazo 1, 3 e 6 meses, a suposição é que ele seja capaz de montar uma curva de juros para esses vencimentos como se ele estivesse no dia $t=-1$, 
outra curva de juros para esses vencimentos como se ele estivesse no dia $t=-2$, e assim por diante.

Adicionalmente, serão observados os comportamentos do valor presente dos fluxos de caixa nestas condições.

Considerando um conjunto de estruturas temporais de taxas de juros de 100 observações no tempo, isto é, de $t=-1, t=-2, \ldots, t=-100$, e sendo conhecidas cada uma das 100 estruturas temporais das taxas de juros, é possível calcular o valor presente dos títulos $\mathrm{F}_{1}, \mathrm{~F}_{2}$ e $\mathrm{F}_{5}$ conforme ilustra a Tabela 9:

\section{Tabela 9: Valor Presente}

\begin{tabular}{|c|c|c|c|}
\hline Data & Valor Presente de $\mathrm{F}_{1}$ & Valor Presente de $\mathrm{F}_{2}$ & Valor Presente de $\mathrm{F}_{5}$ \\
\hline $\mathbf{t}-\mathbf{1}$ & $V P_{1}^{t-1}$ & $V P_{2}^{t-1}$ & $V P_{5}^{t-1}$ \\
\hline $\mathbf{t}-\mathbf{2}$ & $V P_{1}^{t-2}$ & $V P_{2}^{t-2}$ & $V P_{5}^{t-2}$ \\
\hline $\mathbf{t}-\mathbf{3}$ & $V P_{1}^{t-3}$ & $V P_{2}^{t-3}$ & $V P_{5}^{t-3}$ \\
\hline $\mathbf{t}-\mathbf{4}$ & $V P_{1}^{t-4}$ & $V P_{2}^{t-4}$ & $V P_{5}^{t-4}$ \\
\hline $\mathbf{t}-\mathbf{5}$ & $V P_{1}^{t-5}$ & $V P_{2}^{t-5}$ & $V P_{5}^{t-5}$ \\
\hline $\mathbf{t}-\mathbf{6}$ & $V P_{1}^{t-6}$ & $V P_{2}^{t-6}$ & $V P_{5}^{t-6}$ \\
\hline $\mathbf{t}-\mathbf{7}$ & $V P_{1}^{t-7}$ & $V P_{2}^{t-7}$ & $V P_{5}^{t-7}$ \\
\hline$\ldots$ & $\ldots$ & & $\ldots$ \\
\hline $\mathbf{t}-\mathbf{1 0 0}$ & $V P_{1}^{t-100}$ & $V P_{1}^{t-100}$ & $V P_{5}^{t-100}$ \\
\hline
\end{tabular}

Note que $V P_{1}^{t-1}$ é o valor presente do título com valor de face $\mathrm{F}_{1}$ calculado no instante $t-1$ e que $V P_{5}^{t-100}$ é o valor presente do título com valor de face $\mathrm{F}_{5}$ calculado no instante $t-100$.

Conhecidos os valores presentes de $\mathrm{F}_{1}, \mathrm{~F}_{2}$ e $\mathrm{F}_{5}$ para cada um dos 100 dias analisados, é possível obter estimativas para o risco de taxa de juros para cada fluxo considerado.

Para tanto, utiliza-se metodologia similar àquela empregada para o cálculo do retorno logarítmico diário das ações. Contudo, ao invés de se considerar o retorno diário

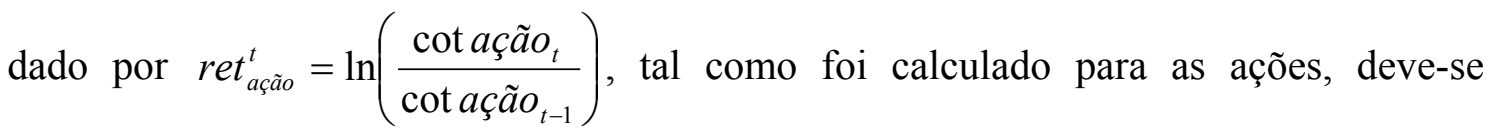
calcular o retorno logarítmico diário de cada fluxo pelas seguintes relações: 
- Retorno diário de $\mathrm{F}_{1}$ é dado por $\operatorname{ret}_{1}^{t}=\ln \left(\frac{V P_{1}^{t}}{V P_{1}^{t-1}}\right)$;

- Retorno diário de $\mathrm{F}_{2}$ é dado por $\operatorname{ret}_{2}^{t}=\ln \left(\frac{V P_{2}^{t}}{V P_{2}^{t-1}}\right)$;

- Retorno diário de $\mathrm{F}_{5}$ é dado por $\operatorname{ret}_{5}^{t}=\ln \left(\frac{V P_{5}^{t}}{V P_{5}^{t-1}}\right)$;

Deve ser salientado que:

- a notação $V P_{1}^{t}$ significa o Valor Presente do título $\mathrm{F}_{1}$ calculado no instante $t$;

- a notação $V P_{2}^{t}$ significa o Valor Presente do título $\mathrm{F}_{2}$ calculado no instante $t$;

- a notação $V P_{5}^{t}$ significa o Valor Presente do título $\mathrm{F}_{5}$ calculado no instante $t$;

Replicando-se este raciocínio, obtém-se a Tabela 10:

Tabela 10: Retornos Logarítmicos

\begin{tabular}{|c|c|c|c|}
\hline Data & $\mathrm{r}_{1}$ & $\mathrm{r}_{2}$ & $\mathrm{r}_{5}$ \\
\hline $\mathbf{t}-\mathbf{1}$ & $r e t_{1}^{t-1}=\ln \left(\frac{V P_{1}^{t-1}}{V P_{1}^{t-2}}\right)$ & $r e t_{2}^{t-1}=\ln \left(\frac{V P_{2}^{t-1}}{V P_{2}^{t-2}}\right)$ & $r e t_{5}^{t-1}=\ln \left(\frac{V P_{5}^{t-1}}{V P_{5}^{t-2}}\right)$ \\
\hline $\mathbf{t}-\mathbf{2}$ & $r e t_{1}^{t-2}=\ln \left(\frac{V P_{1}^{t-2}}{V P_{1}^{t-3}}\right)$ & $r e t_{2}^{t-2}=\ln \left(\frac{V P_{2}^{t-2}}{V P_{2}^{t-3}}\right)$ & $r e t_{5}^{t-2}=\ln \left(\frac{V P_{5}^{t-2}}{V P_{5}^{t-3}}\right)$ \\
\hline $\mathbf{t}-\mathbf{3}$ & $r e t_{1}^{t-3}=\ln \left(\frac{V P_{1}^{t-3}}{V P_{1}^{t-4}}\right)$ & $r e t_{2}^{t-2}=\ln \left(\frac{V P_{2}^{t-3}}{V P_{2}^{t-4}}\right)$ & $r e t_{5}^{t-2}=\ln \left(\frac{V P_{5}^{t-3}}{V P_{5}^{t-4}}\right)$ \\
\hline$\ldots$ & $\ldots$ & $\ldots$ & $\ldots$ \\
\hline $\mathbf{t}-\mathbf{9 9}$ & $r e t_{1}^{t-99}=\ln \left(\frac{V P_{1}^{t-99}}{V P_{1}^{t-100}}\right)$ & $r e t_{2}^{t-99}=\ln \left(\frac{V P_{2}^{t-99}}{V P_{2}^{t-100}}\right)$ & $r e t_{5}^{t-99}=\ln \left(\frac{V P_{5}^{t-99}}{V P_{5}^{t-100}}\right)$ \\
\hline $\mathbf{t}-\mathbf{1 0 0}$ & - & - & - \\
\hline
\end{tabular}

Logo, as covariâncias e desvios a que se referem os sigmas da equação a seguir são justamente as covariâncias e desvios de ret $_{1}$, ret $_{2}$, ret $_{5}$. Em outras palavras, os fatores de risco $F R$ para a carteira de renda fixa estudada é ret $_{1}$, ret $_{2}$, ret $_{5}$. 


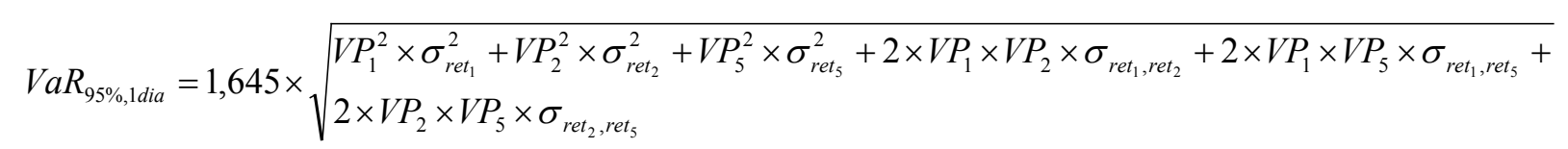

No entanto, a tabela anterior também poderia conter os retornos diários não logarítmicos, o que levaria a uma estimativa do VaR ligeiramente diferente da metodologia que adota retornos logarítmicos. Considerando retornos não logarítmicos, ter-se-ía a seguinte tabela:

Tabela 11: Retornos Discretos

\begin{tabular}{|c|c|c|c|}
\hline Data & $\mathrm{r}_{1}$ & $\mathrm{r}_{2}$ & $\mathrm{r}_{5}$ \\
\hline $\mathbf{t}-\mathbf{1}$ & $r e t_{1}^{t-1}=\frac{V P_{1}^{t-1}}{V P_{1}^{t-2}}-1$ & $r e t_{2}^{t-1}=\frac{V P_{2}^{t-1}}{V P_{2}^{t-2}}-1$ & $r e t_{5}^{t-1}=\frac{V P_{5}^{t-1}}{V P_{5}^{t-2}}-1$ \\
\hline $\mathbf{t}-\mathbf{2}$ & $r e t_{1}^{t-2}=\frac{V P_{1}^{t-2}}{V P_{1}^{t-3}}-1$ & $r e t_{2}^{t-2}=\frac{V P_{2}^{t-2}}{V P_{2}^{t-3}}-1$ & $r e t_{5}^{t-2}=\frac{V P_{5}^{t-2}}{V P_{5}^{t-3}}-1$ \\
\hline $\mathbf{t}-\mathbf{3}$ & $r e t_{1}^{t-3}=\frac{V P_{1}^{t-3}}{V P_{1}^{t-4}}-1$ & $r e t_{2}^{t-2}=\frac{V P_{2}^{t-3}}{V P_{2}^{t-4}}-1$ & $r e t_{5}^{t-2}=\frac{V P_{5}^{t-3}}{V P_{5}^{t-4}}-1$ \\
\hline$\ldots$ & $\ldots$ & $\ldots$ & $\ldots$ \\
\hline $\mathbf{t}-99$ & $r e t_{1}^{t-99}=\frac{V P_{1}^{t-99}}{V P_{1}^{t-100}}-1$ & $r e t_{2}^{t-99}=\frac{V P_{2}^{t-99}}{V P_{2}^{t-100}}-1$ & $r e t_{5}^{t-99}=\frac{V P_{5}^{t-99}}{V P_{5}^{t-100}}-1$ \\
\hline $\mathbf{t}-\mathbf{1 0 0}$ & - & - & - \\
\hline
\end{tabular}

Considerando o título $\mathrm{F}_{1}$, é sabido que $r e t_{1}^{t-1}=\frac{V P_{1}^{t-1}}{V P_{1}^{t-2}}-1=\frac{\frac{V F_{1}}{1+r_{1}^{t-1}}}{\frac{V F_{1}}{1+r_{1}^{t-2}}}-1$, sendo que $r_{1}^{t-1}$ é a taxa ao período obtida a partir da estrutura temporal das taxas de juros construída no instante $t-1$ para o título com valor de face $\mathrm{VF}_{1}$ e que $r_{1}^{t-2}$ é a taxa ao período obtida a partir da estrutura temporal das taxas de juros construída no instante $t-$ 2 para o título com valor de face $\mathrm{VF}_{1}$.

Efetuando-se as transformações algébricas devidas, obtém-se $r e t_{1}^{t-1}=\frac{r_{1}^{t-2}-r_{1}^{t-1}}{r_{1}^{t-1}+1}$.

Replicando este raciocínio para os demais títulos, tem-se que:

$$
-r e t_{1}^{t-1}=\frac{r_{1}^{t-2}-r_{1}^{t-1}}{r_{1}^{t-1}+1}=\frac{\Delta_{1, t-1}}{r_{1}^{t-1}+1}
$$




$$
\begin{aligned}
& -\quad r e t_{2}^{t-1}=\frac{r_{2}^{t-2}-r_{2}^{t-1}}{r_{2}^{t-1}+1}=\frac{\Delta_{2, t-1}}{r_{2}^{t-1}+1} ; \\
& -\quad r e t_{5}^{t-1}=\frac{r_{5}^{t-2}-r_{5}^{t-1}}{r_{5}^{t-1}+1}=\frac{\Delta_{5, t-1}}{r_{5}^{t-1}+1} ;
\end{aligned}
$$

Note que cada $\Delta$ representa a variação entre taxas ao período $r$ entre os instantes $t-2$ e $t$-1. Uma vez que a análise é feita diariamente, o numerador representado por $\Delta$ é na verdade uma taxa diária.

O denominador, por sua vez, é uma taxa ao período que se soma ao valor 1 . Neste momento, introduz-se uma simplificação que faz com que se obtenham as seguintes relações:

$$
\begin{aligned}
& -\quad r e t_{1}^{t-1}=\frac{\Delta_{1, t-1}}{r_{1}^{t-1}+1} \approx \frac{\Delta_{1, t-1}}{\bar{r}_{1}+1} ; \\
& -\quad \operatorname{ret}_{2}^{t-1}=\frac{\Delta_{2, t-1}}{r_{2}^{t-1}+1} \approx \frac{\Delta_{2, t-1}}{\bar{r}_{2}+1} ; \\
& -\quad \operatorname{ret}_{5}^{t-1}=\frac{\Delta_{5, t-1}}{r_{5}^{t-1}+1} \approx \frac{\Delta_{5, t-1}}{\bar{r}_{5}+1} ;
\end{aligned}
$$

Sendo que:

$$
\begin{aligned}
& -\quad \bar{r}_{1}=\sum_{t=-100}^{-1} \frac{r_{1}^{t}}{100} ; \\
& -\quad \bar{r}_{2}=\sum_{t=-100}^{-1} \frac{r_{2}^{t}}{100} ; \\
& -\quad \bar{r}_{5}=\sum_{t=-100}^{-1} \frac{r_{5}^{t}}{100} ;
\end{aligned}
$$

Note que a análise agora é feita supondo que o denominador é igual à taxa ao período média para os títulos de mesmo prazo de vencimento.

Portanto, pode-se montar a Tabela 12: 
Tabela 12: Aproximação para os Retornos

\begin{tabular}{|c|c|c|c|}
\hline Data & $\mathrm{r}_{1}$ & $\mathrm{r}_{2}$ & $\mathrm{r}_{5}$ \\
\hline $\mathbf{t}-\mathbf{1}$ & $r e t_{1}^{t-1} \approx \frac{\Delta_{1, t-1}}{\bar{r}_{1}+1}$ & $r e t_{2}^{t-1} \approx \frac{\Delta_{2, t-1}}{\bar{r}_{2}+1}$ & $r e t_{5}^{t-1} \approx \frac{\Delta_{5, t-1}}{\bar{r}_{5}+1}$ \\
\hline $\mathbf{t}-\mathbf{2}$ & $r e t_{1}^{t-2} \approx \frac{\Delta_{1, t-2}}{\bar{r}_{1}+1}$ & $r e t_{2}^{t-2} \approx \frac{\Delta_{2, t-2}}{\bar{r}_{2}+1}$ & $r e t_{5}^{t-2} \approx \frac{\Delta_{5, t-2}}{\bar{r}_{5}+1}$ \\
\hline$\ldots$ & $\ldots$ & $\ldots$ & $\ldots$ \\
\hline $\mathbf{t}-\mathbf{9 9}$ & $r e t_{1}^{t-99} \approx \frac{\Delta_{1, t-99}}{\bar{r}_{1}+1}$ & $r e t_{2}^{t-99} \approx \frac{\Delta_{2, t-99}}{\bar{r}_{2}+1}$ & $r e t_{5}^{t-99} \approx \frac{\Delta_{5, t-99}}{\bar{r}_{5}+1}$ \\
\hline $\mathbf{t}-\mathbf{1 0 0}$ & - & - & - \\
\hline
\end{tabular}

Sabendo que as covariâncias e desvios a que se referem os sigmas da equação que fornece o VaR são justamente as variâncias e covariâncias de ret $_{1}$, ret $_{2}$, ret r $_{5}$, pode-se dizer que (i) conhecendo o patamar médio das taxas ao período para os títulos de diferentes prazos e (ii) conhecendo as variações das taxas ao período, é possível determinar o Valor em Risco de uma carteira de títulos de renda fixa. 


\section{Capítulo 3: O Método de Dois Fatores para o Cálculo do VaR de uma Carteira de Títulos de Renda Fixa}

\subsection{Visão das Medidas de Risco e a Simplificação no Cálculo do Valor em Risco Paramétrico por Intermédio do Modelo de Dois Fatores}

Conforme visto nos tópicos anteriores, o Valor em Risco de um ativo ou de uma carteira de ativos pode ser calculado por diferentes abordagens. Uma vez que o foco do presente estudo repousa nas carteiras de renda fixa, particular atenção será dispensada para esta modalidade de investimento.

A primeira abordagem vista para a mensuração do risco de uma carteira de renda fixa foi feita por intermédio da duration de Macauley, a qual, segundo BODIE et al. (2000: 320) é o conceito chave na gestão de uma carteira de renda fixa por vários motivos, particularmente por ser uma medida da sensibilidade às taxas de juros de uma carteira de obrigações.

Conforme visto no capítulo anterior, o VaR obtido a partir da duration, apesar de extremamente intuitivo, peca por ser capaz de estimar perdas relacionadas à pequenas variações no patamar das taxas de juros. Isto é, a duration como medida de sensibilidade do preço do título às variações nos juros é uma boa aproximação apenas para pequenas variações nas taxas de juros.

Adicionalmente, estas pequenas variações nas taxas de juros devem ser oriundas de movimentos paralelos nas curvas de juros. Sobre esta questão, FABOZZI (1997: 96) diz que:

A second limitation of duration arises when we calculate the duration of a portfolio. The duration of a portfolio is calculated as the weighted average duration of the portfolio. But how do we interpret the portfolio duration? It is the aproximate percentage change in the portfolio's value when yield changes. But what yield changes? If the portfolio consists of bonds across the maturity spectrum, which yield is assumed to change? It is assumed that the yields for all maturities change by the same basis points. This assumption is commonly referred to as the "parallel yield-curve shift 
assumption". The problem is that yield curves typically do not shift in a parallel fashion.

Isto é:

Uma segunda limitação [ a primeira limitação é o fato dela servir apenas para pequenas mudanças nos juros] para a duration surge quando calculamos a duration de um portfólio. A duração do portfólio é calculada como a média ponderada da duração dos títulos que compõem o portfólio. Porém, como interpretar a duração do portfólio? Ela (a duration) é a mudança percentual aproximada no valor do portfólio quando os yields se alteram. Mas qual alteração no yield deve ser considerada? Se o portfólio consiste de titulos com diferentes maturidades, o yield referente a que maturidade deve ser considerado? Assume-se que os yields para todas as maturidades se alterem igualmente. Esta suposição é comumente referida como "a suposição do movimento paralelo da curva de juros". O problema é que as curvas de juros tipicamente não se movem paralelamente.

Uma maneira de se amenizar a limitação da duration para a previsão de perdas para pequenas variações nos juros é a utilização da convexidade, a qual é capaz de captar com maior acurácia a variação no preço do título dada uma variação no patamar das taxas de juros. Contudo, mesmo a convexidade não contorna os problemas causados pela suposição do movimento paralelo na curva de juros.

Outro caminho para se calcular o risco incorrido numa exposição em títulos de renda fixa seria a utilização da Moderna Teoria de Carteira de Harry Markowitz. Contudo, ainda que o Valor em Risco seja derivado da teoria de Markowitz, o VaR leva a vantagem por resumir em um único número a exposição ao risco da carteira de investimentos. Outra vantagem é que, ao contrário de Markowitz, existem metodologias para o cálculo do VaR que prescindem da matriz de covariâncias. Uma vantagem da Teoria de Markowitz é que, ao contrário do VaR paramétrico, a Moderna Teoria de Carteiras não faz nenhuma suposição quanto à distribuição dos retornos dos ativos estudados.

Para efeito do cálculo do $\mathrm{VaR}$, existem algumas metodologias já consagradas pelo uso. A primeira vista foi a do VaR obtido a partir da simulação histórica, o qual requer o 
conhecimento dos retornos históricos do ativo ou da carteira de ativos objeto de estudo. O ponto positivo para esta abordagem é que esta prescinde de qualquer suposição acerca da distribuição de retornos dos ativos envolvidos bem como prescinde do cálculo das covariâncias entre os ativos que compõem a carteira.

A abordagem que se despendeu mais tempo de pesquisa, mesmo porque é sobre esta que se baseará o presente estudo, é o VaR paramétrico obtido pelo método das variâncias-covariâncias. Para que este método seja utilizado deve-se supor que a distribuição dos retornos dos ativos envolvidos siga uma distribuição paramétrica. Adicionalmente, o cômputo da matriz de correlações/covariâncias bem como os cálculos advindos requerem grande esforço computacional. É justamente a grande quantidade de cálculos envolvidos nesta metodologia que torna, em alguns casos, o seu cálculo assaz complicado.

Ora, o Modelo de Dois Fatores para o cálculo do VaR de uma carteira de ativos de renda fixa se propõe justamente a encontrar um caminho mais simples para a estimativa do VaR paramétrico.

O ponto de partida para o Modelo de Dois Fatores é o trabalho realizado por LITTERMAN \& SCHEINKMAN (1988: 54-61), os quais estabeleceram uma metodologia para decompor a curva de juros de títulos da dívida norte-americana em fatores que explicam $97 \%$ da variabilidade da curva de juros.

NHF (2000: 1903-1932), valendo-se dos trabalhos de LITTERMAN \& SCHEINKMAN (1988: 54-61) estabeleceram uma metodologia alternativa e bem simplificada para o cálculo do VaR de uma carteira de swaps de taxas de juros.

A idéia do presente estudo é aproveitar os trabalhos de NHF (2000: 1903-1932) e montar uma metodologia para o cálculo do VaR de uma carteira de renda fixa.

\subsection{A Decomposição da Curva de Juros Utilizando um Fator}

Os títulos de renda fixa possuem curvas de retornos que descrevem o comportamento da rentabilidade da obrigação ao longo do tempo. Em relação a este conceito, FABOZZI (2000: 121) afirma que a "A representação gráfica da relação entre os retornos do bônus com a mesma qualidade de crédito, mas com vencimentos 
diferentes é conhecida como curva de retornos". A curva de retornos também é conhecida como curva de rentabilidade, ou curva de juros ou ainda yield curve.

Considerando que observações realizadas hoje tenham evidenciado os seguintes retornos de doze títulos zero cupom com mesma qualidade de crédito e com vencimentos variando de um até doze anos:

Tabela 13: Retornos Observados

\begin{tabular}{|c|c|}
\hline $\begin{array}{c}\text { Vencimento } \\
\text { (ano) }\end{array}$ & $\begin{array}{c}\text { Retorno Observado na data t (\% ao ano) } \\
\text { (Taxas a Termo) }\end{array}$ \\
\hline 1 & $4,100 \%$ \\
\hline 2 & $4,130 \%$ \\
\hline 3 & $4,166 \%$ \\
\hline 4 & $4,209 \%$ \\
\hline 5 & $4,260 \%$ \\
\hline 6 & $4,322 \%$ \\
\hline 7 & $4,397 \%$ \\
\hline 8 & $4,486 \%$ \\
\hline 9 & $4,593 \%$ \\
\hline 10 & $4,721 \%$ \\
\hline 11 & $4,875 \%$ \\
\hline 12 & $5,060 \%$ \\
\hline
\end{tabular}

Os dados da Tabela 13 informam que:

- o preço do título com valor de face $C_{1}$ vencendo em um ano é igual a $\frac{C_{1}}{(1+0,041)}$

- o preço do título com valor de face $\mathrm{C}_{2}$ vencendo em dois anos é igual a $\frac{C_{2}}{(1+0,041) \times(1+0,0413)}$;

- o preço do título com valor de face $\mathrm{C}_{3}$ vencendo em três anos é igual a $\frac{C_{3}}{(1+0,041) \times(1+0,0413) \times(1+0,04166)}$, e assim por diante;

Com os dados presentes na tabela anterior, é possível construir a curva de juros dessas obrigações, elaborada conforme SECURATO (1999: 148-155), obtendo o gráfico seguinte: 
Figura 21: Curva de Juros

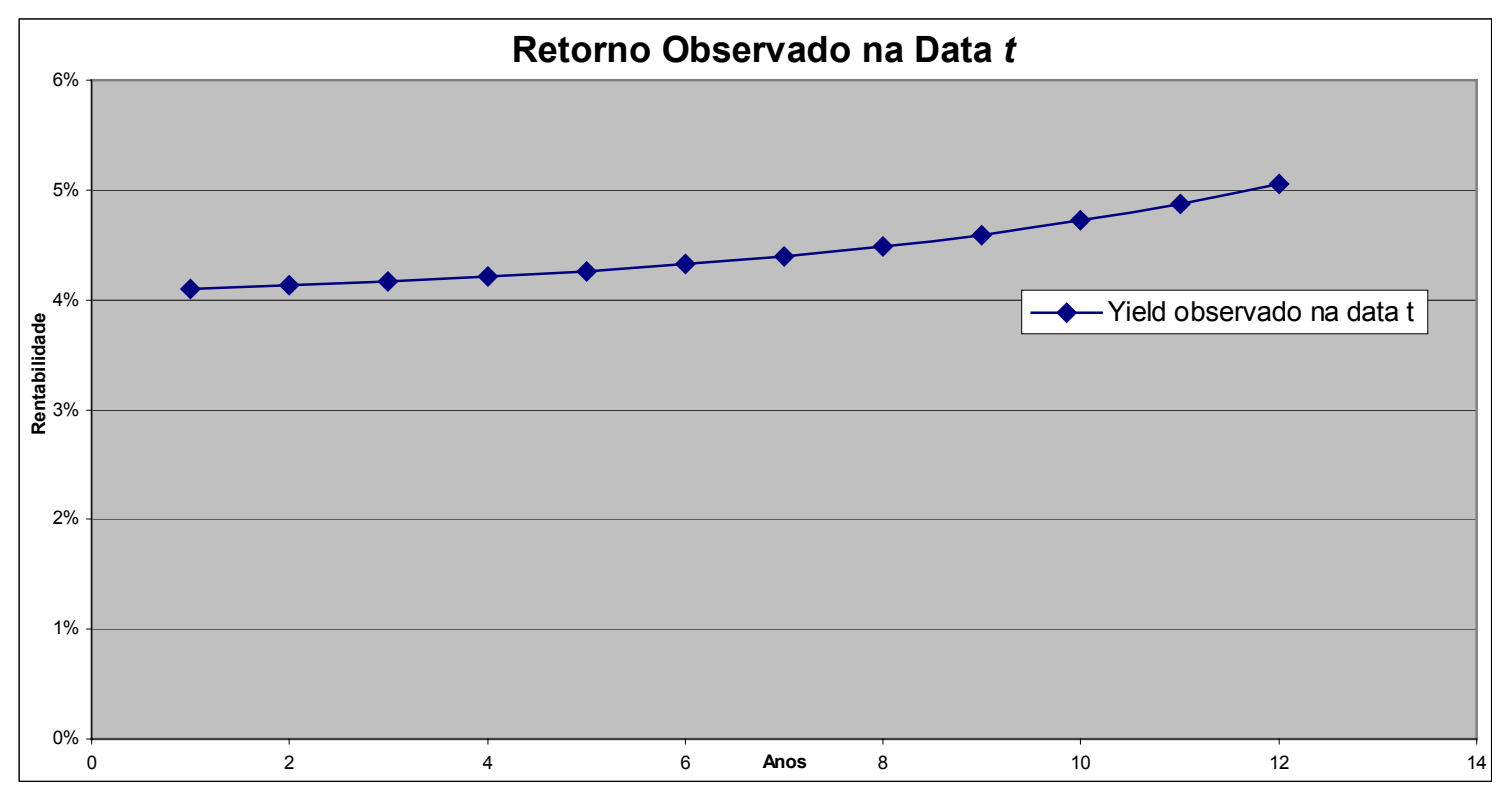

Entretanto, ao se realizar uma nova observação no dia seguinte, é possível que se constatem modificações nos retornos associados aos títulos em análise. No âmbito do mercado de títulos, as alterações nos patamares dos rendimentos constituem fenômeno corriqueiro. Os motivos que ocasionam tais alterações são os mais diversos possíveis, desde a percepção de melhora ou piora nos resultados da empresa que emitiu o título, mudanças da conjuntura econômica e até novas situações de risco do país em função de ocorrências em outros países, como foi o caso da Argentina influenciando o Brasil, particularmente no ano de 2001.

Claro está que se houver alteração na curva de juros, é muito provável que o valor presente da carteira composta por esses títulos sofra modificação. 
Tabela 14: Retornos Observados em $t$ e $t+1$

\begin{tabular}{|c|c|c|}
\hline $\begin{array}{c}\text { Vencimento } \\
\text { (ano) }\end{array}$ & $\begin{array}{c}\text { Retorno Observado na data } \mathbf{t} \\
\text { (\% ao ano) }\end{array}$ & Retorno Observado na data t+1 (\% ao ano) \\
\hline $\mathbf{1}$ & $4,100 \%$ & $4,600 \%$ \\
\hline $\mathbf{2}$ & $4,130 \%$ & $4,630 \%$ \\
\hline $\mathbf{3}$ & $4,166 \%$ & $4,666 \%$ \\
\hline $\mathbf{4}$ & $4,209 \%$ & $4,709 \%$ \\
\hline $\mathbf{5}$ & $4,260 \%$ & $4,760 \%$ \\
\hline $\mathbf{6}$ & $4,322 \%$ & $4,822 \%$ \\
\hline $\mathbf{7}$ & $4,397 \%$ & $4,897 \%$ \\
\hline $\mathbf{8}$ & $4,486 \%$ & $4,986 \%$ \\
\hline $\mathbf{9}$ & $4,593 \%$ & $5,093 \%$ \\
\hline $\mathbf{1 0}$ & $4,721 \%$ & $5,221 \%$ \\
\hline $\mathbf{1 1}$ & $4,875 \%$ & $5,375 \%$ \\
\hline $\mathbf{1 2}$ & $5,060 \%$ & $5,560 \%$ \\
\hline
\end{tabular}

A Tabela 14 evidencia o patamar dos rendimentos da obrigação na data $t$ e no dia seguinte, isto é, em $t+1$, deixando claro que todos os rendimentos sofreram acréscimo de $0,5 \%$ quando se comparam as datas $t$ e $t+1$.

Colocando os rendimentos do mesmo título nas duas datas observadas em um único gráfico, tem-se que:

Figura 22: Curva de Juros

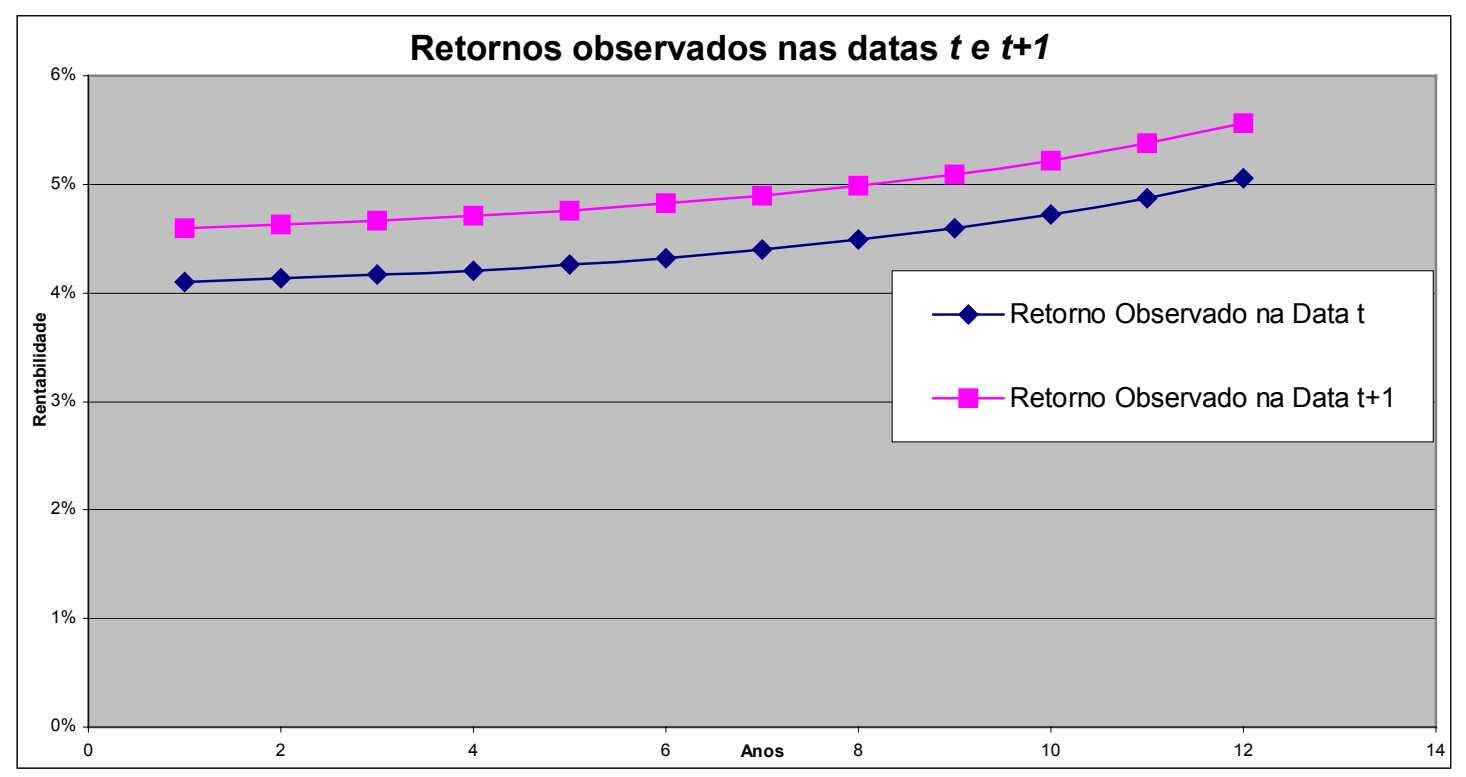

Ora, uma vez que todos os vencimentos tiveram um aumento no yield em exatamente $0,5 \%$, conclui-se que a curva de juros de $t$ para $t+1$ movimentou-se paralelamente para cima. 
Portanto, denomina-se movimento paralelo nas curvas de juro quando todos os rendimentos associados aos vencimentos do papel se alteram em igual valor.

A importância de se analisar como se comporta a curva de juros decorre do fato que, para efeito de cálculo do VaR, não é necessário conhecer o patamar das taxas de desconto, sendo que para este propósito é importante determinar as variações das taxas de juros de um período para outro.

Para o caso em questão, a variação observada entre dois instantes é a mesma para os vários prazos conforme evidencia o gráfico seguinte:

Figura 23: Variação na Curva de Juros

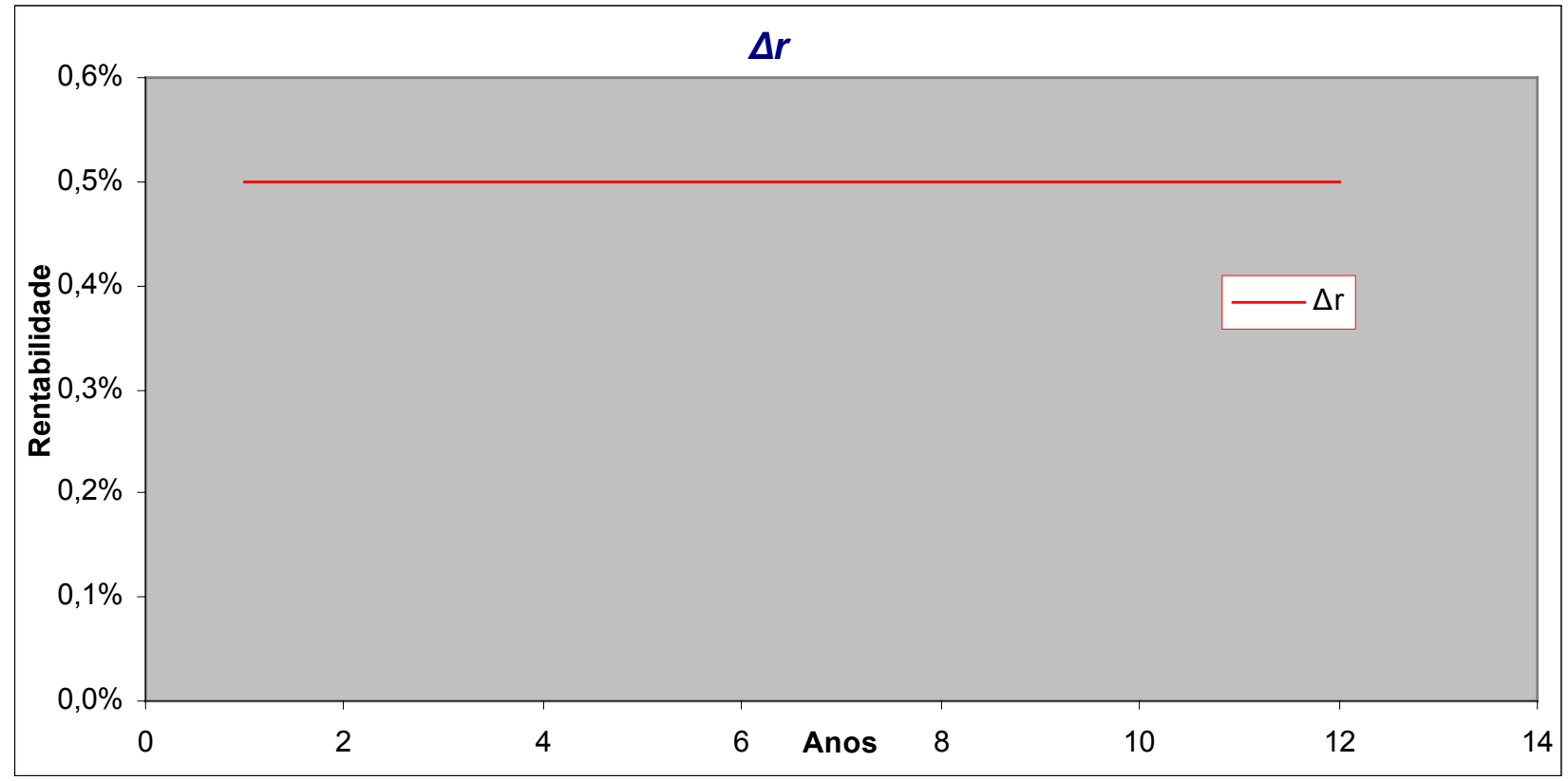

Conclui-se que nos casos em que há apenas movimentos paralelos, o gráfico da variação do retorno para cada vencimento dado por $\Delta r$ será sempre uma reta paralela ao eixo das abscissas, não importando a forma da curva de juros.

Com o objetivo de ser mais preciso na linguagem matemática, ainda que se carregue na notação, será empregado $\Delta r_{i, t}$ para designar a variação entre os instantes $t-1$ e $t$ do patamar das taxas de juros do título de cupom zero com prazo $i$. 
Munido de notação matemática adequada, pode-se afirmar que quando se consideram apenas movimentos paralelos na curva de juros, tem-se $\Delta r_{i, t}=\alpha$, sendo $\alpha$ uma constante. Em outras palavras, considerando uma carteira de títulos com diversos vencimentos, supõe-se que a magnitude da variação das taxas de juros será igual a $\alpha$ para todos os vencimentos.

Nesses casos em que se modelam movimentos da curva de juros com apenas um parâmetro, diz-se que houve a decomposição da curva de juros com um fator. Por conseguinte, caso se utilize desta modelagem para o cálculo do $\mathrm{VaR}$, dir-se-á que o Valor em Risco obtido lançou mão de um modelo de um fator.

Em alguns casos práticos, contudo, ainda que os movimentos das curvas de juros não sejam exclusivamente paralelos, pode-se desprezar os demais movimentos das curvas de juros e assumir que houve apenas movimento paralelo.

Nesses casos, o cálculo de $\alpha$ é obtido por intermédio de uma regressão. De maneira a ilustrar estas considerações, é apresentada a seguinte situação:

Tabela 15: Diferença entre os Retornos Observados em $t$ e $t+1$

\begin{tabular}{|c|c|c|c|}
\hline $\begin{array}{c}\text { Vencimento } \\
\text { (ano) }\end{array}$ & $\begin{array}{c}\text { Retorno Observado na data t } \\
\text { (\% ao ano) }\end{array}$ & $\begin{array}{c}\text { Retorno Observado na data t+1 } \\
\text { (\% ao ano) }\end{array}$ & $\mathbf{\Delta r}_{\text {it }}$ \\
\hline $\mathbf{1}$ & $4,100 \%$ & $4,620 \%$ & $0,520 \%$ \\
\hline $\mathbf{2}$ & $4,130 \%$ & $4,629 \%$ & $0,499 \%$ \\
\hline $\mathbf{3}$ & $4,166 \%$ & $4,680 \%$ & $0,514 \%$ \\
\hline $\mathbf{4}$ & $4,209 \%$ & $4,720 \%$ & $0,511 \%$ \\
\hline $\mathbf{5}$ & $4,260 \%$ & $4,760 \%$ & $0,500 \%$ \\
\hline $\mathbf{6}$ & $4,322 \%$ & $4,822 \%$ & $0,500 \%$ \\
\hline $\mathbf{7}$ & $4,397 \%$ & $4,850 \%$ & $0,453 \%$ \\
\hline $\mathbf{8}$ & $4,486 \%$ & $4,919 \%$ & $0,433 \%$ \\
\hline $\mathbf{9}$ & $4,593 \%$ & $5,093 \%$ & $0,500 \%$ \\
\hline $\mathbf{1 0}$ & $4,721 \%$ & $5,221 \%$ & $0,500 \%$ \\
\hline $\mathbf{1 1}$ & $4,875 \%$ & $5,370 \%$ & $0,495 \%$ \\
\hline $\mathbf{1 2}$ & $5,060 \%$ & $5,570 \%$ & $0,509 \%$ \\
\hline
\end{tabular}

Ao se elaborar o gráfico das variações constantes da Tabela 15, obtém-se o gráfico da Figura 24: 
Figura 24: Variação na Curva de Juros

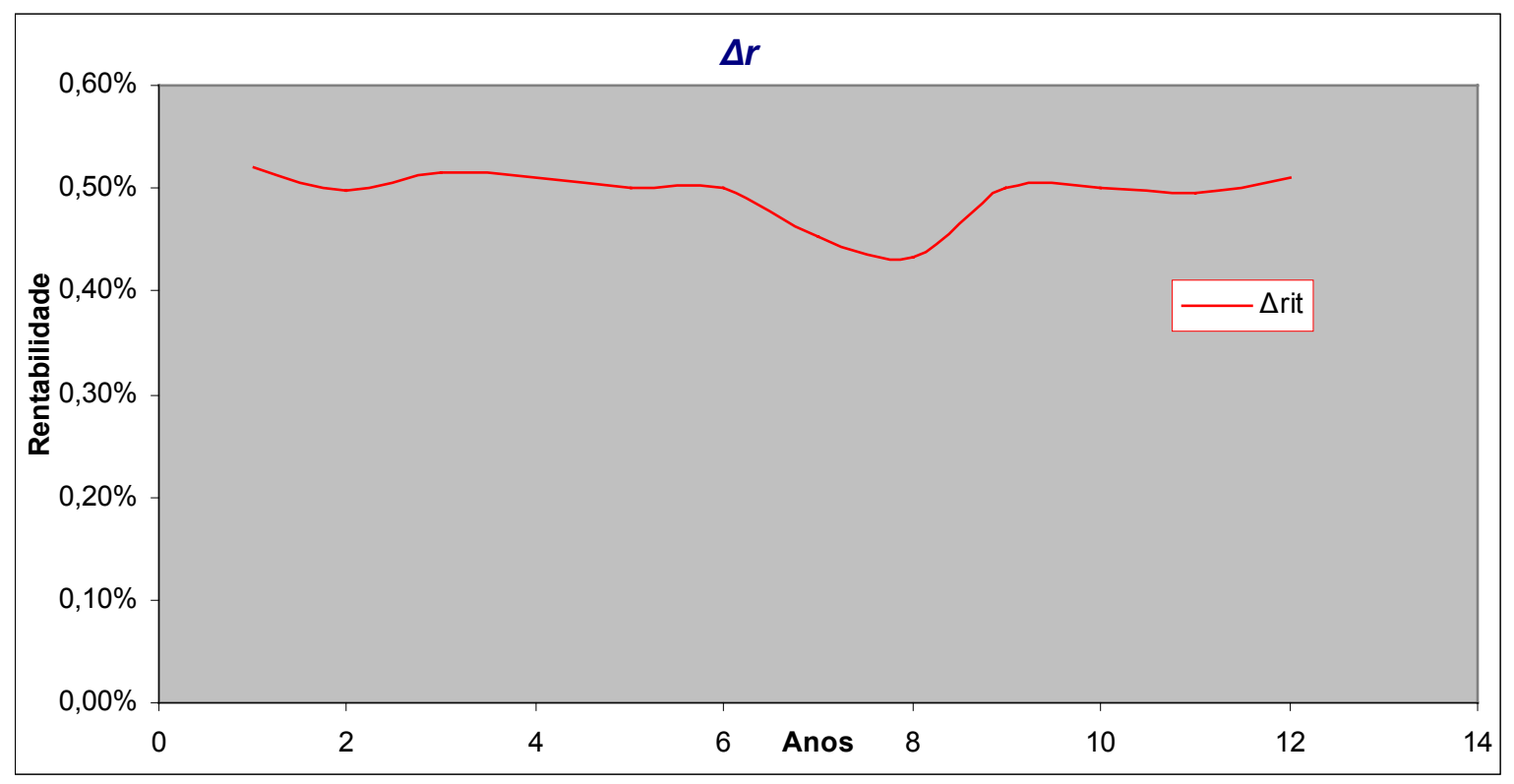

A tabela com retornos acima e sua respectiva yield curve indicam que o movimento não é perfeitamente paralelo.

Contudo, se o analista quiser modelar a curva $\Delta r_{i, t}$ com apenas um fator, isto poderá ser feito através de uma simples regressão que encontre uma estimativa para $\alpha$ dado por $\hat{\alpha}$ tal que se minimize o erro quadrático expresso por $S$ entre $\Delta r_{i, t}$ e $\hat{\alpha}$, obtendo-se $\hat{\alpha}=\frac{\sum_{t=1}^{N}\left(\Delta r_{i, t}\right)}{N}$, sendo $N$ o número de vencimentos analisados.

Portanto, para o modelo de um fator, tem-se que $\hat{\alpha}$ é simplesmente a média aritmética de $\Delta r_{i, t}$, que para o conjunto de valores apresentados faz com que $\hat{\alpha}=$ $0,49470 \%$. 
Figura 25: Variação na Curva de Juros

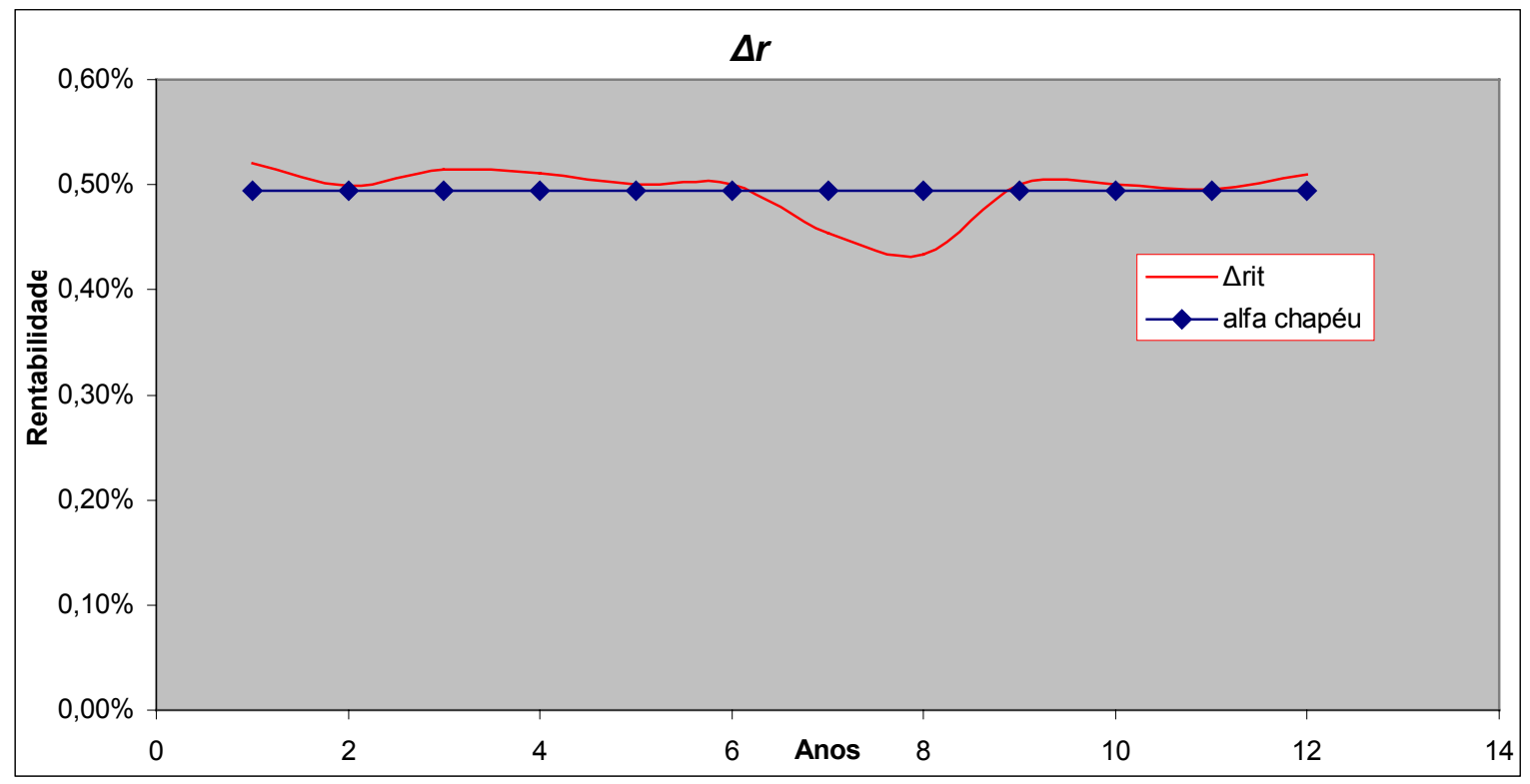

Percebe-se do gráfico acima que o modelo de um fator é uma aproximação do real comportamento de $\Delta r_{i, t}$.

\subsection{A Decomposição da Curva de Juros Utilizando dois Fatores}

Entrementes, admitir um movimento exclusivamente paralelo na curva de juros pode ser uma suposição pouco sustentável. Isto pode ser evidenciado pelo conjunto de dados que se segue.

Os dados a seguir não revelam os patamares das taxas de juros nos instantes $t \mathrm{e}$ $t+1$, apenas $\Delta r_{i, t}$ pois, conforme foi explicado, para efeito de cálculo do $\mathrm{VaR}$ apenas interessa conhecer as diferenças nos patamares das taxas de juros de um período para outro.

Tabela 16: Diferença entre os Retornos Observados em $t$ e $t+1$

\begin{tabular}{|c|c|}
\hline Vencimento (anos) & $\Delta r_{i, t}$ \\
\hline $\mathbf{2}$ & $0,073 \%$ \\
\hline $\mathbf{3}$ & $0,064 \%$ \\
\hline $\mathbf{4}$ & $0,118 \%$ \\
\hline $\mathbf{5}$ & $0,155 \%$ \\
\hline $\mathbf{6}$ & $0,148 \%$ \\
\hline $\mathbf{7}$ & $0,141 \%$ \\
\hline $\mathbf{8}$ & $0,162 \%$ \\
\hline
\end{tabular}




\begin{tabular}{|c|c|}
\hline $\mathbf{9}$ & $0,185 \%$ \\
\hline $\mathbf{1 0}$ & $0,139 \%$ \\
\hline
\end{tabular}

Fonte: NHF (2000: 1913)

Considerando o modelo de um fator, calculou-se a média das variações observadas, obtendo-se $\hat{\alpha}=0,139$.

\section{Figura 26: Modelagem da Curva de Juros}

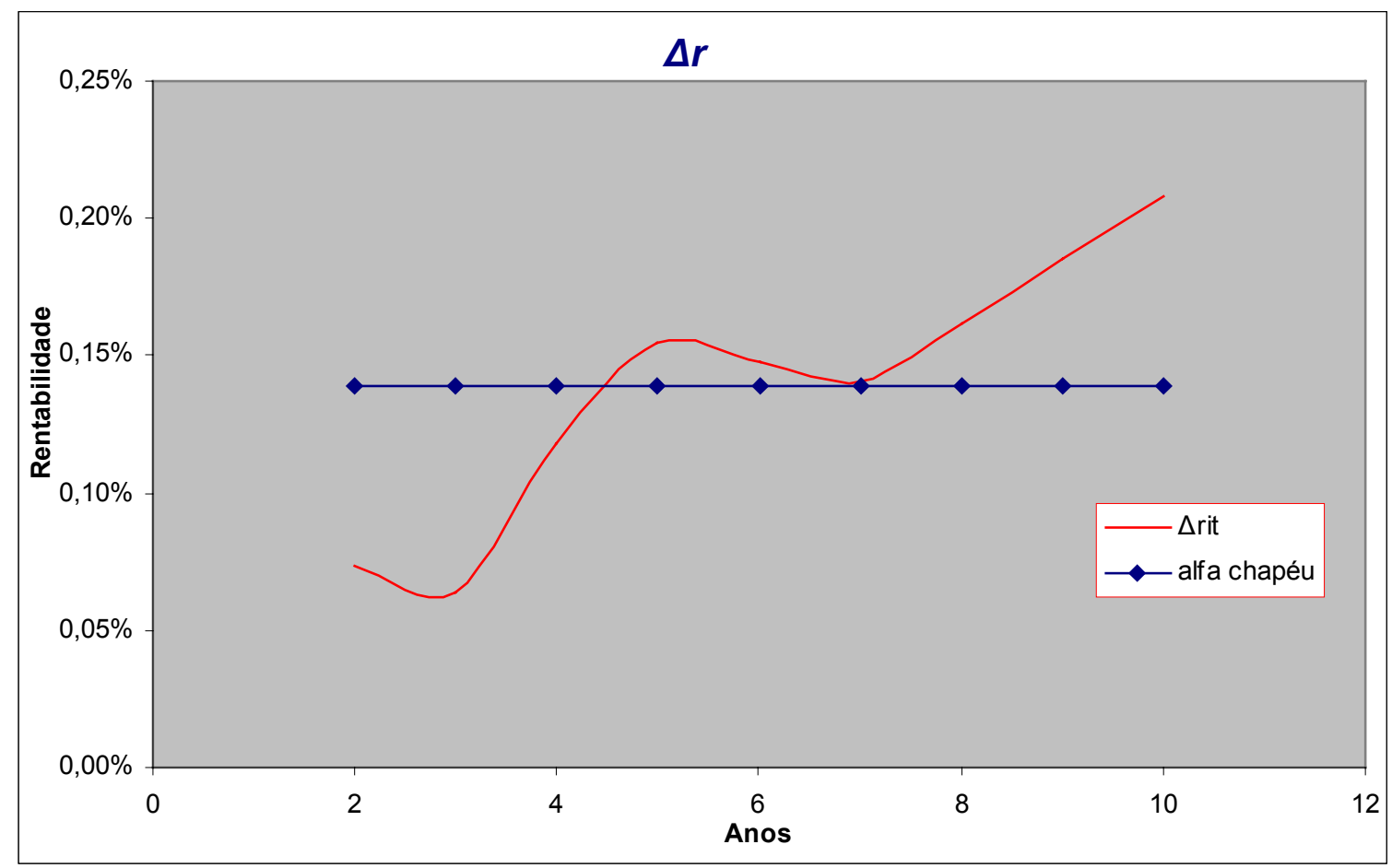

Fonte: NHF (2000: 1914)

Depreende-se da Figura 26 que o modelo de um fator pode ser uma aproximação inadequada do real comportamento de $\Delta r_{i, t}$.

Surge então a possibilidade de se modelar as variações na curva de juros com dois fatores.

A metodologia sugerida por NHF (2000: 1903-1932) para encontrar o segundo fator requer uma transformação linear nos dados, a saber:

- Cada $\Delta r_{i, t}$ deve ser subtraído por $\hat{\alpha}$, passando a chamar $\mathrm{Y}_{\mathrm{i}}$, sendo que esta variável procura captar o erro entre o valor de $\Delta r_{i, t}$ e sua estimativa $\hat{\alpha}$; 
- Cada vencimento $i$ deve ser subtraído por uma constante $i^{*}$, passando a chamar $\mathrm{X}_{\mathrm{i}}$.

- Para o caso que se está analisando, a constante a ser subtraída será arbitrariamente definida como sendo igual a 6 , sendo que no tópico seguinte será evidenciado como obtê-la analiticamente.

- Em síntese, até o presente momento, a metodologia NHF (2000: 1903-1932) não passa de uma simples transformação linear da referência tempo, sendo que a variável de análise é a variação nas curvas de juros entre dois instantes de tempo;

Efetuando-se as devidas transformações, o conjunto de dados passa a ser o seguinte:

Tabela 17: Conjunto de Dados Transformado

\begin{tabular}{|l|l|l|l|l|l|l|l|l|l|}
\hline $\mathbf{X i}=\boldsymbol{i}-i^{*}=\boldsymbol{i}-6$ & -4 & -3 & -2 & -1 & 0 & 1 & 2 & 3 & 4 \\
\hline $\mathbf{Y i}=\Delta r_{i, t}-\hat{\alpha}$ & $-0,066$ & $-0,075$ & $-0,021$ & 0,015 & 0,008 & 0,001 & 0,023 & 0,046 & 0,069 \\
\hline
\end{tabular}

Fonte: NHF (2000: 1914)

O gráfico do novo conjunto de dados consta da Figura 27: 
Figura 27: Modelagem da Curva de Juros

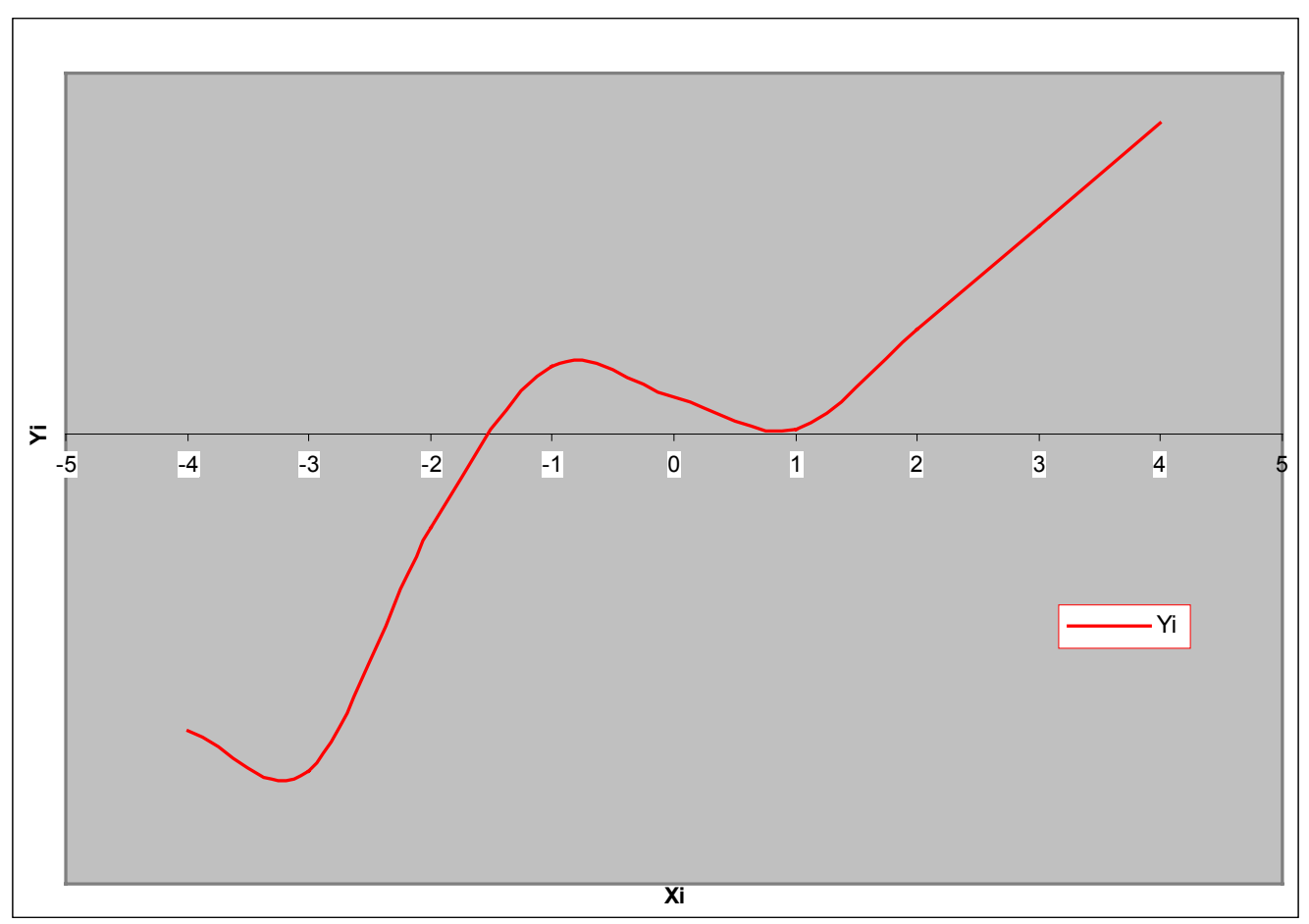

Fonte: NHF (2000: 1914)

Como já foi evidenciado anteriormente, o modelo de um fator aproximaria a curva de variação da taxa a uma reta paralela ao eixo das abscissas. Porém, se esta reta for rotacionada em um ângulo adequado, então fornecerá um resultado correspondendo a um modelo que possa captar de forma mais aproximada as variações de $\Delta r_{i, t}$.

Isto corresponde a considerar um termo que capte o efeito de rotação e que será designado por $\hat{\beta}$, o qual nada mais é que o coeficiente angular obtido numa regressão linear.

Logo, o que se tem a fazer é aproximar a curva do gráfico anterior por $\Delta r_{i, t}=\alpha+\beta \times\left(i-i^{*}\right)+\varepsilon$, sendo épsilon a parcela que não poderá ser explicada pela regressão linear.

Considerando a referida aproximação por $\Delta r_{i, t}=\hat{\alpha}+\hat{\beta} \times\left(i-i^{*}\right)$, tem-se que: 


$$
\begin{aligned}
& \hat{\beta}=\frac{\operatorname{cov}(X, Y)}{\operatorname{var}(X)}=\frac{\sum_{i=1}^{N}\left(X_{i}-\bar{X}\right)\left(Y_{i}-\bar{Y}\right)}{\sum_{i=1}^{N}\left(X_{i}-\bar{X}\right)^{2}} \\
& \hat{\alpha}=\frac{\sum_{i=1}^{N} Y_{i}}{N}-\hat{\beta} \times \frac{\sum_{i=1}^{N} X_{i}}{N} .
\end{aligned}
$$

Ao se realizar a regressão, obtém-se o gráfico dado pela Figura 28:

\section{Figura 28: Regressão}

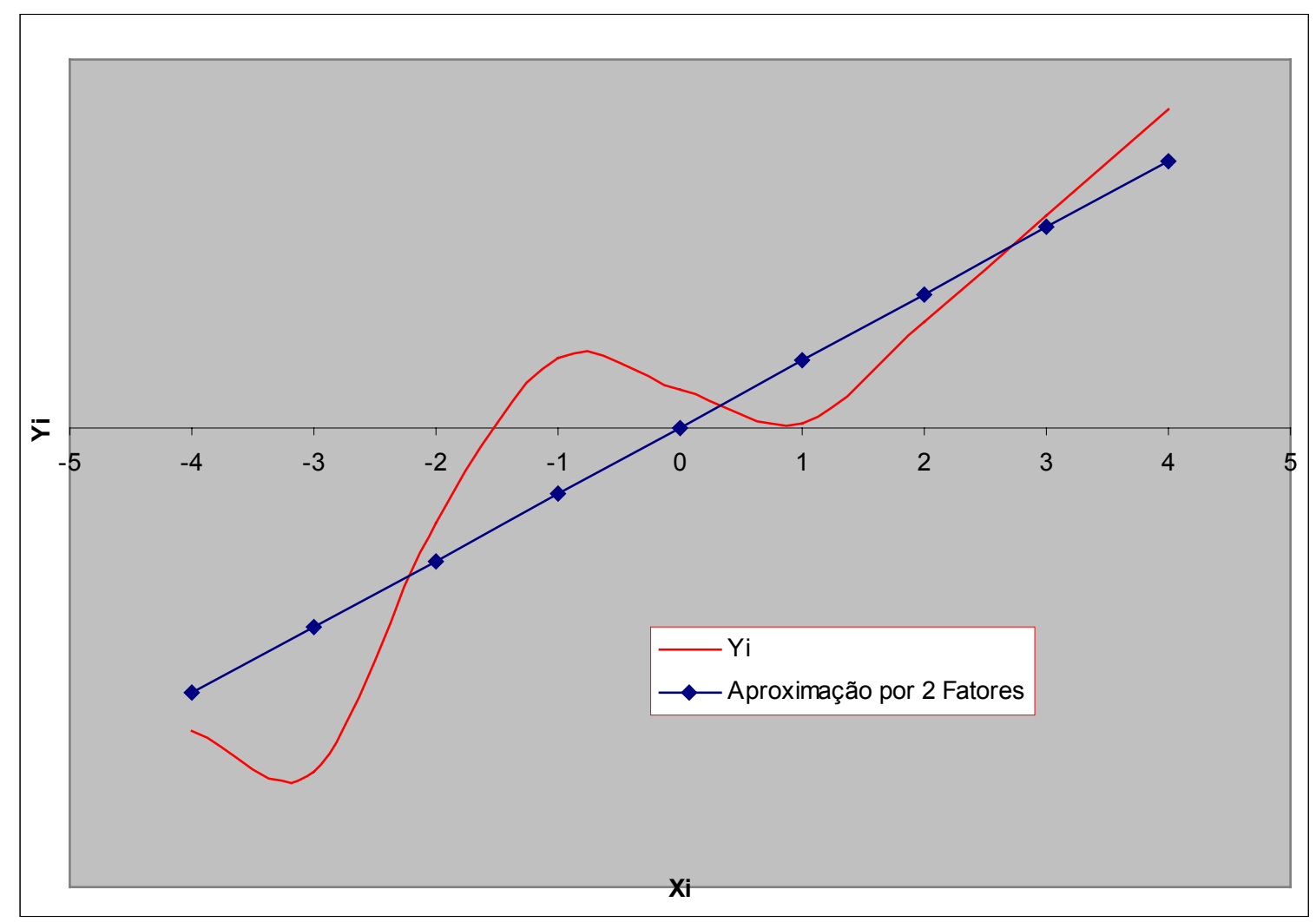

Portanto, um modelo de dois fatores quais sejam, movimento paralelo e rotação, nada mais é que um modelo dado por uma regressão linear das variações observadas nas taxas de juros.

A única diferença é o ajuste que deve ser feito nos vencimentos, pois os mesmos são subtraídos por uma constante $i^{*}$. 
Vê-se, por conseguinte, que o modelo $\operatorname{NHF}\left(2000\right.$ : 1904) utiliza $\Delta r_{i, t}$, variações das taxas de juros observadas entre os instantes $t-1$ e $t$, para estudar o comportamento das curvas de juros e assim desenvolver uma metodologia alternativa para o cálculo do VaR de uma carteira de swaps de taxas de juros.

Contudo, o presente trabalho objetiva utilizar o modelo NHF (2000: 1903-1932) para o cálculo do VaR de uma carteira de títulos de renda fixa. Uma vez que o cálculo do VaR de um swap difere do cômputo do VaR de uma carteira de renda fixa, faz-se necessário introduzir algumas alterações no modelo proposto por NHF (2000: 19031932).

Cabe, então, calcular o Valor em Risco de uma carteira de títulos nessas condições e evidenciar as mudanças introduzidas no modelo original.

\subsection{A Dedução do Modelo de Dois Fatores para o Cálculo do VaR}

A dedução do modelo de dois fatores para o cálculo do Valor em Risco de uma carteira, seja de swaps, seja de títulos de renda fixa, parte da curva de juros de cada ativo que compõe a carteira.

A dedução é apresentada a seguir, sendo que a mesma foi secionada em quatro partes para facilitar o seu entendimento.

\section{Parte I}

Assume-se que durante $T$ períodos, por exemplo, dias, tenha se observado as curvas de juros obtidas a partir dos lançamentos de títulos de cupom zero, ou de swaps, com diversos vencimentos, sendo que os mesmos farão parte de uma determinada carteira de investimentos.

Dadas duas curvas de juros dos papéis que compõem a carteira mencionada, uma calculada no instante $t-1$ e outra calculada no instante $t$, é possível modelar a variação no patamar de juros $r$ de um dia para outro considerando uma regressão linear dada por:

$$
\Delta r_{i, t}=p_{t}+b_{t}\left(i-i^{*}\right)+\varepsilon ;
$$

Sendo: 
- $\Delta r_{i, t}$ é a diferença da taxa ao período $r$ entre os instantes $t-1$ e $t$ para o título de cupom zero e prazo $i$;

- $p_{t}$ é o parallel shift que também será chamado de $\alpha$;

- $b_{t}$ é a rotation que também será chamado de $\beta$;

- $\quad i$ é o prazo ou a maturity;

- $\quad i^{*}$ é o prazo em que há a rotação;

- $\varepsilon$ é a parcela que não poderá ser explicada pela regressão linear.

Logo, uma vez que se considerou que durante $T$ dias tenha se acompanhado a emissão de títulos de renda fixa com $N$ vencimentos ou de swaps com $N$ vencimentos, para cada dia da análise pôde-se construir uma curva de juros.

As $T$ curvas de juros observadas nos $T$ dias conduzirão a $T$ - 1 regressões lineares dadas por $\Delta r_{i, t}=p_{t}{ }^{*}+b_{t}^{*}\left(i-i^{*}\right)$, onde $p^{*}{ }_{t}$ e $b^{*}{ }_{t}$ são os estimadores obtidos para $p_{t} \mathrm{e}$ $b_{t}$, respectivamente.

Já foi demonstrado no item 2.5.1 que o VaR para uma carteira de $N$ ativos, cada ativo correspondendo a um vencimento, pode ser escrito da seguinte maneira:

- $V a R_{C}=C I \times \sqrt{\sum_{i=1}^{N} \sum_{j=1}^{N} \operatorname{cov}(F R i, F R j) \times V P_{i} \times V P_{j}}$, sendo $F R$ o fator de risco e $V P$ o valor presente do ativo.

Neste instante, é de importância substantiva ressaltar que se o Valor em Risco a ser calculado for de uma carteira de swaps, os $F R$ serão justamente as diferenças nos patamares dos juros de um período para outro dados por $\Delta r_{i, t}=p_{t}^{*}+b_{t}^{*}\left(i-i^{*}\right)$, tal como evidencia NHF (2000: 1921).

Porém, o presente trabalho deseja calcular o VaR de uma carteira de renda fixa, portanto considerar o $F R$ igual a $\Delta r_{i, t}=p_{t}^{*}+b_{t}^{*}\left(i-i^{*}\right)$ não é adequado.

Note que $\Delta r_{i, t}=p_{t}^{*}+b_{t}^{*}\left(i-i^{*}\right)$ é considerado $F R$ quando se pretende estudar o VaR 
de carteira de swaps.

Conforme demonstrado no item 2.5.3, o VaR de uma carteira de títulos de renda fixa pode ser obtido considerando como fator de risco $F R$ igual a diferença entre os instantes $t-1$ e $t$ das taxas ao período do título com prazo de vencimento dado por $i$, dividido por uma constante.

Portanto, para efeito do cálculo do VaR de títulos de renda fixa, tem-se que $\Delta r_{i, t}$ modela a diferença da taxa $r$ ao período entre os instantes $t-1$ e $t$ para o título de cupom zero e prazo $i$, sendo que o fator de risco $F R$ é dado por $\frac{\Delta r_{i, t}}{1+\bar{r}_{i}}$, sendo $\bar{r}_{i}$ igual à taxa ao período média para os títulos de mesmo prazo de vencimento.

Para efeito de simplificação, será considerado $S$ tal que:

- $\quad S=\sum_{i=1}^{N} \sum_{j=1}^{N} \operatorname{cov}(F R i, F R j) \times V P_{i} \times V P_{j}$

É sabido que a covariância entre $X$ e $Y$ é dada por:

$\operatorname{cov}(X ; Y)=E[X . Y]-E[X] . E[Y]$

Portanto, pode-se reescrever a equação de $S$ da seguinte maneira:

$$
S=\sum_{i=1}^{N} \sum_{j=1}^{N} V P_{i} \times V P_{j} \times\{E[F R i \times F R j]-E[F R i] \times E[F R j]\}
$$

Vale ressaltar mais uma vez que o que interessa para este estudo são as variações na curva de juros de um período para outro, sendo que a observação de $T$ dias conduzirá a (T-1) variações designadas por $\Delta r_{i, t}$ e obtidas conforme uma regressão linear.

Logo, deve-se substituir os fatores de risco $F R$ por $\frac{\Delta r_{i, t}}{1+\bar{r}_{i}}$ e $\frac{\Delta r_{j, t}}{1+\bar{r}_{j}}$, sendo que $\Delta r_{i, t}=p_{t}^{*}+b_{t}^{*}\left(i-i^{*}\right)$ e $\Delta r_{j, t}=p_{t}^{*}+b_{t}^{*}\left(j-i^{*}\right)$, obtém-se a relação a seguir:

$$
S=\sum_{i=1}^{N} \sum_{j=1}^{N} \frac{V P_{i} \times V P_{j}}{\left(1+\bar{r}_{i}\right) \times\left(1+\bar{r}_{j}\right)} \times\left\{E\left[\Delta r_{i, t} \times \Delta r_{j, t}\right]-E\left[\Delta r_{i, t}\right] \times E\left[\Delta r_{j, t}\right]\right\}
$$


Efetuando-se as devidas substituições na equação acima, tem-se que:

$S=\sum_{i=1}^{N} \sum_{j=1}^{N} \frac{V P_{i} \times V P_{j}}{\left(1+\bar{r}_{i}\right) \times\left(1+\bar{r}_{j}\right)} \times\left\{E\left[\left(p_{t}^{*}+b_{t}^{*}\left(i-i^{*}\right)\right) \times\left(p_{t}^{*}+b_{t}^{*}\left(j-i^{*}\right)\right)\right]-E\left[p_{t}^{*}+b_{t}^{*}\left(i-i^{*}\right)\right] \times E\left[p_{t}^{*}+b_{t}^{*}\left(j-i^{*}\right)\right]\right\}$

$S=\sum_{i=1}^{N} \sum_{j=1}^{N} \frac{V P_{i} \times V P_{j}}{\left(1+\bar{r}_{i}\right) \times\left(1+\bar{r}_{j}\right)} \times\left\{\begin{array}{l}E\left[\left(p_{t}^{*}\right)^{2}+p_{t}^{*} \times b_{t}^{*} \times\left(j-i^{*}\right)+p_{t}^{*} \times b_{t}^{*} \times\left(i-i^{*}\right)+\left(b_{t}^{*}\right)^{2} \times\left(i-i^{*}\right) \times\left(j-i^{*}\right)\right]+ \\ -E\left[p_{t}^{*}+b_{t}^{*} \times\left(i-i^{*}\right)\right] \times E\left[p_{t}^{*}+b_{t}^{*} \times\left(j-i^{*}\right)\right]\end{array}\right\}$

Isolando os termos que estão dentro da fórmula da esperança, tem-se que:

$S=\sum_{i=1}^{N} \sum_{j=1}^{N} \frac{V P_{i} \times V P_{j}}{\left(1+\bar{r}_{i}\right) \times\left(1+\bar{r}_{j}\right)} \times\left\{\begin{array}{l}E\left[\left(p_{t}^{*}\right)^{2}\right]+E\left[p_{t}^{*} \times b_{t}^{*} \times\left(j-i^{*}\right)\right]+E\left[p_{t}^{*} \times b_{t}^{*} \times\left(i-i^{*}\right)\right]+E\left[\left(b_{t}^{*}\right)^{2} \times\left(i-i^{*}\right) \times\left(j-i^{*}\right)\right]+ \\ -\left\{E\left[p_{t}^{*}\right]^{2}+E\left[p_{t}^{*}\right] \times E\left[b_{t}^{*} \times\left(j-i^{*}\right)\right]+E\left[b_{t}^{*} \times\left(i-i^{*}\right)\right] \times E\left[p_{t}^{*}\right]+\right. \\ \left.+E\left[b_{t}^{*} \times\left(i-i^{*}\right)\right] \times E\left[b_{t}^{*} \times\left(j-i^{*}\right)\right]\right\}\end{array}\right.$

Note que é possível identificar no conteúdo das chaves um conjunto de variâncias e covariâncias, a saber:

$-\operatorname{cov}\left(p_{t}^{*} ; p_{t}^{*}\right)=E\left[p_{t}^{*} \times p_{t}^{*}\right]-E\left[p_{t}^{*}\right] \times E\left[p_{t}^{*}\right]=E\left[\left(p_{t}^{*}\right)^{2}\right]-E\left[p_{t}^{*}\right]^{2}=\operatorname{var}\left(p_{t}^{*}\right)$

$-\operatorname{cov}\left(p_{t}^{*} ; b_{t}^{*} \times\left(j-i^{*}\right)\right)=E\left[p_{t}^{*} \times\left(b_{t}^{*} \times\left(j-i^{*}\right)\right)\right]-E\left[p_{t}^{*}\right] \times E\left[b_{t}^{*} \times\left(j-i^{*}\right)\right]$

$-\operatorname{cov}\left(p_{t}^{*} ; b_{t}^{*} \times\left(i-i^{*}\right)\right)=E\left[p_{t}^{*} \times\left(b_{t}^{*} \times\left(i-i^{*}\right)\right)\right]-E\left[p_{t}^{*}\right] \times E\left[b_{t}^{*} \times\left(i-i^{*}\right)\right]$

$-\operatorname{cov}\left(b_{t}^{*} \times\left(j-i^{*}\right) ; b_{t}^{*} \times\left(i-i^{*}\right)\right)=E\left[\left(b_{t}^{*} \times\left(j-i^{*}\right)\right) \times\left(b_{t}^{*} \times\left(i-i^{*}\right)\right)\right]-E\left[b_{t}^{*} \times\left(j-i^{*}\right)\right] \times E\left[b_{t}^{*} \times\left(i-i^{*}\right)\right]$

Fazendo as devidas substituições, a função que define $S$ sofre uma significativa simplificação:

$S=\sum_{i=1}^{N} \sum_{j=1}^{N} \frac{V P_{i} \times V P_{j}}{\left(1+\bar{r}_{i}\right) \times\left(1+\bar{r}_{j}\right)} \times\left\{\operatorname{var}\left(p_{t}^{*}\right)+\operatorname{cov}\left(p_{t}^{*} ; b_{t}^{*}\right) \times\left(j-i^{*}\right)+\operatorname{cov}\left(p_{t}^{*} ; b_{t}^{*}\right) \times\left(i-i^{*}\right)+\operatorname{var}\left(b_{t}^{*}\right) \times\left(i-i^{*}\right) \times\left(j-i^{*}\right)\right\}$

Fazendo mais algumas simplificações, tem-se que: 


$$
S=\sum_{i=1}^{N} \sum_{j=1}^{N} \frac{V P_{i} \times V P_{j}}{\left(1+\bar{r}_{i}\right) \times\left(1+\bar{r}_{j}\right)} \times\left\{\operatorname{var}\left(p_{t}^{*}\right)+\operatorname{var}\left(b_{t}^{*}\right) \times\left(i-i^{*}\right) \times\left(j-i^{*}\right)+\operatorname{cov}\left(p_{t}^{*} ; b_{t}^{*}\right) \times\left(i+j-2 i^{*}\right)\right\}
$$

Note que os valores presentes são conhecidos, $N$ é o número de ativos, $j$ e $i$ são os índices dos somatórios, $p_{t}^{*}$ e $b_{t}^{*}$ são os estimadores da regressão. Portanto, é possível depreender da relação acima que, afora a covariância, os demais fatores que compõem a somatória de $S$ podem ser calculados com extrema facilidade e com pouco esforço computacional.

\section{Parte II}

Sabendo-se que:

$$
\begin{aligned}
& \operatorname{cov}\left(p_{t}^{*} ; b_{t}^{*}\right)=E\left[p_{t}^{*} \times b_{t}^{*}\right]-E\left[p_{t}^{*}\right] \times E\left[b_{t}^{*}\right] \text { e que } \\
& p_{t}^{*}=E\left[\Delta r_{i t}\right]-b_{t}^{*} \times E\left[i-i^{*}\right] \quad \text { (obtido da regressão linear) }
\end{aligned}
$$

Substituindo uma equação na outra:

$$
\operatorname{cov}\left(p_{t}^{*} ; b_{t}^{*}\right)=E\left[\left(E\left[\Delta r_{i t}\right]-b_{t}^{*} \times E\left[i-i^{*}\right]\right) \times b_{t}^{*}\right]-E\left[E\left[\Delta r_{i t}\right]-b_{t}^{*} \times E\left[i-i^{*}\right]\right] \times E\left[b_{t}^{*}\right]
$$

Efetuando os produtos, chega-se a:

$$
\operatorname{cov}\left(p_{t}^{*} ; b_{t}^{*}\right)=E\left[b_{t}^{*} \times E\left[\Delta r_{i t}\right]\right]-E\left[\left(b_{t}^{*}\right)^{2} \times E\left[i-i^{*}\right]\right]-E\left[E\left[\Delta r_{i t}\right]\right] \times E\left[b_{t}^{*}\right]+E\left[b_{t}^{*} \times E\left[i-i^{*}\right]\right] \times E\left[b_{t}^{*}\right]
$$

Note que é possível identificar na relação anterior um conjunto de covariâncias, a saber:

$$
\begin{aligned}
& -\operatorname{cov}\left(b_{t}^{*} ; E\left[\Delta r_{i t}\right]\right)=E\left[b_{t}^{*} \times E\left[\Delta r_{i t}\right]\right]-E\left[b_{t}^{*}\right] \times E\left[E\left[\Delta r_{i t}\right]\right] \\
& -\operatorname{cov}\left(b_{t}^{*} ; b_{t}^{*} \times E\left[i-i^{*}\right]\right)=E\left[b_{t}^{*} \times b_{t}^{*} \times E\left[i-i^{*}\right]\right]-E\left[b_{t}^{*}\right] \times E\left[b_{t}^{*} \times E\left[i-i^{*}\right]\right]
\end{aligned}
$$

O que permite obter a seguinte relação simplificada:

$$
\operatorname{cov}\left(p_{t}^{*} ; b_{t}^{*}\right)=\operatorname{cov}\left(b_{t}^{*} ; E\left[\Delta r_{i t}\right]\right)-E\left[i-i^{*}\right] \times E\left[\left(b_{t}^{*}\right)^{2}\right]+E\left[i-i^{*}\right] \times\left(E\left[b_{t}^{*}\right]\right)^{2}
$$




$$
\operatorname{cov}\left(p_{t}^{*} ; b_{t}^{*}\right)=\operatorname{cov}\left(b_{t}^{*} ; E\left[\Delta r_{i t}\right]\right)-\operatorname{var}\left(b_{t}^{*}\right) \times E\left[i-i^{*}\right]
$$

\section{Parte III}

Faz-se necessário obter $i^{*}$ conveniente, que será denominado de $i^{* *}$, de tal sorte que haja independência dos movimentos paralelo e de rotação.

Isto significa que ter-se-á que determinar $i^{* *}$ que de tal forma que $\operatorname{cov}\left(p_{t}^{*} ; b_{t}^{*}\right)=0$ :

$$
\operatorname{cov}\left(b_{t}^{*} ; E\left[\Delta r_{i t}\right]\right)-\operatorname{var}\left(b_{t}^{*}\right) \times E\left[i-i^{* *}\right]=0
$$

Sabendo que $E\left[i-i^{* *}\right]=E[i]-E\left[i^{* *}\right]$, tem-se que:

$$
\begin{aligned}
& \operatorname{cov}\left(b_{t}^{*} ; E\left[\Delta r_{i t}\right]\right)-\operatorname{var}\left(b_{t}^{*}\right) \times E[i]=-\operatorname{var}\left(b_{t}^{*}\right) \times E\left[i^{* *}\right] \\
& i^{* *}=E[i]-\frac{\operatorname{cov}\left(b_{t}^{*} ; E\left[\Delta r_{i t}\right]\right)}{\operatorname{var}\left(b_{t}^{*}\right)}
\end{aligned}
$$

Logo, por construção, tem-se $i^{* *}$. O fato do $i^{* *}$ ser um valor obtido por intermédio de uma imposição permite que ele seja retirado da esperança.

Por conseguinte: $p_{t}^{* *}=E\left[\Delta r_{i t}\right]-b_{t}^{*} \times E\left[i-i^{* *}\right]$

\section{Parte IV}

Pelas simplificações introduzidas, o $S$ assume a seguinte forma:

$$
S=\sum_{i=1}^{N} \sum_{j=1}^{N} \frac{V P_{i} \times V P_{j}}{\left(1+\bar{r}_{i}\right) \times\left(1+\bar{r}_{j}\right)} \times\left\{\operatorname{var}\left(p_{t}^{* *}\right)+\operatorname{var}\left(b_{t}^{*}\right) \times\left(i-i^{* *}\right) \times\left(j-i^{* *}\right)\right\}
$$

Vale salientar que $i^{* *}$ é o valor no qual a reta faz a rotação e é obtido por construção.

Fazendo um rearranjo, tem-se que: 


$$
S=\operatorname{var}\left(p_{t}^{* *}\right) \times \sum_{i=1}^{N} \sum_{j=1}^{N} \frac{V P_{i} \times V P_{j}}{\left(1+\bar{r}_{i}\right) \times\left(1+\bar{r}_{j}\right)}+\operatorname{var}\left(b_{t}^{*}\right) \times \sum_{i=1}^{N} \sum_{j=1}^{N} \frac{V P_{i} \times V P_{j}}{\left(1+\bar{r}_{i}\right) \times\left(1+\bar{r}_{j}\right)} \times\left(i-i^{* *}\right) \times\left(j-i^{* *}\right)
$$

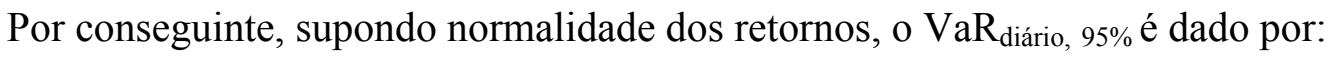

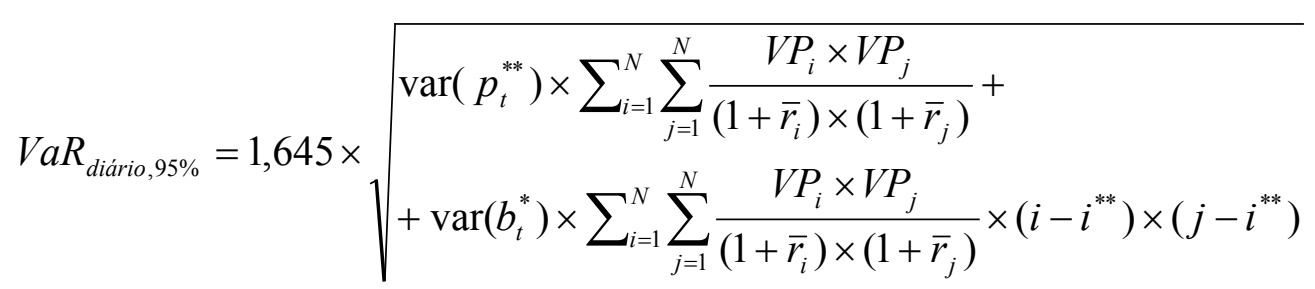

Note que o VaR obtido pelo modelo NHF (2000: 1903-1932) modificado é paramétrico e prescinde do cálculo das covariâncias.

A constatação de que o modelo não requer o cômputo de covariâncias consiste numa grande virtude da modelagem feita NHF (2000: 1903-1932) na medida em que este fato provoca sensível redução nos cálculos requeridos para a estimação do VaR.

O modelo acima obtido, mantendo a forma de cálculo da modelagem feita por NHF (2000: 1903-1932) na qual prescinde-se do cálculo das covariâncias entre os fatores de risco, amplia a aplicação da modelagem original para o cálculo do VaR de carteiras formadas por títulos de renda fixa na medida em que o formato original proposto por NHF (2000: 1903-1932) objetivava o cálculo do VaR para carteiras formadas por swaps.

O passo seguinte consiste na aplicação do modelo para o mercado brasileiro, mais especificamente para uma carteira arbitrária de títulos de renda fixa formada por títulos públicos federais, comparar a estimativa do VaR pelo modelo ora apresentado com a estimativa do VaR obtida pela metodologia tradicional e realizar o back-testing. 


\section{Capítulo 4: Aplicação do Modelo e Discussão dos Resultados}

De maneira a se responder a pergunta de pesquisa que indaga se é possível afirmar que o Valor em Risco calculado utilizando a metodologia baseada em NHF (2000: 1903-1932) é uma medida adequada do risco de mercado de uma particular carteira de renda fixa composta por títulos públicos federais, faz-se necessário realizar as seguintes tarefas:

- coletar as informações necessárias sobre os títulos que comporão a carteira de renda fixa;

- estabelecer os valores investidos em cada um dos ativos que compõem a carteira;

- calcular o Valor em Risco pelo método dos dois fatores;

- realizar o back-testing de maneira a se analisar a qualidade do Valor em Risco calculado;

\subsection{Caracterização da Carteira de Títulos a ser Analisada}

Os títulos públicos federais que comporão a carteira serão da modalidade Letra do Tesouro Nacional - LTN, o período a ser considerado será de 01/06/2001 até 31/10/2001 o que compreende 106 dias úteis, os dados dos PUs das LTNs foram coletados diretamente da página da Internet da Secretaria do Tesouro Nacional, os PUs utilizados na análise correspondem à média do valor negociado da LTN em cada dia no mercado secundário, a carteira considerada será composta por LTNs vencendo em 1 mês, três meses e seis meses.

Escolheu-se as LTNs pois as mesmas são no momento em que se escreveu o presente trabalho os títulos públicos federais pré-fixados mais importantes do país. A importância se deve por critérios de liquidez e por volumes de negociação nos mercados primário e secundário.

O valor investido na LTN vencendo em 1 mês será de $R \$ 1.000,00$; o valor investido na LTN vencendo em 3 meses será de R $\$ 1.000,00$; o valor a ser investido na LTN vencendo em 6 meses será de R $\$ 1.000,00$. 
Escolheu-se os prazos de 1, 3 e 6 meses pois são nestes prazos que se encontram o maior volume negociação dos títulos. Caso se optasse por LTNs mais longas, grande seria a dificuldade em se encontrar negociação no mercado secundário, fato que dificultaria sobremaneira o presente estudo.

Portanto, tem-se que:

Tabela 18: Composição da Carteira

\begin{tabular}{|c|c|c|}
\hline \multicolumn{2}{|c|}{ Composição da Carteira de Títulos de Renda Fixa } \\
\hline Tipo do Título & Valor Investido & Percentual \\
\hline LTN 1 Mês & $\mathrm{R} \$ 1.000,00$ & $33,33 \%$ \\
\hline LTN 3 Meses & $\mathrm{R} \$ 1.000,00$ & $33,33 \%$ \\
\hline LTN 6 Meses & $\mathrm{R} \$ 1.000,00$ & $33,33 \%$ \\
\hline Total & R\$ 3.000,00 & $\mathbf{1 0 0 \%}$ \\
\hline
\end{tabular}

Aqui cabe uma definição operacional para os três prazos de vencimento para as LTNs que comporão a carteira a ser analisada:

- Considerar-se-á uma LTN de um mês se o prazo entre a data de negociação e seu vencimento for de 21 dias úteis;

- Considerar-se-á uma LTN de um três meses se o prazo entre a data de negociação e seu vencimento for de 63 dias úteis;

- Considerar-se-á uma LTN de seis meses se o prazo entre a data de negociação e seu vencimento for de 126 dias úteis

Os dados utilizados para a realização dos testes são oriundos do mercado secundário. Caso se desejasse utilizar as taxas praticadas no mercado primário, deverse-ia voltar as atenções aos leilões primários de LTN, os quais são realizados semanalmente. 
Contudo, contatou-se que no intervalo considerado não houve sequer um dia em que Letras do Tesouro Nacional - LTN tenham sido leiloadas com mais de dois vencimentos.

Ora, como se pretende analisar uma carteira composta por LTNs vencendo em um mês, três meses e seis meses, se apenas o mercado primário fosse considerado, a construção das respectivas curvas de juros ficaria bastante prejudicada pela falta de liquidez para os três vencimentos adotados.

Dentre o período de 01/06/2001 até 31/10/2001, foram consideradas as LTNs que possuíam os seguintes vencimentos:

\section{Tabela 19: Vencimentos}

\begin{tabular}{|c|}
\hline vencimento \\
\hline $06 / 06 / 2001$ \\
\hline $04 / 07 / 2001$ \\
\hline $01 / 08 / 2001$ \\
\hline $05 / 09 / 2001$ \\
\hline $03 / 10 / 2001$ \\
\hline $07 / 11 / 2001$ \\
\hline $05 / 12 / 2001$ \\
\hline $09 / 01 / 2002$ \\
\hline $06 / 02 / 2002$ \\
\hline $03 / 04 / 2002$ \\
\hline $01 / 05 / 2002$ \\
\hline $03 / 07 / 2002$ \\
\hline
\end{tabular}

Ao se estudar o mercado secundário, verifica-se que existe negociação diária de LTNs com diversos prazos de vencimento, algo que não ocorre com o mercado primário. Esta liquidez faz com que a construção de curva de juros diária para os vencimentos 1,3 e 6 meses se torne factível.

\subsection{A Construção dos Vértices}

Entretanto, mesmo considerando o mercado secundário, não é possível verificar a negociação diária de LTNs vencendo exatamente em 21, 63 e 126 dias úteis.

Considerando as LTNs negociadas em 20/06/2001 constantes na tabela a seguir, tem-se que a coluna Data significa a data da negociação dos títulos no mercado 
secundário, a coluna Vencimento indica o vencimento da LTN, a coluna $d u$ indica a quantidade de dias úteis entre a data de negociação e o respectivo vencimento do título, a coluna pu_médio mostra a média dos PUs negociados em 20/06/2001 e a coluna taxa é a taxa ao ano over obtida por quem comprasse a LTN pelo PU médio e a carregasse até sua maturidade.

Tabela 20: PU de Negociação

\begin{tabular}{|c|c|c|c|c|}
\hline Data & Vencimento & $d u$ & pu_médio & taxa \\
\hline $\mathbf{2 0 / 6 / 2 0 0 1}$ & $07 / 11 / 2001$ & 97 & 926,62 & 21,895 \\
\hline $\mathbf{2 0 / 6 / 2 0 0 1}$ & $03 / 04 / 2002$ & 189 & 845,45 & 25,087 \\
\hline $\mathbf{2 0 / 6 / 2 0 0 1}$ & $06 / 02 / 2002$ & 159 & 879,80 & 22,503 \\
\hline $\mathbf{2 0 / 6 / 2 0 0 1}$ & $09 / 01 / 2002$ & 139 & 902,10 & 20,536 \\
\hline $\mathbf{2 0 / 6 / 2 0 0 1}$ & $05 / 12 / 2001$ & 116 & 913,57 & 21,697 \\
\hline $\mathbf{2 0 / 6 / 2 0 0 1}$ & $03 / 10 / 2001$ & 74 & 944,73 & 21,365 \\
\hline $\mathbf{2 0 / 6 / 2 0 0 1}$ & $05 / 09 / 2001$ & 55 & 959,20 & 21,027 \\
\hline $\mathbf{2 0 / 6 / 2 0 0 1}$ & $04 / 07 / 2001$ & 10 & 993,53 & 17,772 \\
\hline $\mathbf{2 0 / 6 / 2 0 0 1}$ & $03 / 07 / 2002$ & 259 & 802,40 & 23,887 \\
\hline $\mathbf{2 0 / 6 / 2 0 0 1}$ & $01 / 08 / 2001$ & 30 & 980,71 & 17,773 \\
\hline
\end{tabular}

Observa-se que em 20/06/2001, nenhuma LTN negociada no mercado secundário teve seu vencimento em dias úteis coincidentes com os vencimentos de 21, 63 e 126 dias úteis necessários para caracterizar a LTN de um mês, três e seis meses, respectivamente.

A data 20/06/2001 é representativa do intervalo considerado de 01/06/2001 até $31 / 10 / 2001$ no que tange ao fato de que em nenhum dia deste período de tempo ter sido verificada a negociação de LTNs vencendo em exatamente 21, 63 ou 126 dias úteis.

Isto é, em determinados dias em particular, pode-se encontrar LTN com vencimento em exatamente 21 ou 63 ou 126 dias úteis, porém não houve o caso de no 
mesmo dia se encontrar uma LTN vencendo em 21 du, outra LTN vencendo 63 du e outra LTN em 126 du.

Portanto, faz-se necessário encontrar uma metodologia para se obter, ainda que sinteticamente, uma LTN vencendo em 21 du, outra em 63 du e outra em 121 du.

A metodologia proposta neste trabalho envolve alguns passos, a saber:

O primeiro passo foi, para cada dia de negociação dentro do intervalo considerado, encontrar as LTNs com prazos até o vencimento que obedeçam as seguintes características:

- Para a construção do vértice de 21 dias úteis, serão escolhidas 2 LTNs cujos prazos até o vencimento, denominados de $d u 2 \ln$ e $d u 21 p$, deverão obedecer a seguinte relação: $d u 2 \ln \leq 21 \leq d u 21 p$;

- Para a construção do vértice de 63 dias úteis, serão escolhidas 2 LTNs cujos prazos até o vencimento, denominados de $d u 63 n$ e $d u 63 p$, deverão obedecer a seguinte relação: $d u 63 n \leq 63 \leq d u 63 p$;

- Para a construção do vértice de 126 dias úteis, serão escolhidas 2 LTNs cujos prazos até o vencimento, denominados de $d u 126 n$ e $d u 126 p$, deverão obedecer a seguinte relação: $d u 126 n \leq 126 \leq d u 126 p$;

Desta feita, com os dados disponíveis, foi montada a Tabela 21 com a seguinte configuração: 
Tabela 21: Tabela Auxiliar

\begin{tabular}{|c|r|r|r|r|r|r|r|r|r|r|r|r|}
\hline Data & $d u 21 n$ & $d u 21 p$ & $d u 63 n$ & $d u 63 p$ & $d u 126 n$ & $d u 126 p$ & $\operatorname{taxa21n}$ & $\operatorname{taxa21p}$ & $\operatorname{taxa63n}$ & $\operatorname{taxa63p}$ & $\operatorname{taxa126n}$ & $\operatorname{taxa126p}$ \\
\hline $\mathbf{0 1 / 6 / 2 0 0 1}$ & 3 & 22 & 42 & 67 & 109 & 128 & 16,85 & 18,02 & 17,67 & 19,19 & 20,68 & 20,18 \\
\hline $\mathbf{0 4 / 6 / 2 0 0 1}$ & 21 & 21 & 41 & 66 & 85 & 127 & 17,20 & 17,20 & 18,32 & 19,81 & 20,53 & 20,53 \\
\hline $\mathbf{0 5 / 6 / 2 0 0 1}$ & 20 & 40 & 40 & 65 & 126 & 126 & 17,39 & 17,96 & 17,96 & 20,15 & 20,76 & 20,76 \\
\hline $\mathbf{0 6 / 6 / 2 0 0 1}$ & 19 & 39 & 39 & 64 & 125 & 148 & 17,47 & 17,92 & 17,92 & 18,71 & 19,75 & 20,65 \\
\hline $\mathbf{0 7 / 6 / 2 0 0 1}$ & 18 & 38 & 63 & 63 & 124 & 147 & 17,35 & 17,73 & 19,09 & 19,09 & 19,92 & 20,39 \\
\hline $\mathbf{0 8 / 6 / 2 0 0 1}$ & 17 & 37 & 62 & 81 & 123 & 146 & 17,31 & 17,60 & 18,67 & 18,82 & 19,15 & 20,10 \\
\hline $\mathbf{1 1 / 6 / 2 0 0 1}$ & 16 & 36 & 61 & 80 & 122 & 145 & 17,30 & 17,67 & 18,13 & 18,63 & 19,15 & 20,04 \\
\hline
\end{tabular}

A estrutura da tabela anterior é replicada considerando as negociações do mercado secundário até 31/10/2001, conforme evidencia a Tabela 22:

Tabela 22: Tabela de Negociações no Mercado Secundário

\begin{tabular}{|c|c|c|c|c|c|c|c|c|c|c|c|c|}
\hline Data & $d u 21 n$ & $d u 21 p$ & $d u 63 n$ & $d u 63 p$ & $d u 126 n$ & $d u 126 p$ & $\operatorname{taxa21n}$ & $\operatorname{taxa21p}$ & $\operatorname{taxa63n}$ & $\operatorname{taxa63p}$ & $\operatorname{taxa126n}$ & $\operatorname{taxa126p}$ \\
\hline $18 / 10 / 2001$ & 13 & 32 & 55 & 75 & 112 & 132 & 19,88 & 20,35 & 21,41 & 22,54 & 23,06 & 23,37 \\
\hline $19 / 10 / 2001$ & 12 & 31 & 54 & 74 & 111 & 131 & 19,81 & 20,37 & 21,15 & 21,44 & 22,84 & 23,65 \\
\hline $22 / 10 / 2001$ & 11 & 30 & 53 & 73 & 110 & 130 & 20,10 & 18,98 & 21,39 & 21,45 & 23,01 & 22,85 \\
\hline $23 / 10 / 2001$ & 10 & 29 & 52 & 72 & 109 & 129 & 19,49 & 19,91 & 20,98 & 21,65 & 22,65 & 22,80 \\
\hline $24 / 10 / 2001$ & 9 & 28 & 51 & 71 & 108 & 128 & 19,58 & 20,14 & 20,97 & 21,60 & 22,43 & 22,99 \\
\hline $25 / 10 / 2001$ & 8 & 27 & 50 & 70 & 107 & 127 & 19,43 & 20,25 & 21,05 & 21,65 & 22,60 & 23,01 \\
\hline $26 / 10 / 2001$ & 7 & 26 & 49 & 69 & 126 & 126 & 19,92 & 20,29 & 21,10 & 21,76 & 22,88 & 22,88 \\
\hline $29 / 10 / 2001$ & 6 & 25 & 48 & 68 & 125 & 168 & 19,66 & 20,13 & 21,01 & 21,65 & 23,02 & 24,73 \\
\hline $30 / 10 / 2001$ & 5 & 24 & 47 & 67 & 124 & 167 & 19,56 & 20,15 & 21,09 & 21,38 & 23,04 & 22,78 \\
\hline $31 / 10 / 2001$ & 4 & 23 & 46 & 66 & 123 & 166 & 19,55 & 20,28 & 21,12 & 21,37 & 23,12 & 23,83 \\
\hline
\end{tabular}


Para o prazo em que os cálculos serão realizados, isto é, de 01/06/2001 até 31/10/2001, há 106 dias úteis.

Note que para o dia 01/06/2001, os dois vencimentos mais próximos de 21 dias úteis foram 3 e $22 \mathrm{du}$. Os dois vencimentos mais próximos de 63 dias úteis foram 42 e 67 du. Os dois vencimentos mais próximos de 126 dias úteis foram 109 e $128 \mathrm{du}$.

O próximo passo foi encontrar os vencimentos desejados, isto é, 21, 63 e 126 du ao se interpolar linearmente. Como ilustração e considerando o dia 01/06/2001, a taxa interpolada para 21 dias úteis é obtida da seguinte maneira:

$$
\text { taxa_int_21 }=16,85+\frac{(21-3) \times(18,02-16,85)}{22-3}=17,96 \%
$$

Ainda considerando o dia 01/06/2001, a taxa interpolada para 63 dias úteis é obtida da seguinte maneira:

$$
\text { taxa_int_63=17,67+ } \frac{(63-42) \times(19,19-17,67)}{67-42}=18,95 \%
$$

Por fim, considerando o dia 01/06/2001, a taxa interpolada para 126 dias úteis é obtida da seguinte maneira:

$$
\text { taxa_int } 126=20,68+\frac{(126-109) \times(20,18-20,68)}{128-109}=20,24 \%
$$

Desta maneira, foi possível montar outra tabela com as taxas de rendimento ao ano over calculadas por intermédio da interpolação linear descrita acima. 
Tabela 23: Taxas Interpoladas

\begin{tabular}{|c|c|c|c|c|c|c|c|c|c|}
\hline Data & du21n & du21p & du63n & du63p & du126n & du126p & $\begin{array}{c}\text { Taxa } \\
\text { interp21 }\end{array}$ & $\begin{array}{c}\text { Taxa } \\
\text { interp63 }\end{array}$ & $\begin{array}{c}\text { Taxa } \\
\text { interp126 }\end{array}$ \\
\hline $\mathbf{1 / 6 / 2 0 0 1}$ & 3 & 22 & 42 & 67 & 109 & 128 & 17,966 & 18,95 & 20,24 \\
\hline $\mathbf{4 / 6 / 2 0 0 1}$ & 21 & 21 & 41 & 66 & 85 & 127 & 17,20 & 19,64 & 20,53 \\
\hline $\mathbf{5 / 6 / 2 0 0 1}$ & 20 & 40 & 40 & 65 & 126 & 126 & 17,42 & 19,98 & 20,76 \\
\hline $\mathbf{6 / 6 / 2 0 0 1}$ & 19 & 39 & 39 & 64 & 125 & 148 & 17,51 & 18,68 & 19,79 \\
\hline $\mathbf{7 / 6 / 2 0 0 1}$ & 18 & 38 & 63 & 63 & 124 & 147 & 17,41 & 19,09 & 19,97 \\
\hline $\mathbf{8 / 6 / 2 0 0 1}$ & 17 & 37 & 62 & 81 & 123 & 146 & 17,37 & 18,68 & 19,28 \\
\hline $\mathbf{1 1 / 6 / 2 0 0 1}$ & 16 & 36 & 61 & 80 & 122 & 145 & 17,39 & 18,18 & 19,31 \\
\hline
\end{tabular}




\subsection{Cálculo do VaR de um dia Útil com $95 \%$ de Confiança pelo Método de Dois Fatores Modificado}

Uma vez que se deseja calcular o VaR pela metodologia NHF (2000: 1903-1932) modificada, faz-se necessário converter as taxas ao ano over para taxa ao período. Desta maneira, obteve-se o seguinte conjunto de dados:

Tabela 24: Rentabilidades ao Período

\begin{tabular}{|c|c|c|c|c|}
\hline & & & LTN 3 MESES & LTN 6 MESES \\
\hline DATA & & $\begin{array}{l}\text { Rentabilidade } \\
\text { (ao período) }\end{array}$ & $\begin{array}{l}\text { Rentabilidade } \\
\text { (ao período) }\end{array}$ & $\begin{array}{l}\text { Rentabilidade } \\
\text { (ao período) }\end{array}$ \\
\hline 01/06/01 & & $1,386 \%$ & $4,435 \%$ & $9,654 \%$ \\
\hline 04/06/01 & 1 & $1,331 \%$ & $4,585 \%$ & $9,790 \%$ \\
\hline 05/06/01 & 2 & $1,348 \%$ & $4,659 \%$ & $9,893 \%$ \\
\hline 06/06/01 & 3 & $1,354 \%$ & $4,376 \%$ & $9,451 \%$ \\
\hline 07/06/01 & 4 & $1,347 \%$ & $4,466 \%$ & $9,531 \%$ \\
\hline 08/06/01 & 5 & $1,344 \%$ & $4,376 \%$ & $9,216 \%$ \\
\hline $11 / 06 / 01$ & 6 & $1,345 \%$ & $4,266 \%$ & $9,230 \%$ \\
\hline $12 / 06 / 01$ & 7 & $1,346 \%$ & $4,357 \%$ & $8,969 \%$ \\
\hline $13 / 06 / 01$ & 8 & $1,339 \%$ & $4,440 \%$ & $9,484 \%$ \\
\hline $15 / 06 / 01$ & 9 & $1,353 \%$ & $4,353 \%$ & $9,713 \%$ \\
\hline 18/06/01 & 10 & $1,379 \%$ & $4,538 \%$ & $9,635 \%$ \\
\hline 19/06/01 & 11 & $1,431 \%$ & $4,715 \%$ & $10,510 \%$ \\
\hline
\end{tabular}

\begin{tabular}{|c|c|c|c|c|}
\hline $18 / 10 / 01$ & $\mathbf{9 6}$ & $1,537 \%$ & $5,069 \%$ & $11,032 \%$ \\
\hline $19 / 10 / 01$ & $\mathbf{9 7}$ & $1,536 \%$ & $4,943 \%$ & $11,110 \%$ \\
\hline $22 / 10 / 01$ & $\mathbf{9 8}$ & $1,497 \%$ & $4,973 \%$ & $10,855 \%$ \\
\hline $23 / 10 / 01$ & $\mathbf{9 9}$ & $1,513 \%$ & $4,958 \%$ & $10,807 \%$ \\
\hline $24 / 10 / 01$ & $\mathbf{1 0 0}$ & $1,527 \%$ & $4,958 \%$ & $10,876 \%$ \\
\hline $25 / 10 / 01$ & $\mathbf{1 0 1}$ & $1,531 \%$ & $4,978 \%$ & $10,905 \%$ \\
\hline $26 / 10 / 01$ & $\mathbf{1 0 2}$ & $1,545 \%$ & $5,004 \%$ & $10,853 \%$ \\
\hline $29 / 10 / 01$ & $\mathbf{1 0 3}$ & $1,534 \%$ & $4,988 \%$ & $10,933 \%$ \\
\hline $30 / 10 / 01$ & $\mathbf{1 0 4}$ & $1,535 \%$ & $4,952 \%$ & $10,922 \%$ \\
\hline $31 / 10 / 01$ & $\mathbf{1 0 5}$ & $1,546 \%$ & $4,955 \%$ & $10,985 \%$ \\
\hline
\end{tabular}

Note que pelo conjunto de dados obtido, para os 106 dias úteis considerados, é possível construir 106 curvas de juros.

Contudo, conforme foi evidenciado na dedução do modelo NHF (2000: 1903-1932), 
o mesmo estuda diferenças nos patamares dos juros de um período para outro. Portanto, faz-se necessário para cada dia do intervalo considerado e para cada vencimento $i$ calcular a variação da taxa de rendimento ao período $r$ entre o dia anterior e o dia em estudo.

Desta forma, obtém-se uma tabela com 105 variações, tal como se observa na Tabela 25:

Tabela 25: Tabela de Variações das Taxas de Juros ao Período

\begin{tabular}{|c|c|c|c|c|c|c|c|}
\hline DATA & & Rentabilidade & Rentabilidade & Rentabilidade & $\begin{array}{c}\text { Variação } \\
\text { (t;t-1) LTN } \\
1 \text { MÊS }\end{array}$ & $\begin{array}{l}\text { Variação } \\
\text { (t;t-1) LTN } \\
3 \text { MESES }\end{array}$ & $\begin{array}{c}\text { Variação } \\
(\mathrm{t} ; \mathrm{t}-1) \text { LTN } \\
6 \text { MESES }\end{array}$ \\
\hline 01/06/01 & & $1,386 \%$ & $4,435 \%$ & $9,654 \%$ & & & \\
\hline 04/06/01 & 1 & $1,331 \%$ & $4,585 \%$ & $9,790 \%$ & $0,0547 \%$ & $-0,1499 \%$ & $-0,1360 \%$ \\
\hline 05/06/01 & 2 & $1,348 \%$ & $4,659 \%$ & $9,893 \%$ & $-0,0162 \%$ & $-0,0742 \%$ & $-0,1031 \%$ \\
\hline 06/06/01 & 3 & $1,354 \%$ & $4,376 \%$ & $9,451 \%$ & $-0,0067 \%$ & $0,2836 \%$ & $0,4423 \%$ \\
\hline 07/06/01 & 4 & $1,347 \%$ & $4,466 \%$ & $9,531 \%$ & $0,0075 \%$ & $-0,0909 \%$ & $-0,0797 \%$ \\
\hline 08/06/01 & 5 & $1,344 \%$ & $4,376 \%$ & $9,216 \%$ & $0,0028 \%$ & $0,0908 \%$ & $0,3149 \%$ \\
\hline $11 / 06 / 01$ & 6 & $1,345 \%$ & $4,266 \%$ & $9,230 \%$ & $-0,0013 \%$ & $0,1099 \%$ & $-0,0141 \%$ \\
\hline $12 / 06 / 01$ & 7 & $1,346 \%$ & $4,357 \%$ & $8,969 \%$ & $-0,0006 \%$ & $-0,0910 \%$ & $0,2615 \%$ \\
\hline $13 / 06 / 01$ & 8 & $1,339 \%$ & $4,440 \%$ & $9,484 \%$ & $0,0067 \%$ & $-0,0832 \%$ & $-0,5153 \%$ \\
\hline
\end{tabular}

\begin{tabular}{|r|c|c|c|c|c|c|c|}
\hline $22 / 10 / 01$ & $\mathbf{9 8}$ & $1,497 \%$ & $4,973 \%$ & $10,855 \%$ & $0,0397 \%$ & $-0,0299 \%$ & $0,2547 \%$ \\
\hline $23 / 10 / 01$ & $\mathbf{9 9}$ & $1,513 \%$ & $4,958 \%$ & $10,807 \%$ & $-0,0167 \%$ & $0,0149 \%$ & $0,0482 \%$ \\
\hline $24 / 10 / 01$ & $\mathbf{1 0 0}$ & $1,527 \%$ & $4,958 \%$ & $10,876 \%$ & $-0,0134 \%$ & $-0,0004 \%$ & $-0,0695 \%$ \\
\hline $25 / 10 / 01$ & $\mathbf{1 0 1}$ & $1,531 \%$ & $4,978 \%$ & $10,905 \%$ & $-0,0038 \%$ & $-0,0197 \%$ & $-0,0284 \%$ \\
\hline $26 / 10 / 01$ & $\mathbf{1 0 2}$ & $1,545 \%$ & $5,004 \%$ & $10,853 \%$ & $-0,0140 \%$ & $-0,0260 \%$ & $0,0514 \%$ \\
\hline $29 / 10 / 01$ & $\mathbf{1 0 3}$ & $1,534 \%$ & $4,988 \%$ & $10,933 \%$ & $0,0110 \%$ & $0,0156 \%$ & $-0,0801 \%$ \\
\hline $30 / 10 / 01$ & $\mathbf{1 0 4}$ & $\mathbf{1 , 5 3 5 \%}$ & $4,952 \%$ & $10,922 \%$ & $-0,0019 \%$ & $0,0360 \%$ & $0,0111 \%$ \\
\hline $31 / 10 / 01$ & $\mathbf{1 0 5}$ & $\mathbf{1 , 5 4 6 \%}$ & $4,955 \%$ & $10,985 \%$ & $-0,0105 \%$ & $-0,0029 \%$ & $-0,0628 \%$ \\
\hline
\end{tabular}

Agora que se tem os 105 conjuntos de diferenças para os 3 vencimentos, o próximo passo é fazer 105 regressões lineares das variações e encontrar $105 \Delta r_{i, t}$ na seguinte forma:

$$
\Delta r_{i, t}=p^{* *}{ }_{t}+b^{*}{ }_{t}\left(i-i^{* *}\right)
$$

Sendo que: 
- Cada $b^{*}{ }_{t}$ é obtido pela seguinte relação: $b^{*}{ }_{t}=\frac{\operatorname{cov}\left(\Delta r_{i, t} ; i\right)}{\operatorname{var}(i)}$, sendo $i$ os vencimentos 21, 63 e 126 dias úteis.

- Cada $p^{* *}{ }_{t}$ é obtido pela seguinte relação: $p_{t}^{* *}=E\left[\Delta r_{i t}\right]-b_{t}^{*} \times E\left[i-i^{* *}\right]$, sendo que $i^{* *}=E[i]-\frac{\operatorname{cov}\left(b_{t}^{*} ; E\left[\Delta r_{i t}\right]\right)}{\operatorname{var}\left(b_{t}^{*}\right)}, i^{* *}=37,22$ dias úteis.

Mais uma vez, deve-se lembrar que o modelo sugerido por NHF (2000: 1903-1932) não constrói as covariâncias requeridas pelo VaR paramétrico com base no patamar das taxas de juros tampouco na variação da taxa de rendimento $r$ entre os instantes $t-1$ e $t$.

Na verdade, o referido modelo constrói as covariâncias a partir das regressões calculadas diariamente e dadas por $\Delta r_{i, t}=p^{* *}{ }_{t}+b^{*}{ }_{t}\left(i-i^{* *}\right)$. Portanto, após se realizar as 105 regressões, ter-se-á 105 conjuntos de $p^{* *}{ }_{t}$ e 105 conjuntos de $b^{*}{ }_{t}$ tal como evidencia a Tabela 26:

Tabela 26: Resultado das Regressões

\begin{tabular}{|c|c|c|c|c|}
\hline DATA & & $\begin{array}{l}\text { Delta(t-1;t) } \\
\text { LTN } 1 \text { MÊS }\end{array}$ & $\begin{array}{l}\text { Delta(t-1;t) LTN } \\
3 \text { MESES }\end{array}$ & $\begin{array}{l}\text { Delta(t-1;t) LTN } \\
6 \text { MESES }\end{array}$ \\
\hline \multicolumn{5}{|l|}{$01 / 06 / 01$} \\
\hline $04 / 06 / 01$ & 1 & $0,0547 \%$ & $-0,1499 \%$ & $-0,1360 \%$ \\
\hline 05/06/01 & 2 & $-0,0162 \%$ & $-0,0742 \%$ & $-0,1031 \%$ \\
\hline 06/06/01 & 3 & $-0,0067 \%$ & $0,2836 \%$ & $0,4423 \%$ \\
\hline $07 / 06 / 01$ & 4 & $0,0075 \%$ & $-0,0909 \%$ & $-0,0797 \%$ \\
\hline $08 / 06 / 01$ & 5 & $0,0028 \%$ & $0,0908 \%$ & $0,3149 \%$ \\
\hline $11 / 06 / 01$ & 6 & $-0,0013 \%$ & $0,1099 \%$ & $-0,0141 \%$ \\
\hline $12 / 06 / 01$ & 7 & $-0,0006 \%$ & $-0,0910 \%$ & $0,2615 \%$ \\
\hline
\end{tabular}

$b^{*} \mathbf{t}$

$\mathbf{p}^{* *} \mathbf{t}$

$-0,0000166$

$-0,000228$

$-0,0000080$

0,0000414

$-0,0000075$

0,0000302

$-0,0000027$

0,0000274
$-0,000383$

0,001041

$-0,000298$

0,000373

0,000403

$-0,000332$

\begin{tabular}{|r|c|c|c|c|}
\cline { 4 - 5 } $22 / 10 / 01$ & $\mathbf{9 8}$ & $0,0397 \%$ & $-0,0299 \%$ & $0,2547 \%$ \\
\hline $23 / 10 / 01$ & $\mathbf{9 9}$ & $-0,0167 \%$ & $0,0149 \%$ & $0,0482 \%$ \\
\hline $24 / 10 / 01$ & $\mathbf{1 0 0}$ & $-0,0134 \%$ & $-0,0004 \%$ & $-0,0695 \%$ \\
\hline $25 / 10 / 01$ & $\mathbf{1 0 1}$ & $-0,0038 \%$ & $-0,0197 \%$ & $-0,0284 \%$ \\
\hline $26 / 10 / 01$ & $\mathbf{1 0 2}$ & $-0,0140 \%$ & $-0,0260 \%$ & $0,0514 \%$ \\
\hline $29 / 10 / 01$ & $\mathbf{1 0 3}$ & $0,0110 \%$ & $0,0156 \%$ & $-0,0801 \%$ \\
\hline $30 / 10 / 01$ & $\mathbf{1 0 4}$ & $-0,0019 \%$ & $0,0360 \%$ & $0,0111 \%$ \\
\hline $31 / 10 / 01$ & $\mathbf{1 0 5}$ & $-0,0105 \%$ & $-0,0029 \%$ & $-0,0628 \%$ \\
\hline
\end{tabular}

0,0000224

0,0000061

$-0,0000058$

$-0,0000023$

0,0000067

$-0,0000092$

0,0000008

$-0,0000053$
0,000147

$-0,000046$

$-0,000088$

$-0,000098$

$-0,000181$

0,000123

0,000124

$-0,000079$ 
Sabendo que:

$V a R_{\text {diário }, 95 \%}=1,645 \times \sqrt{\begin{array}{l}\operatorname{var}\left(p_{t}^{* *}\right) \times \sum_{i=1}^{N} \sum_{j=1}^{N} \frac{V P_{i} \times V P_{j}}{\left(1+\bar{r}_{i}\right) \times\left(1+\bar{r}_{j}\right)}+ \\ +\operatorname{var}\left(b_{t}^{*}\right) \times \sum_{i=1}^{N} \sum_{j=1}^{N} \frac{V P_{i} \times V P_{j}}{\left(1+\bar{r}_{i}\right) \times\left(1+\bar{r}_{j}\right)} \times\left(i-i^{* *}\right) \times\left(j-i^{* *}\right)\end{array}}$

Tem-se que para o período compreendido entre $01 / 06 / 2001$ até $31 / 10 / 2001$, todos os parâmetros necessários para o cálculo do VaR já foram obtidos e constam das tabelas anteriores, exceto as taxas médias ao período para os três prazos analisados, as quais são iguais a:

Tabela 27: Taxas Médias ao Período

\begin{tabular}{|c|c|c|}
\hline $\bar{r}_{1 m \hat{e} s}$ & $\bar{r}_{3 \text { meses }}$ & $\bar{r}_{6 \text { meses }}$ \\
\hline $\mathbf{1 , 5 1 4 \%}$ & $\mathbf{5 , 0 8 4 \%}$ & $\mathbf{1 0 , 9 6 7 \%}$ \\
\hline
\end{tabular}

Efetuando-se os devidos cálculos, tem-se que o $V_{a} R_{\text {diário,95\% }}$ pelo modelo de dois fatores para a carteira dada pela Tabela 28 e considerando o período de 01/06/2001 até $31 / 10 / 2001$ é igual a $\mathrm{R} \$ 10,7092$.

Tabela 28: Composição da Carteira

\begin{tabular}{|c|c|c|}
\hline \multicolumn{2}{|c|}{ Composição da Carteira de Títulos de Renda Fixa } \\
\hline Tipo do Título & Valor Investido & Percentual \\
\hline LTN 1 Mês & R\$ $1.000,00$ & $33,33 \%$ \\
\hline LTN 3 Meses & R\$ 1.000,00 & $33,33 \%$ \\
\hline LTN 6 Meses & R\$ 1.000,00 & $33,33 \%$ \\
\hline Total & R\$ 3.000,00 & $\mathbf{1 0 0 \%}$ \\
\hline
\end{tabular}

A carteira é composta com estes vencimentos pois procurou-se utilizar os títulos cujos vencimentos tivessem maior liquidez. 


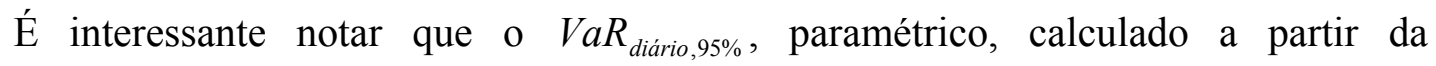
metodologia tradicional, é igual a R\$10,7690.

Mais uma vez, cabe ressaltar que o modelo de dois fatores forneceu uma estimativa paramétrica do VaR.

\subsection{O Back-testing}

Apesar do VaR obtido pelo modelo de dois fatores ser razoavelmente próximo do VaR paramétrico obtido pela metodologia tradicional, sua qualidade será aquilatada por intermédio do procedimento chamado de back-testing, o qual já foi discutido na revisão bibliográfica.

Para a realização do back-testing, tudo se passa como se na manhã do dia 17/08/2001, antes da abertura do mercado, desejou-se calcular o $V a R_{\text {diário,95\% }}$ por intermédio do modelo de dois fatores para a carteira em estudo.

Nessas condições, a janela de estudo foi do dia 01/06/2001 até 16/08/2001, compreendendo 54 dias úteis. Neste período, calculou-se:

- Esperança dos retornos diários dos títulos de um, três e seis meses;

- $\quad \operatorname{VaR}_{\text {diário, } 95 \%}$ pelo método de dois fatores, sendo o mesmo igual a $\mathrm{R} \$ 10,7092$;

Uma vez que se tem as esperanças dos retornos diários dos títulos de 1,3 e 6 meses, é possível calcular o valor esperado para a carteira ao final do dia 17/08/2001.

Sabendo que:

\section{Tabela 29: Esperança}

\begin{tabular}{|c|c|c||}
\hline $\begin{array}{c}\text { Esperança do retorno diário da LTN } \\
\text { de 1 Mês considerando o período } \\
\text { de 01/06/2001 até 16/08/2001 }\end{array}$ & $\begin{array}{c}\text { Esperança do retorno diário da LTN } \\
\text { de } 3 \text { Meses considerando o período } \\
\text { de 01/06/2001 até 16/08/2001 }\end{array}$ & $\begin{array}{c}\text { Esperança do retorno diário da LTN } \\
\text { de } 6 \text { meses considerando o período } \\
\text { de 01/06/2001 até 16/08/2001 }\end{array}$ \\
\hline \hline$-0,00350 \%$ & $-0,01478 \%$ & $-0,01888 \%$ \\
\hline
\end{tabular}

Portanto, o valor esperado para a carteira para o final do dia 17/08/2001 é igual a: 
$1000 \times(1-0,000035)+1000 \times(1-0,0001478)+1000 \times(1-0,0001888)=R \$ 2.999,63$

Ao final do dia 17/08/2001, apurou-se que a carteira estava valendo R $\$ 3.004,48$.

Conclui-se que a carteira ao final do dia considerado valia mais que o esperado.

Deve-se repetir o raciocínio anterior para o dia 18/08/2001. Isto é, deve-se supor que na manhã do dia 18/08/2001, antes da abertura do mercado, se desejou calcular o $\operatorname{VaR}_{\text {diário, } 95 \%}$. Contudo, a nova janela de estudo será do dia 02/06/2001 até 17/08/2001, compreendendo 54 dias úteis.

O back-testing consistiu justamente em replicar esse raciocínio dia-a-dia até $31 / 10 / 2001$ e contar quantas vezes o $V_{a} R_{\text {diário, } 95 \%}$ calculado pelo modelo de dois fatores foi superado pela perda apurada no dia, isto é, a diferença entre o que se esperava ter de valor na carteira ao final do dia e o valor efetivo da carteira apurado ao final do dia.

No intervalo de tempo considerado, seguindo a metodologia descrita acima, a estimativa do $\operatorname{VaR}_{\text {diarrio, } 95 \%}$, tanto pela metodologia tradicional como pelo modelo de dois fatores, foi superada pela perda efetiva em um dia, conforme pode ser observado pela Figura 29:

Figura 29: Comparação via Back-testing

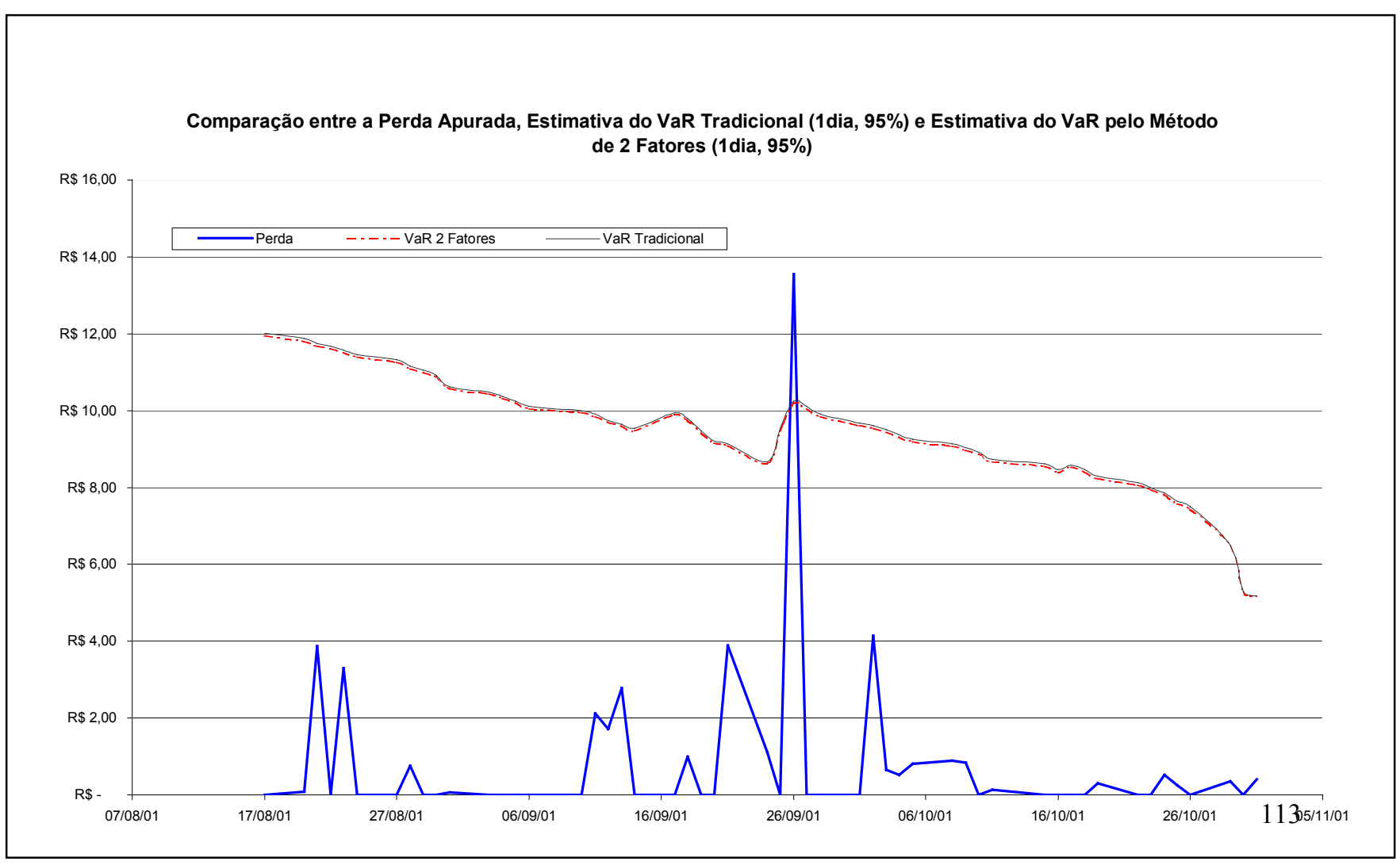


Deve ser salientado que o back-testing realizado e evidenciado na Figura 29 utilizou janela móvel de 55 dados históricos e foi empregada para se testar o VaR em 52 dias úteis. Isto é, durante 52 dias úteis foram utilizados os 55 dias úteis anteriores para se estimar o VaR em uma ocasião a estimativa do VaR pelo modelo de dois fatores foi superada pela perda efetiva.

A Figura 29, contudo, não é capaz de evidenciar quão próximas estão as estimativas do Valor em Risco calculadas pela metodologia tradicional e pelo modelo de dois fatores. Por esta razão, o mesmo gráfico dado pela Figura 29 é mostrado a seguir pela Figura 30 com uma mudança na escala de maneira a salientar a proximidade das duas estimativas do VaR obtidas ao se realizar o back-testing.

Figura 30: Comparação via Back-testing

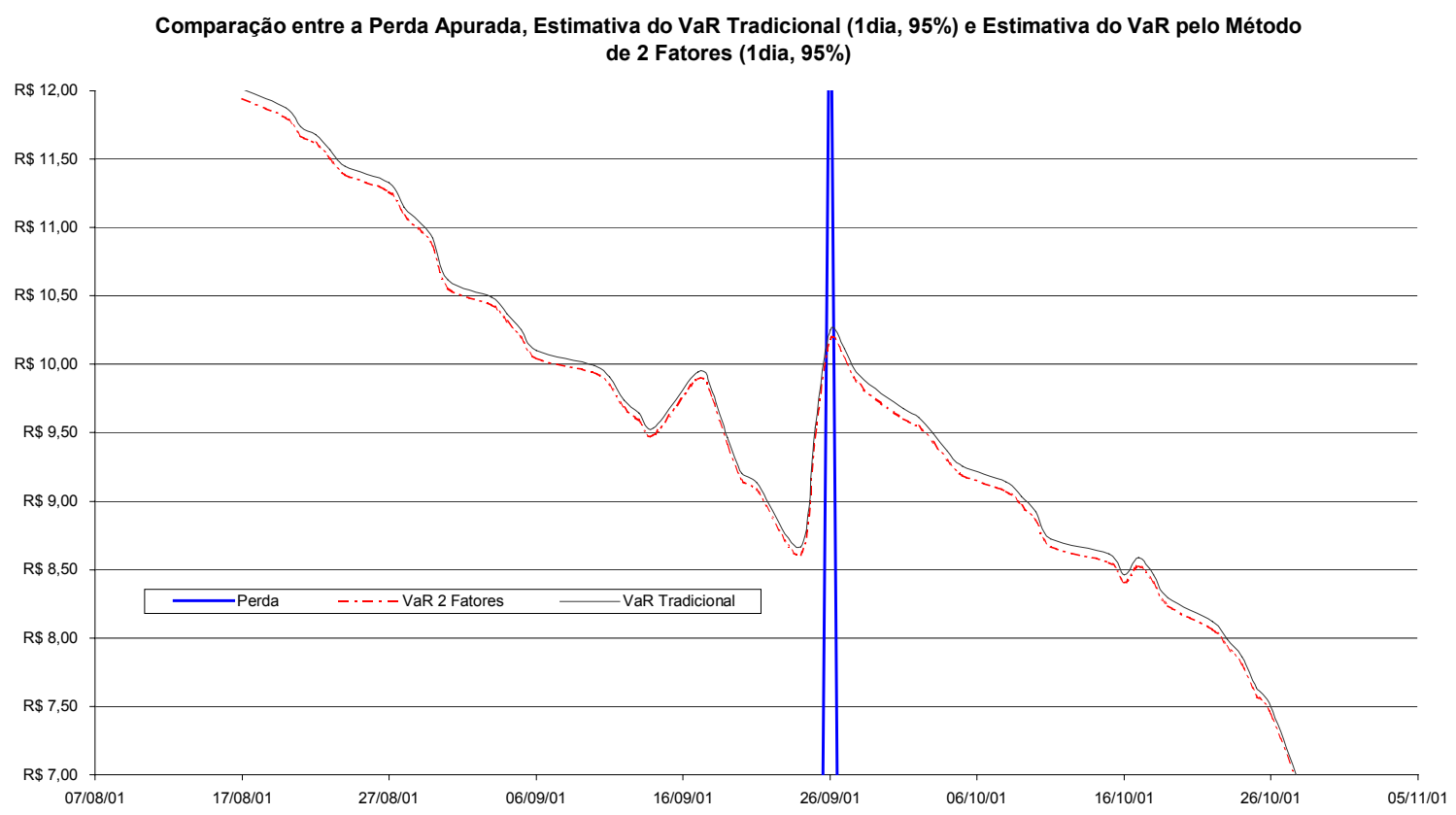




\section{Capítulo 5: Análise e Discussão das Limitações dos Modelos}

Existem algumas argumentações contra o modelo tradicional que calcula o Valor em Risco. Serão discutidas algumas delas.

\subsection{A Suposição da Normalidade e as Caudas Gordas}

Inicialmente deve-se considerar que o nível de confiança CI é uma estimativa correta quando se considera que a distribuição do fator de risco, no caso as variações de um dia para outro na taxa de juros, segue uma normal ou qualquer outra função cumulativa de probabilidade que possa ser caracterizada pelo parâmetro desvio padrão.

Sobre a esta suposição de normalidade, GREENSPAN em um discurso realizado em 1997, citado por DARBHA (2001:2), assevera que:

...the biggest problem we now have with the whole evolution of the risk is the fat-tailed problem, which is really creating very large conceptual dificulties. Because as we all know, the assumption of normality enables us to drop the huge amount of complexity in our equations. Because once you start putting in non-normality assumptions, which is unfortunately what characterizes the real world, then these issues become extremely dificult.

Isto é:

... o maior problema que nós enfrentamos agora com toda a evolução do risco é o problema das caudas gordas, que está realmente criando grandes dificuldades conceituais. Isto ocorre, pois como todos sabemos, a suposição de normalidade nos possibilita deixar de lado toda a complexidade de nossas equações. Quando você começa a adotar suposições de não normalidade, o que infelizmente é o que caracteriza o mundo real, então estas questões se tornam extremamente dificeis.

DOWD (1999: 1) argumenta que um dos maiores problemas concernentes ao VaR é o fato dele ser o quantil extremo na distribuição de retornos ao mesmo tempo em que relativamente poucas observações extremas são obtidas. Portanto, a estimativa do VaR é imprecisa e se torna ainda mais na medida em que se aproxima da cauda da distribuição. Esta falta de precisão é particularmente séria se o analista estiver interessado numa 
estimativa do VaR que esteja além dos dados disponíveis. Ainda segundo o referido autor, o analista que tenha que realizar um cálculo desta natureza terá que se basear em suposições de maneira a suprir a falta de dados. Uma suposição comum é que a distribuição dos retornos é normal, o que faz com que o cálculo do VaR seja sensivelmente simplificado. Contudo, os retornos financeiros encontrados na prática possuem caudas gordas, o que faz com que a suposição de normalidade conduza a estimativas otimistas do $\mathrm{VaR}$. Este constatação de DOWD sobre o otimismo das estimativas do VaR em que se supõe normalidade é corroborada por O'BRIEN \& BERKOWITZ (1997: 3) que, ao estudarem as estimativas do VaR utilizadas por um conjunto de seis grandes bancos comerciais sujeitos aos requisitos estabelecidos pelo Acordo da Basiléia, chegaram à conclusão que tais estimativas para o percentil de $99 \%$ eram conservadoras.

Este problema adquire maior relevo quando se considera que as instituições que regulam as instituições financeiras tipicamente escolhem o quantil associado a 99\% para o cálculo do valor em risco, pois, segundo DARBHA (2001: 3), tais instituições têm a tendência natural para o conservadorismo.

Ora, quando se fazem suposições de normalidade quando, na verdade a distribuição verificada é outra, quanto maior for o quantil, maior será a imprecisão associada. Esta imprecisão é traduzida em valores para o VaR modestos, encobrindo os reais riscos ao se assumir a posição.

Uma suposição mais satisfatória é considerar que os retornos seguem uma distribuição com caudas gordas. Ainda assim há problemas.

Uma vez que a maioria das observações obtidas são centrais, a distribuição construída com caudas gordas a partir dos dados observados tende a produzir boas aproximações para as observações centrais e aproximações de má qualidade para as observações extremas.

McNeil (1996: 19), citado por DOWD (1999: 2), observa que:

In a sense, it is never possible to have enough data in an extreme value analysis. (...) our inference about the tail of the distribution is less certain, since only a few points enter the tail region.(...) [Moreover] inference is very 
sensitive to the largest observed losses and the introduction of new extreme losses to the dataset may have a substantial impact.

Isto é:

De certo modo, nunca é possível ter dados suficientes numa análise de valores extremos (...) nossa inferência sobre a cauda da distribuição é menos correta, uma vez que poucos pontos entram na cauda da região. (...) [Adicionalmente] inferência é muito sensível à maior das perdas observadas e a introdução de novos valores extremos ao conjunto de dados pode causar um impacto substancial.

Ainda segundo o referido autor, uma saída para este problema vem do Teorema do Valor Extremo, o qual consiste de uma abordagem desenvolvida para resolver tais questões. A abordagem desta teoria foge ao escopo de estudo desta dissertação, porém poderá servir de objeto de estudo de pesquisas posteriores.

\subsection{A Estimativa do VaR como Máxima Perda}

Conforme já foi salientado, JORION (1997: 86) afirma que o “... VAR summarizes the expected maximum loss (worst loss) over a target horizon within a given confidence interval”. Isto é, o “(...) o VaR sumaria a máxima perda esperada dentro de um intervalo de tempo e dado um intervalo de confiança".

Outros autores, como BENNINGA \& WIENER (1998: 1), teceram definições similares para o valor em risco.

Contudo, pode ser argumentado que o VaR não exatamente fornece a máxima perda dado um horizonte de tempo. (DARBHA: 2001; 3)

Isto é, se o $V a R_{\text {diário, } 95 \%}$ for igual a $\mathrm{R} \$ 1.000 .000,00$, tem-se que dado um horizonte de tempo, digamos 100 dias úteis, não mais que cinco dias poderão apresentar perdas superiores a R\$ 1.000.000,00. Contudo, ainda que o número de vezes que a perda verificada ultrapasse o valor em risco calculado seja inferior a 5 dias, o $V a R_{\text {diário,95\% }}$ não fornece um limite para a máxima perda que pode ocorrer nestes dias.

Portanto, se uma carteira de investimentos de $\mathrm{R} \$ 300.000 .000,00$ possuir um 
$V a R_{\text {diário, } 95 \%}$ igual a $\mathrm{R} \$ 1.000 .000,00$, nada impede que em um dia a perda verificada seja de $\mathrm{R} \$ 200.000 .000,00$ !

Eis o motivo de DARBHA(2001: 3) afirmar que a técnica de Valor em Risco não fornece a máxima perda esperada.

Contudo, ainda que DARBHA não apresente o argumento seguinte, há de considerar que a definição do VaR é a máxima perda esperada para um horizonte de tempo, dado um intervalo de confiança. Portanto, ainda que o referido autor exponha suas idéias com bastante eloqüência, não é falacioso afirmar que o VaR fornece a máxima perda esperada.

Contudo, o referido autor sugere outras metodologias como Expected Shortfall (ES) ou Tail Conditional Excpectation (TCE) para se determinar a máxima perda que pode ser esperada ao se assumir uma posição a partir de uma abordagem que o VaR não é capaz e também não se propõe a evidenciar. O presente estudo não deseja tecer comentários adicionais sobre ES e TCE de forma a não pecar por abordar temas de relativa complexidade de forma rasa. Mais uma vez, estes temas podem servir de substrato para pesquisas posteriores.

\subsection{Limitações do VaR Simplificado}

Existem algumas argumentações contra o modelo que calcula o Valor em Risco utilizando as decomposições apresentadas.

A primeira limitação, é que o modelo de dois fatores advém de um modelo de VaR paramétrico, herdando, portanto, os inconvenientes citados anteriormente.

O segundo inconveniente e que se soma aos anteriores é que a depender da curva de juros que se tenha, a interpolação linear que o modelo de dois fatores sugere pode não ser adequada.

Isto é, se a curva de juros para determinado dia tiver a forma dada pela Figura 31, nota-se que a interpolação linear não é o melhor método de ajuste de curva. 
Figura 31: Curva de Juros e Regressão

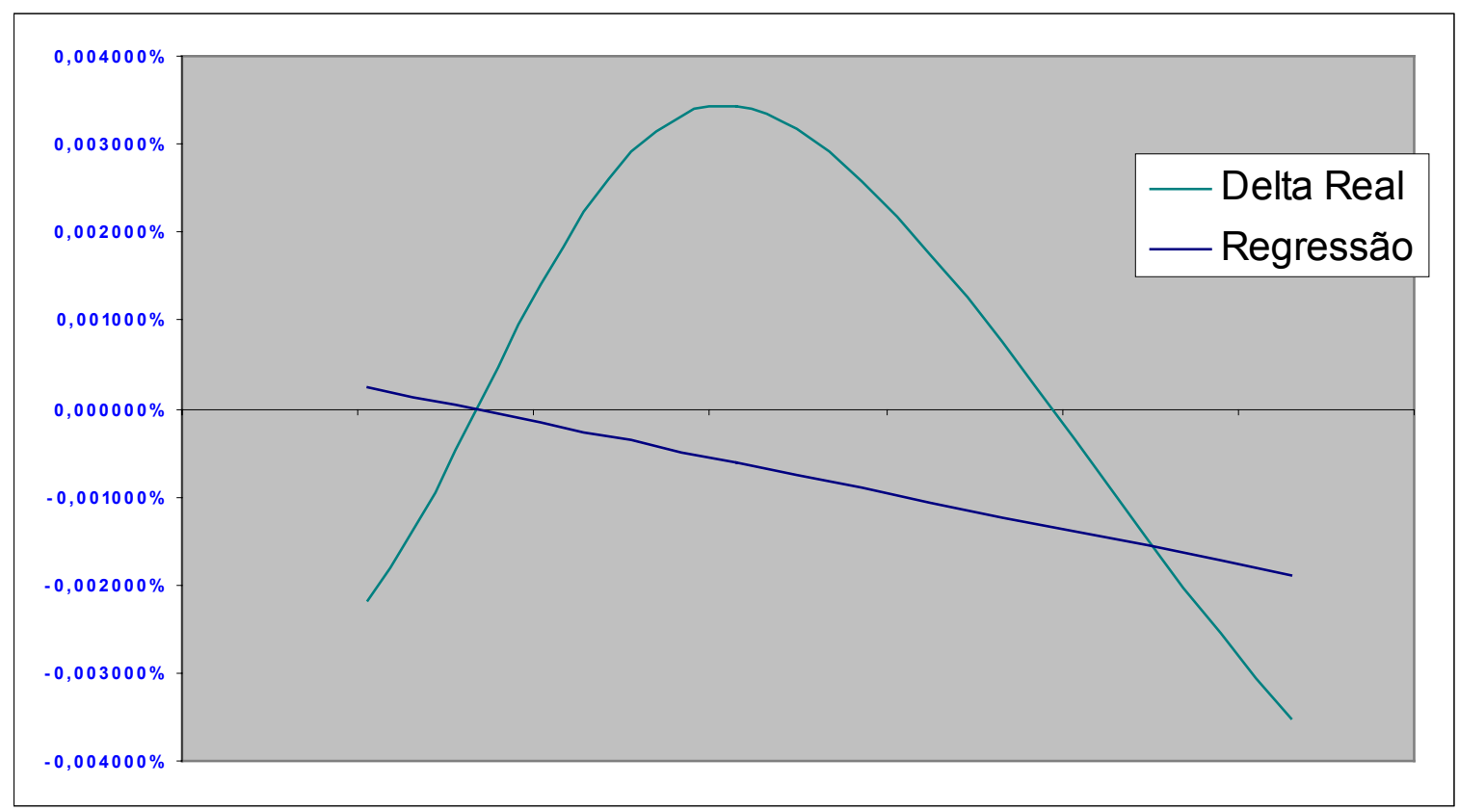

No entanto, se a curva de juros tiver a forma do gráfico da Figura 32, a interpolação linear sugerida no modelo poderá ser satisfatória.

\section{Figura 32: Curva de Juros e Regressão}

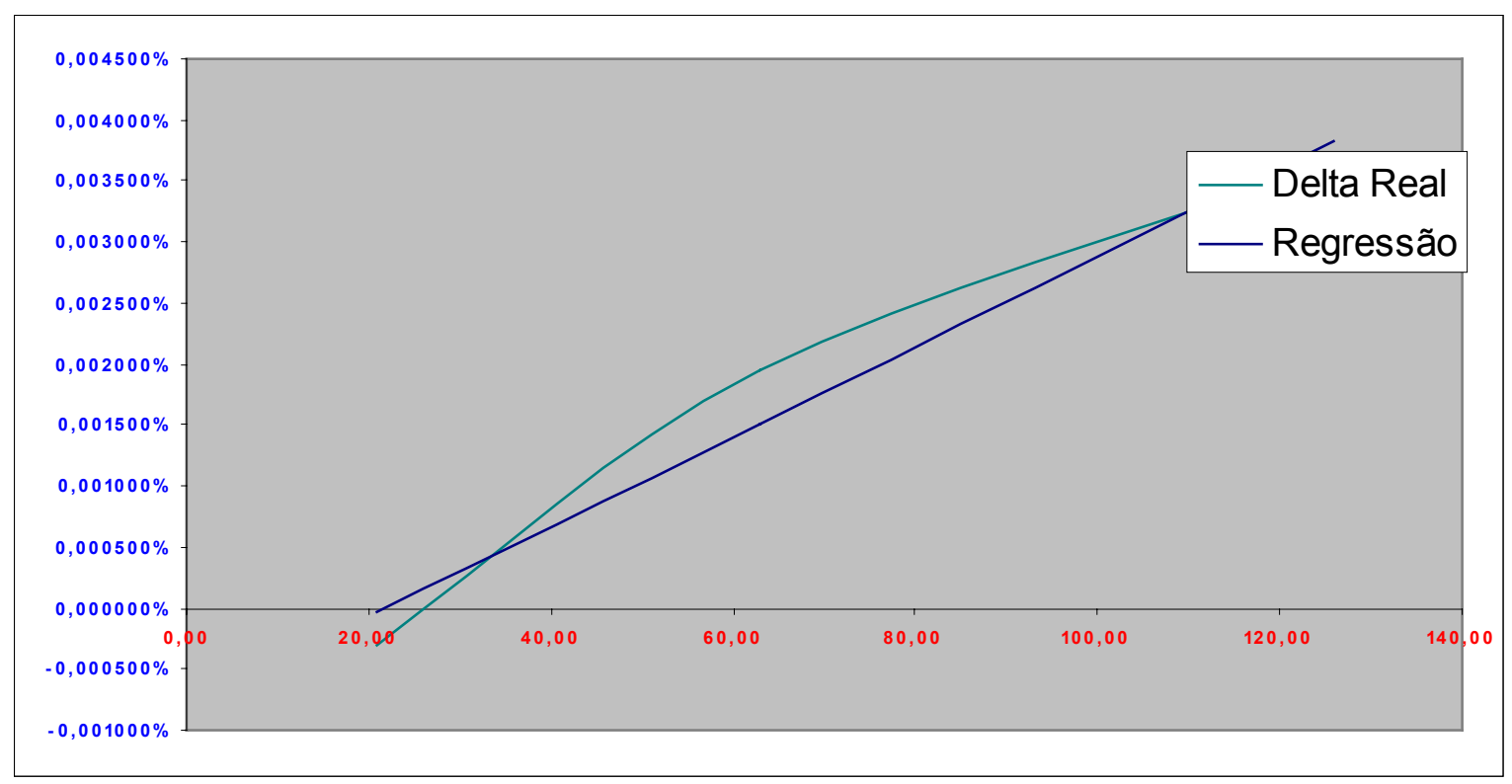

Outra limitação do modelo advém do fato de se ter introduzido uma aproximação que o modelo NHF (2000: 1903-1932) não possuía, que é justamente supor um patamar médio de taxa de juros para cada um dos vencimentos dos títulos analisados, tal como se 
evidenciou quando afirma-se que o fator de risco FR é dado por $\frac{\Delta r_{i, t}}{1+\bar{r}_{i}}$ e $\frac{\Delta r_{j, t}}{1+\bar{r}_{j}}$. Na verdade, para cada data de observação dada por $t$, ter-se-ía uma taxa dada por $\mathrm{r}_{\mathrm{i}, \mathrm{t}}$. 


\section{Capítulo 6: Considerações Finais}

$\mathrm{O}$ problema de pesquisa proposto neste trabalho estabelecia que deveria ser respondida a questão se era possível afirmar que o VaR calculado a partir das metodologias apresentadas LS (1988: 54-61) e NHF (2000: 1903-1932), adaptadas pelo presente trabalho para o cômputo do VaR de uma carteira de renda fixa, é uma medida adequada do risco de uma particular carteira composta por títulos públicos federais brasileiros.

Uma consideração importante que foi salientada na dedução no modelo NHF (2000: 1903-1932) é que esta abordagem foi desenvolvida para o cálculo do Valor em Risco de swaps de taxas de juros. Todavia, os ativos estudados neste trabalho são títulos de renda fixa.

Por conseguinte, o autor deste trabalho introduziu modificações no modelo NHF (2000: 1903-1932) para que este fosse capaz de calcular o Valor em Risco de carteiras compostas por títulos de renda fixa.

Foi definido que a carteira a ser analisada consistiria de Letras do Tesouro Nacional - LTN vencendo em 1, 3 e 6 meses, sendo que o valor investido em cada papel era de, respectivamente, $\mathrm{R} \$ 1.000,00 ; \mathrm{R} \$ 1.000,00 ; \mathrm{e} \mathrm{R} \$ 1.000,00$, totalizando um investimento de $\mathrm{R} \$ 3.000,00$.

Uma vez estabelecido que o horizonte de tempo a ser considerado abrangia a data de 01/06/2001 até 31/10/2001, foi calculado o VaR de um dia a um nível de confiança de $95 \%$ tanto pela metodologia tradicional como pelo modelo de dois fatores conduzindo a resultados extremamente próximos.

Em seguida, de modo a verificar que o VaR calculado pela metodologia dos dois fatores era uma medida do risco de mercado adequado, foi realizado o back-testing de acordo com a metodologia apresentada, sendo que em apenas um dia do horizonte estudado a perda verificada ultrapassou a estimativa do VaR.

$\mathrm{O}$ autor concluiu que, para a carteira estudada, para o horizonte de tempo selecionado, a estimativa do Valor em Risco pelo método dos dois fatores forneceu uma boa medida do risco de mercado. 
Como último comentário, o autor salienta que o presente estudo, por se valer da metodologia do estudo de caso, não teve a pretensão de validar ou generalizar os resultados obtidos a partir dos modelos estudados. Contudo, para a carteira em estudo, nas condições de mercado vigentes à época do estudo, os modelos conduziram a resultados satisfatórios. 


\section{Bibliografia}

ALMEIDA, F.C., DUMONTIER, P. O uso de redes neurais em avaliações de riscos de inadimplência. RAE - Revista de Administração de Empresas, v.31, n.1, p.52-63, jan.-mar. 1996.

ANDREZO, A. F., LIMA, I. S. Mercado Financeiro: Aspectos Históricos e Conceituais. 1. Ed. São Paulo: Pioneira, 1999.

ASSAF NETO, A. Mercado Financeiro. 3. Ed. São Paulo: Atlas, 2000.

BENNINGA, S, WIENER, Z. Value-at-Risk (VAR). Mathematica in Education and Research, v.7, n.4, p.1-8, 1998. Disponível em: < http://pluto.mscc.huji.ac.il/ mswiener/research/Benninga74.pdf $>$. Acesso em 30 mai.2002.

BERNSTEIN, P. L., DAMODARAN, A. (orgs). Investment Management. 1. Ed. New York: John Wiley \& Sons, Inc, 1998.

BODIE, Z., KANE, A., MARCUS, A. J. Fundamentos de Investimentos. 3. Ed. Porto Alegre: Bookman, 2000.

CARNEIRO, L. H., CARNEIRO, L.G. Cenários Macroeconômicos, Curvas de Juros e Seleção de Maturidades: Homero, um Simulador Top Down. São Paulo: Resenha BM\&F, n. 140, p. 24-28, jul-ago. 2000.

CASAROTTO FILHO, N, KOPITTKE, B. M. Análise de Investimentos. 8. Ed São Paulo: Atlas, 1998.

CHIESA, D.A. Introdução ao Mercado Aberto. 1. Ed. Porto Alegre: Sulina, 1983.

DARBHA, Value-at-Risk for Fixed Income Portfolios - A comparison of Alternative Models. National Stock Exchange: India, 2001. 
DERMAN, E. Model Risk. Quantitative Strategies Resarch Notes: Goldman Sachs, abr. 1996. Disponível em < http://www.gs.com/qs/doc/model_risk.pdf $>$. Acesso em 20 nov. 2001.

DIXIT, A. K., PINDYCK, R. S. Investment under Uncertainty. 1. Ed. New Jersey: Princeton University Press, 1994.

DOWD, K. The Extreme Value Approach to VaR. Financial Engineering News, 1999. Issue 11 de Agosto de 1999. Disponível em < http://fenews.com/1999/Issue11/089905.html >. Acesso em 20 ago.2001.

DUARTE JUNIOR, A. A Importância do Gerenciamento de Riscos Corporativos. $\begin{array}{llll}\text { [artigo } & \text { científico]. } & \text { Disponível }\end{array}$ $<$ http://www.risktech.com.br/PDFs/RISCORPO.pdf>. Acesso em: 29 mai. 2002.

ECO, H. Como se faz uma tese. São Paulo, Editora Perspectiva, 1977.

EMERY, D. R., FINNERTY, F. D. Corporate Financial Management. 1. Ed. New Jersey: Prenticel Hall, 1997.

FABOZZI, F. Handbook of Fixed Income Securities. 5. Ed. California: McGrawHill, 1997.

FABOZZI, F. Mercados, Análise e Estratégias de Bônus (Títulos de Renda Fixa). 3. Ed. Rio de Janeiro: Quality Mark, 2000.

FRANCIS, J.C. Investments: Analysis and Management. 3. Ed. New York: McGrawHill, 1980.

GITMAN, L. J. Princípios de Administração Financeira. 7. Ed. São Paulo: Harbra, 1997.

GOMES de FARIA, R. Matemática Comercial e Financeira. 5. Ed. São Paulo: Makron, 2000.

HAUGEN, R. A. Modern Investment Theory. 1. Ed. Illinois: PRENTICE-HALL, 1986. 
HAZZAN, S, POMPEO, J. N. Matemática Financeira. 5. Ed. São Paulo: Saraiva, 2001.

JORION, P. Value at Risk: The New Benchmark for Controlling Derivatives Risk. 1. Ed. California: McGraw-Hill, 1997.

LAKATOS, E. M., MARCONI, M. A. Metodologia Científica. 2. Ed. São Paulo: Atlas, 1991.

LEVY, H, SARNAT, M. Portfolio and Investment Selection: Theory and Practice. 1. Ed. New Jersey: Prentice-Hall International, 1984.

LITTERMAN, R, SCHEINKMAN, J. Common Factors Affecting Bond Returns. The Journal of Fixed Income 1, 54-61, 1988.

MACAUlEY, F. Some Theoritical Problems Suggested by the Movements os Interest Rates, Bond Yields, and Stock Prices in the United States Since 1856. New York: National Bureau of Economic Research, 1938.

MATHIAS, A.B., SIQUEIRA, J. O. Risco Bancário: Modelo de Previsão de Insolvência de Bancos no Brasil. RAE - Revista de Administração de Empresas, v.31, n.2, p.19-28, abr.-jun. 1996.

MISHKIN, F. Moedas, Bancos e Mercados Financeiros, 5. Ed. Rio de Janeiro: LTC, 2000.

NEWBOLD, P. Statistics for Business and Economics, 4. Ed. New Jersey: PrenticeHall, 1995.

NIFFIKEER, C.I., HEWINS, R. D., FLAVELL, R.B. A Synthetic Factor Approach to the Estimation of Value-at-risk of a Portfolio of Interest Rate Swaps. Journal of Banking \& Finance, p. 1903-1932. 2000.

O'BRIEN, J, BERKOWITZ, J. How Accurate are Value-at-Risk Models at Commercial Banks. Disponível em: < http://www.bis.org/bcbs/oslo/berkowitz.pdf $>$ Acesso em 20 out.2001. 
OLIVEIRA, Edson Ferreira. Contribuição à Modelagem de Avaliação de Empresas em Condições de Risco. São Paulo, 2001. Tese (Doutorado) - Faculdade de Economia, Administração e Contabilidade da Universidade de São Paulo.

ROGÉ FERREIRA, L.F., ANDRADE, R. S. A Duration e um Modelo Alternativo: um Teste Empírico. RAE - Revista de Administração de Empresas, v.39, n.4, p.60-69, out.-dez. 1999.

RUSSO, M. Perfil da Indústria de fundos de Investimento.Disponível em: < www.risktech.com.br.>. Acesso em 13 nov.2002.

SAMANEZ, C. P. Matemática Financeira. Aplicações à Análise de Investimentos 2. Ed. São Paulo: Makron Books, 1999.

SECURATO, J.R. Decisões Financeiras em Condições de Risco. 1. Ed. São Paulo: Atlas, 1993.

STIGUM, M, ROBINSON F. Money Market \& Bond Calculations. 1. Ed. California: McGraw-Hill, 1996.

TEIXEIRA, R. Atribuição de Valor Utilizando Cenários Probabilísticos. São Paulo, 1999. Tese (Doutorado) - Faculdade de Economia, Administração e Contabilidade da Universidade de São Paulo.

VIEIRA SOBRINHO, J. D. V. Matemática Financeira. 2. Ed. São Paulo: Atlas, 1984.

WESTON, J.F., BRIGHAM, E.F. Fundamentos da Administração Financeira, 10. Ed. São Paulo: Makron, 2000.

YIN, R.K. Case Study Research: Design and Methods. Newbury Park, CA: Sage Publications, Inc., 1989. 